NBER WORKING PAPER SERIES

\title{
EXPERIMENTAL EVIDENCE ON THE EFFECTIVENESS OF NON-EXPERTSFOR IMPROVING VACCINE DEMAND
}

\author{
Marcella Alsan \\ Sarah Eichmeyer \\ Working Paper 28593 \\ http://www.nber.org/papers/w28593 \\ NATIONAL BUREAU OF ECONOMIC RESEARCH \\ 1050 Massachusetts Avenue \\ Cambridge, MA 02138 \\ March 2021, Revised February 2022
}

\begin{abstract}
We thank Minjeong Joyce Kim, Nikhil Shankar and Lukas Leister for excellent research assistance. We also thank Mackenzie Alston, Luca Braghieri, Amitabh Chandra, Stefano DellaVigna, Esther Duflo, Amy Finkelstein, Matthew Gentzkow, Mirelle Jacobson, Damon Jones, Heather Royer, Kosali Simon, Marianne Wanamaker, Crystal Yang, JPAL North America Board and Reviewers as well as participants in seminars at ASSA, Brown University, Harvard/ MIT/BU Health Economics, Stanford, UCSB, UCSD, and Washington University in St. Louis for comments. The study was approved by IRB at Harvard University (IRB19-1424) and registered at ClinicalTrials.gov (NCT04160975), AEA RCT registry (AEARCTR-0004796), and OSF (DOI 10.17605/OSF.IO/XJ5WP). Funding was provided by J-PAL North America and Harvard Kennedy School. Research reported in this publication was also supported by the National Institute on Aging under award number P30AG064190. The content is solely the responsibility of the authors and does not necessarily represent the official views of the National Institutes of Health or the National Bureau of Economic Research. The authors have no conflicts to disclose. Previously circulated under the title: "Persuasion in Medicine: Messaging to Increase Vaccine Demand".
\end{abstract}

NBER working papers are circulated for discussion and comment purposes. They have not been peer-reviewed or been subject to the review by the NBER Board of Directors that accompanies official NBER publications.

(C) 2021 by Marcella Alsan and Sarah Eichmeyer. All rights reserved. Short sections of text, not to exceed two paragraphs, may be quoted without explicit permission provided that full credit, including () notice, is given to the source. 
Experimental Evidence on the Effectiveness of Non-Experts for Improving Vaccine Demand Marcella Alsan and Sarah Eichmeyer

NBER Working Paper No. 28593

March 2021, Revised February 2022

JEL No. I1,I12,I14

\begin{abstract}
$\underline{\text { ABSTRACT }}$
We experimentally vary signals and senders to identify which combination will increase vaccine demand among a disadvantaged population in the United States - Black and White men without a college education. Our main finding is that laypeople (non-expert concordant senders) are most effective at promoting vaccination, particularly among those least willing to become vaccinated. This finding points to a trade-off between the higher qualifications of experts on the one hand, but lower social proximity to low socio-economic status populations on the other hand, which may undermine credibility in settings of low trust.
\end{abstract}

Marcella Alsan

Kennedy School of Government

Harvard University

79 John F. Kennedy St.

Rubenstein Bldg R403

Cambridge, MA 02138

and NBER

marcella_alsan@hks.harvard.edu

Sarah Eichmeyer

Economics Department

University of Munich

Ludwigstraße 33

80539 Munich

Munich 80538

Germany

sarah.eichmeyer@econ.lmu.de 


\section{Introduction}

Preventive health investments can yield considerable benefits for individuals and society, yet are often adopted at low rates (see Newhouse 2020). Immunization against infectious diseases is a leading example of a measure that improves health and reduces employee absenteeism (CDC 2020; Nichol, Mallon and Mendelman 2003). ${ }^{1}$ However, despite near universal recommendation of the seasonal influenza vaccine for individuals over the age of 6 months in the United States and federally mandated zero cost-sharing under the Affordable Care Act, take-up rates among adults average only $45 \%$ (CMS 2010; CDC 2021a). Take-up rates are particularly low among certain demographic groups, such as men, individuals without a four-year college degree, and non-Hispanic Black Americans (see Panel A of Appendix Figure A1; CDC 2018; Newhouse and Insurance Experiment Group 1993).

Among the groups with the lowest vaccination rates, the reasons frequently reported for not taking up flu vaccines relate to pessimistic views on the benefits or non-pecuniary costs of vaccinations, as opposed to financial costs or lack of recommendation by a health professional. ${ }^{2}$ These findings echo prior research on higher levels of medical mistrust among Black Americans as well as among individuals with less education (Blendon, Benson and Hero 2014; Kinlock et al. 2017; Nanna et al. 2018; Hammond et al. 2010; Idan et al. 2020). This mistrust likely has deep historical roots, including the government-led experiment in Tuskegee, Alabama, as well as contemporaneous racism in medicine (Alsan and Wanamaker 2018; Bajaj and Stanford 2021; Brandt 1978). The findings on beliefs also relate to growing scholarship on misperceptions in the net benefits of preventive care (i.e. behavioral hazard) leading to underutilization (Handel and Kolstad 2015; Bhargava, Loewenstein and Benartzi 2017; Ericson and Sydnor 2017; Brot-Goldberg

\footnotetext{
${ }^{1}$ The seasonal influenza vaccine alone averts 3,500 to 12,000 deaths a year and reduces work loss due to the illness by nearly one-fifth (CDC 2020).

${ }^{2}$ See Appendix Figure A2, which explores reasons for not vaccinating among our sample. Note that vaccination take-up among Hispanic men is also relatively low, but this population was not included in this study.
} 
et al. 2017; Handel and Schwartzstein 2018; Chandra, Flack and Obermeyer 2021). There is scope, then, to change individuals' views on vaccination through the provision of credible and accurate information (Kamenica and Gentzkow 2011).

In this study, we aim to evaluate the effectiveness of messaging interventions designed to shift knowledge, beliefs, and take-up behavior regarding vaccines among low socio-economic status (SES) populations. We randomly assigned respondents recruited online to one of four video messages with information about flu vaccination. We then elicited beliefs and behaviors regarding flu vaccination as well as spillovers to COVID-19 vaccination, including at a follow-up survey a few weeks later. Our sample consists of 2,893 White and Black men without a college education who had not received their seasonal influenza vaccine at the time of recruitment. ${ }^{3}$

Understanding the determinants of demand for preventive health care, including vaccines, has been of great interest to researchers. Important experimental work has shown the effectiveness of celebrity messages (Alatas et al. 2019), cues and nudges (Milkman et al. 2011) or increased accessibility (Brewer et al. 2017; Banerjee et al. 2010), particularly among those planning to be vaccinated. There is limited evidence, however, on how to persuade those who are not already intending to be immunized (in our sample, nearly half of respondents report they are completely unwilling to receive an influenza vaccine). Which messages will resonate under such circumstances? And could some well-intentioned messages backfire? The urgency of answering such questions is underscored by the disproportionate impact of COVID-19 on disadvantaged communities, the unequal vaccination rates across racial and ethnic groups in the U.S., as well as the potential for new variants and COVID-19 endemicity.

Our videos, which were narrated by ten separate senders, held information about the safety and effectiveness of the influenza vaccine constant and

\footnotetext{
${ }^{3}$ The education cutoff still represents a substantial fraction of US men (approximately $50 \%$ of Black men and $35 \%$ of Non-Hispanic White men in the US population (Health Day News 2021)).
} 
varied along three policy-relevant dimensions: (1) the perceived medical expertise of the sender ("expertise"), (2) the admission/omission of acknowledgement of past injustice committed by the medical community by discordant senders ("acknowledgement"), and (3) the race of the sender ("concordance"). We tailored the expertise and acknowledgement interventions to Black respondents since Black men continue to comprise less than three percent of the U.S. physician workforce, with their representation among admitted medical students stagnant since the late 1970s (Gallegos 2016; AAMC 2019). In general, the White US population has not faced the systematic exploitation by the medical profession as Black Americans. Similarly, for White patients, racially concordant physicians are widely available and discrimination by health care providers is less common lessening the need for lay senders (Sun et al. 2022). Understanding the potential of concordant community members to substitute for medical experts, as well as the role of acknowledgement of past injustice by discordant physicians may play in bridging trust gaps, holds relevance amidst challenges in diversifying the physician workforce and persistent racial health inequalities (Street et al. 2008; Williams and Rucker 2000).

The layperson sender intervention was motivated by the ambiguous effects expertise may have on belief and behavior change. Medical doctors, the relevant experts in our study, have specialized training and experience and may therefore be considered more credible sources of health information than peers, all else equal. They are, however, also more socially distant from those who are disadvantaged, and such class cleavages could engender skepticism (Gauchat 2012; Eichengreen, Aksoy and Saka 2021). Recent research in economics has revisited the role of expertise: Sapienza and Zingales (2013) find that providing ordinary Americans with information on the consensus opinions of academic economists does not move their beliefs, while DellaVigna and Pope (2018) document that non-experts perform similar to experts in forecasting the rank of interventions. Representative surveys on trust and credibility indicate that respondents find "a person like yourself" as credible as academic experts and show a growing gap in insti- 
tutional trust between individuals of high and low SES (Ries 2016). Experimentally, the variation we induce is between senders wearing a white coat and stethoscope (expert condition) versus the same senders wearing a white short-sleeved shirt (layperson condition), narrating the same script. ${ }^{4}$ In a separate survey conducted on Amazon Mechanical Turk (MTurk), senders in layperson attire are rated by respondents as 1.7 standard deviation units less educated than those in a laboratory coat (Appendix Table B1), indicating that our experimental variation had the intended effect (i.e. a "firststage").

The concordant expert arm was motivated by recent research showing that treatment by a race-concordant physician in an in-person setting can increase demand among Black Americans for preventive care as well as improve health outcomes (Alsan, Garrick and Graziani 2019; Cooper-Patrick et al. 1999; Cooper et al. 2003; Greenwood, Carnahan and Huang 2018; Greenwood et al. 2020; Hill, Jones and Woodworth 2020). Evidence is limited, however, on whether these effects exist in one-way communication settings. In a pair of randomized evaluations of video messages recorded by physicians regarding mask-wearing and social distancing during the COVID-19 pandemic, the first such messaging study found small but robust sender concordance effects among Black respondents on information-seeking behavior (Alsan et al. 2020). However, the second study, by the same set of authors and using a more complicated design, failed to detect such effects (Torres et al. 2021). This paper builds on and extends the prior studies to include vaccination views and behavior.

The acknowledgement arm, in which some White senders acknowledge past breaches of trust committed by the medical community, could provide an alternative, scalable way to increase trust in medical recommendations amidst a largely non-Black physician workforce. While acknowledgement of historical medical injustice can be expressed through a variety of ap-

\footnotetext{
${ }^{4}$ In the remainder of the paper, we refer to senders in the expert condition as expert senders while senders in the layperson condition as layperson senders. For experimentation on doctor attire see Varnado-Sullivan et al. (2019) and Petrilli et al. (2018).
} 
proaches, we developed a short statement corresponding closely to the one proposed for use by physicians in an Annals of Internal Medicine editorial on responding to vaccination concerns (Opel, Lo and Peek 2021). The proposed script from Annals reads "I understand why you have a lot of mistrust. The government and research systems have not always treated your community fairly," and can be compared to our script found in Section II. Before distributing this type of message at scale, however, it is imperative to test its effectiveness, as unintended negative consequences are also conceivable.

We establish three main results. First, when comparing layperson to expert senders, we find that lay senders are rated by respondents as substantially less qualified and trustworthy (0.54 standard deviation units) to give general medical advice. However, individuals in the non-expert condition exhibit greater recall of factual signal content and increase their willingness to receive the COVID-19 vaccine by 8.8 percentage points $(20 \%)$. Furthermore, respondents assigned to lay senders were 15 percentage points (39\%) more likely to report that they or their household members had received the flu vaccine in the weeks between the baseline and follow-up surveys. There is substantial attrition between the baseline and follow-up (the latter was conducted several weeks later to allow individuals time to receive a flu shot). Such attrition is not uncommon after such a length of time or among studies of vulnerable populations, but suggests caution in interpreting results on take-up. Nevertheless, attrition did not vary across arms and the layperson intervention is the only intervention with a take-up rate that is statistically significantly different from (namely, higher than) that of other interventions.

Second, we find concordance effects on sender and signal ratings are present exclusively among Black respondents, with no such effects evident among White respondents. We further find that acknowledgement of past breaches of trust by a race-discordant expert sender increases ratings of the signal by approximately the same magnitude as a race-concordant expert sender providing the standard signal without acknowledgement (an increase of 0.14 standard deviation units). Neither intervention, however, signifi- 
cantly affects vaccine take-up as measured in the follow-up survey, although coefficient estimates on intent to vaccinate against influenza and COVID-19 are weakly positive in both arms.

Third, we find striking heterogeneity by treatment arm across respondents with varying levels of vaccination reluctance. Viewing previous flu vaccination experience as a proxy for distance from a take-up "threshold," we divided the sample into "most hesitant", "moderately hesitant", and "least hesitant" based on the date of a respondent's last influenza vaccine. We find that both the concordance and acknowledgement interventions demonstrate significant effects on flu and COVID-19 vaccination intent among those least hesitant-those who had received seasonal flu vaccines within the past two years (about a quarter of the sample). In sharp contrast, the effectiveness of non-experts was strongest among those most hesitant-those who had never previously received a flu vaccine (another quarter of the sample) -with individuals in this group rating the signal from a non-expert (relative to that of the expert) significantly higher than respondents who had previously taken up the flu vaccine and exhibiting substantial increases in flu and COVID-19 vaccination intent (by $47 \%$ and $49 \%$, respectively).

Taken together, these findings represent a step towards identifying effective ways to influence immunization views and behaviors. While messages from concordant and empathetic experts may resonate most among individuals familiar with vaccination, our study suggests that peer figures, such as community health workers or citizen ambassadors, could play an important role in communicating benefits and dispelling myths about vaccines among those least inclined to receive one.

\section{Experimental Design}

\section{Experiment Overview}

We collected data in two flu seasons: 2019-2020 and 2020-2021. Respondents were recruited via survey panels from Qualtrics, Lucid, CloudResearch, 
and Facebook and participated in the experiment through an online survey on Qualtrics. We timed the experiment so that it would fall into the middle of the flu season (between December to February in 2019-2020 and between late October to January in 2020-2021), so as to ensure recruitment of participants who would be unlikely to get the flu vaccine in the absence of our intervention. ${ }^{5}$ Upon completing the consent process, participants answered a set of questions to determine eligibility based on self-identified gender (male), race (Black or White), age (25-51), education (no college), and flu vaccine status (had not yet been vaccinated for influenza in the current season). ${ }^{6}$

Eligible respondents continued to answer basic demographic questions, reported their baseline attitudes and beliefs about the flu vaccine, and then watched a video infomercial, described in the next paragraph. After the infomercial, we gathered the main survey-based outcome measures and distributed a coupon for a free flu shot. We note that many places distribute free flu shots for indigent populations and that many insurance providers cover flu shots. However, in the event that cost was a barrier for a handful of individuals the coupon removed it, thus leaving only non-monetary barriers to vaccination. At least two weeks later, participants were invited to complete a follow-up survey to measure medium-term impacts of our video treatment and to measure respondents' self-reported flu vaccination status. See Appendix Figure A3 for an overview of the study design. Participants received a financial incentive for completing the baseline and follow-up survey (between $\$ 5$ and $\$ 20$ ), in the form of an electronic gift card.

\footnotetext{
${ }^{5}$ By the fourth week of October 2020, flu shot distribution was on par with the first week of December 2019 (165 and 169 million doses, respectively), likely accelerated by the pandemic (CDC 2021b).

${ }^{6}$ We did not recruit participants aged older than 51 because a different vaccine than the one covered by our flu shot coupon is advised for older individuals. We also excluded those aged between 18 and 24 because we aimed to recruit individuals without a college education, and they may still be in college. Appendix Figure A2 demonstrates the relatively low vaccine take-up among low SES men, which motivates our focus on that particular demographic group.
} 


\section{Treatment Variation}

In order to test whether the expertise of the sender, race concordance, and acknowledgement statements influence the key outcomes of interest, we aimed to produce videos that held all other factors precisely constant. This required tight control over key features of the video, such as the lighting, script, intonation, speaking rate, and sender appearance (such as age, height, facial hair, and clothes). Ensuring such consistency necessitated the use of a professional recording studio, as well as the use of actors for the recording of the videos. ${ }^{7}$

We produced videos with a total of five Black and five White male actors ("senders"), recruited from the same casting agency. Each sender recorded the video in four variations, representing the experimental variation in expertise (expert vs. non-expert layperson) and signal content (standard vs. including an acknowledgement statement). ${ }^{8}$ Within each treatment condition, subjects were randomly assigned in equal proportions to one of five recorded senders of the assigned race. The randomization was stratified by season and recruitment platform. All senders wore the exact same clothes, provided by the research team. In the expert role, the senders wore a buttondown blue shirt, striped tie, laboratory coat and stethoscope. In the layperson role, they wore a white short-sleeved shirt.

The standard signal (video script S1) was 40 seconds long and read: ${ }^{9}$

\footnotetext{
${ }^{7}$ In prior work (Alsan, Garrick and Graziani (2019); Alsan et al. (2020); Torres et al. (2021)), our team used licensed medical doctors for messaging. However, given the fine titration of all elements of the messaging and the need for the same person to play multiple roles, we used actors in this instance. Note that the same person who delivered the message as an expert recorded as a non-expert too, thus either experts would have had to have acted as non-experts or vice-versa. We debriefed respondents about the use of non-expert actors in the influenza infomercials as well as the tracking of coupons, per IRB guidance, at the end of the follow-up survey.

${ }^{8}$ Because of the low marginal cost of recording additional videos, we had each actor record all four video variations; however, for power considerations and because pipeline issues for medical professionals are not as relevant for White respondents nor the shameful history of medical exploitation, we only used the standard lay and standard expert videos for Black actors, and the standard expert and acknowledgement expert videos for White actors in the experiment.

${ }^{9}$ See Appendix Section D for links to the videos we recorded.
} 
The Centers for Disease Control and Prevention, or CDC, recommends everyone 6 months and older get the flu shot. The shot protects you from getting sick by cutting your chance of catching the flu in half. It's also very safe: less than 1 in 100 vaccinated people experiences a side effect such as fever or chills. The flu shot does not contain an active flu virus, so you cannot get the flu virus from the shot. I get the flu shot every year to protect myself, my family, and my community. I recommend you look into getting vaccinated as soon as possible. ${ }^{10}$

The script of acknowledgement signal (S2) was identical to the above, except that three sentences were added acknowledging historical injustices committed by the medical establishment. They were placed in between the first and second sentence of script S1, and read: I know some people are nervous to follow medical advice about vaccines. In the past, there may have been times when the medical community broke your trust. But I hope that sharing some information with you can help you understand how important the flu shot is.

We aimed for the two groups of actors to have a similar distribution of age and training in acting. We validated the former criterion via external MTurk ratings of each actor (in each role) on age and also collected perceptions of attractiveness and educational attainment from the MTurk sample. Columns (1) through (3) of Appendix Table B1 reveal that Black MTurkers rate lay senders as less educated, less attractive, and younger than the same set of senders wearing white coats. Such results support the notion that the senders in casual attire were perceived as less advantaged than expert senders.

There are no statistically significant differences in perceived age and education between concordant and discordant expert senders among Black MTurk respondents (Appendix Table B1, columns (4) to (5)). Black respondents do, however, rate Black expert senders as more attractive (column (6)) .

Consistent with implicit bias, White MTurkers perceive Black expert senders wearing a white coat as 0.53 standard deviations younger and 2.84 standard deviations less educated than White senders in a white coat (columns (7)

\footnotetext{
${ }^{10}$ In the layperson video, we replaced the word "cannot" with "can't" in the script.
} 
to (8)). These differences are statistically significant. They should be kept in mind when interpreting the (null) results among White respondents. Appendix Figure A4 presents perceived within-sender education differences (white coat vs. casual attire for Black vs. White senders). We observe that the penalty for a Black male wearing casual attire is much greater than for a White male, as they are perceived to be significantly less educated. These findings connect to a broader literature about stereotypes and the profiling of Black men in the U.S. (Hester and Gray 2018; Oliver 2003).

\section{Outcome Variables}

We consider four primary and four secondary outcomes, described in detail in the next sub-sections and summarized in brief here.

Our primary outcomes include both measures of perceptions of the message and messenger — which are important to elucidate mechanisms—as well as measures of the intent to get vaccinated. As secondary outcomes, we include additional measures aimed at elucidating mechanisms (including information recall, and beliefs about the safety of flu shots), and measures of vaccine demand and take-up: we elicited an incentive compatible measure of demand for a free flu shot, and we collected information about selfreported vaccine take-up as measured via a follow-up survey. However, because flu shots are widely available for free, and because of sizeable attrition to the follow-up survey, respectively, we consider both to be relatively noisy, suggestive measures of the underlying outcomes of interest.

Appendix Section E presents the survey question text underlying our outcome measures. Several of our outcomes are constructed as an index composed of answers to several survey questions that are proxies for the same outcome. The advantage of using indices is that it reduces noise, as well as the risk of false positives (in terms of statistical significance) due to multiple hypothesis testing. We construct each such index as an inverse covariance-weighted average, as described in Anderson (2008). Construc- 
tion of outcomes follows our pre-analysis plan. ${ }^{11}$

\section{Primary Outcomes}

(1) Rating of sender: this outcome is an index comprised of responses to survey questions regarding whether the respondent was interested in further medical advice from the given sender, trusted advice from the sender, and the respondent's assessment of the sender's qualification to provide medical advice.

(2) Rating of signal: this outcome is an index comprised of responses to survey questions on recommending the video to friends and family, recommending the flu shot to friends and family, and the respondent's assessment of the extent to which the information contained in the video was useful.

(3) Flu vaccination intent: this refers to the respondent's self-reported likelihood to receive the flu vaccine before the end of the flu season. It was elicited on an 11-point Likert scale, once before and once after the video message treatment. We present results on posterior intent (instead of changes in intent) to keep in parallel with the COVID-19 vaccination outcome measure. We re-scaled this outcome to have support 0 to 1.

(4) COVID-19 vaccination intent: this refers to the respondent's selfreported likelihood to take up the COVID-19 vaccine if made available free of charge, elicited on the same scale as flu vaccination intent. We re-scaled this outcome to have support 0 to 1 . Since COVID-19 was not yet prevalent during the 2019-2020 flu season, we asked this question only in the second wave of data collection, i.e. during the 2020-2021 flu season.

\footnotetext{
${ }^{11}$ We make one meaningful deviation from our pre-analysis plan: to accommodate referee comments remarking that a full set of outcomes elicited is difficult to parse, we split the set of eight main outcomes into four primary and four secondary ones, presenting results on the latter in the appendix. The decision about which results to designate as secondary outcomes mainly followed considerations about data quality outlined above.
} 


\section{Secondary Outcomes}

(1) Signal content recall: this outcome is an index comprised of responses to survey questions on the age group for whom the flu vaccine is recommended and whether the flu shot contains the flu virus (recall of information discussed in the video).

(2) Safety beliefs: this outcome is an index comprised of the point belief and the certainty on the likelihood to contract the flu from the flu shot, measured by a Likert scale and balls and bins method, respectively. Both measures were elicited twice, once before and once after the video message treatment, and we use the posterior-prior difference of each in our index.

(3) Coupon interest: this outcome is an index comprised of two revealed preference measures of demand for a free flu shot coupon - willingness to pay (WTP) for the coupon, as well as demand for information regarding locations to redeem the coupon; both were elicited in an incentive compatible manner-see Appendix Section E for details. Since only 3\% of individuals in our sample mention cost as a major barrier to vaccination take-up (see Appendix Figure A2), we consider this outcome to be a relatively noisy proxy for flu shot demand.

(4) Flu vaccine take-up: this outcome is binary and equals one if respondents reported in the follow-up survey that they or their family members had received the flu shot, or if we observed redemption of the coupon. It is not a primary outcome, because attrition to the follow-up survey is sizeable, and because coupon redemption data likely provides a very incomplete picture of actual flu vaccine take-up. ${ }^{12}$

\footnotetext{
${ }^{12}$ Pharmacies reported to TotalWellness, Inc., the coupon vendor, whether the coupon was used and shared this information with the study team. Because well below $1 \%$ of coupons were recorded as redeemed, we combine self-reported flu shot receipt as reported at follow-up with the coupon redemption data into a single outcome. The low recorded redemption rate stands in contrast to self-reported usage rates of $15.5 \%$ as per our followup survey. The gap is likely due to pharmacists billing insurance instead of using coupons $-74 \%$ of respondents with discrepancies were insured. If we recode all inconsistencies as not having been vaccinated, the conclusions reported herein are unchanged. We also show results on redemption separately in Appendix Table B2.
} 


\section{Descriptive Statistics, Balance and Attrition}

Our main sample includes all respondents who fulfilled our eligibility criteria (see Section II), passed our quality check, and completed the survey. Attrition after randomization was low: among all respondents who arrive at the video treatment stage of the survey, $89 \%$ completed the survey. Appendix Table B3 tests for imbalance in attrition by treatment status both during the baseline survey (Columns 1 and 2) and between the baseline and follow-up surveys (Columns 3 and 4). The only statistically significant differential attrition we detect in the former is among White respondents who were assigned to a Black sender: they exited the baseline survey at a higher rate (2.3 percentage points, $\mathrm{p}$-value 0.09 ), suggesting those who remained were not as averse to discordant senders. Attrition between the baseline and follow-up is substantial, though such high attrition is not entirely unexpected given the lengthier time period between the two surveys - necessitated in order to observe vaccine seeking behavior - and the sample composition, as socially disadvantaged individuals tend to have lower response rates and higher loss to follow-up. Appendix Table B3 Columns (3) and (4) demonstrate that there is no differential attrition across treatment arms.

Summary statistics are presented in Appendix Table B4. We recruited approximately 400 Black respondents for each of the interventions (concordant expert, concordant lay, discordant expert, discordant expert plus acknowledgement) and approximately 600 White respondents for each of the two interventions to which White respondents were assigned (concordant expert, discordant expert). Respondents were on average 37 years old and about $53 \%$ reported an annual household income below $\$ 30,000$. Approximately $27 \%$ of the sample had never received a flu vaccine, while $28 \%$ received one in the past two years and the remainder more than two years ago. Among the latter group, the majority (66\%) received the flu vaccine more than five years ago. Before viewing the infomercial, respondents report a mean likelihood of receiving the flu vaccine of 2.57 on a $0-10$ point scale.

We detect differences across racial groups that reflect broader social in- 
equality: Black respondents report lower incomes, rates of high school completion, and health insurance coverage rates, although they express slightly higher average subjective health status. The relationship between COVID19 vaccination intent and flu vaccination intent (as measured following the video intervention) is strongly positive (correlation coefficient $=0.58$, Appendix Figure A5), indicating there may be a generic aversion to immunization.

Observable characteristics and pre-intervention views are well-balanced across treatment assignment in the baseline survey (Appendix Table B5). As noted above, there was a lower response rate for the follow-up survey, though we do not detect differential response rates across study conditions. Characteristics are generally well-balanced across conditions in the followup survey although a handful of exceptions are observed (see Appendix Table B6).

\section{Results}

\section{A Main Treatment Effects}

Results are organized corresponding to the four study arms (i.e. lay vs. expert sender among Black respondents, acknowledgement vs. standard signal among Black respondents, concordance vs. discordant expert senders for Black respondents, and concordance vs. discordant expert senders for White respondents). We report estimates with robust standard errors obtained from a linear regression of the variables described in Section III on treatment indicators. We include the stratifying variables of recruitment season and survey platform (combining the Facebook and CloudResearch platforms given their low recruitment numbers) in all regressions.

We present our main results from the baseline survey in Table 1. There are four columns, one for each primary outcome. Outcomes in columns (1) and (2) are normalized to mean zero and standard deviation one, while outcomes in columns (3) and (4) are the self-reported likelihood (i.e., intent) 
Table 1: Treatment Effect Estimates

\begin{tabular}{|c|c|c|c|c|}
\hline & $\begin{array}{c}(1) \\
\text { Rating } \\
\text { Sender }\end{array}$ & $\begin{array}{l}(2) \\
\text { Rating } \\
\text { Signal }\end{array}$ & $\begin{array}{c}(3) \\
\text { Flu Vaccine } \\
\text { Intent }\end{array}$ & $\begin{array}{c}(4) \\
\text { COVID-19 } \\
\text { Vaccine Intent }\end{array}$ \\
\hline \multicolumn{5}{|c|}{ PANEL A: Layperson vs. Expert - Black Respondents } \\
\hline Layperson Treat & $\begin{array}{l}-0.540 \\
(0.071) \\
{[0.000]}\end{array}$ & $\begin{array}{l}-0.081 \\
(0.067) \\
{[0.231]}\end{array}$ & $\begin{array}{c}0.019 \\
(0.025) \\
{[0.455]}\end{array}$ & $\begin{array}{c}0.088 \\
(0.030) \\
{[0.003]}\end{array}$ \\
\hline Mean in control & 0.00 & 0.00 & 0.37 & 0.43 \\
\hline Observations & 845 & 845 & 845 & 592 \\
\hline \multicolumn{5}{|c|}{ PANEL B: Standard vs. Acknowledgement Signal - Black Respondents } \\
\hline Acknowledgement Signal Treat & $\begin{array}{c}0.100 \\
(0.068) \\
{[0.145]}\end{array}$ & $\begin{array}{c}0.142 \\
(0.069) \\
{[0.040]}\end{array}$ & $\begin{array}{c}0.027 \\
(0.025) \\
{[0.287]}\end{array}$ & $\begin{array}{c}0.054 \\
(0.031) \\
{[0.080]}\end{array}$ \\
\hline Mean in control & 0.00 & 0.00 & 0.34 & 0.40 \\
\hline Observations & 827 & 827 & 827 & 581 \\
\hline p-value & 0.004 & 0.100 & 0.487 & 0.512 \\
\hline \multicolumn{5}{|c|}{ PANEL C: Concordant vs. Discordant Expert Sender - Black Respondents } \\
\hline Concordance Treat & $\begin{array}{c}0.183 \\
(0.067) \\
{[0.007]}\end{array}$ & $\begin{array}{c}0.139 \\
(0.070) \\
{[0.049]}\end{array}$ & $\begin{array}{c}0.026 \\
(0.025) \\
{[0.302]}\end{array}$ & $\begin{array}{c}0.035 \\
(0.031) \\
{[0.254]}\end{array}$ \\
\hline Mean in control & 0.00 & 0.00 & 0.34 & 0.40 \\
\hline Observations & 832 & 832 & 832 & 587 \\
\hline \multicolumn{5}{|c|}{ PANEL D: Concordant vs. Discordant Expert Sender - White Respondents } \\
\hline Concordance Treat & $\begin{array}{c}-0.075 \\
(0.057) \\
{[0.189]}\end{array}$ & $\begin{array}{l}-0.009 \\
(0.057) \\
{[0.876]}\end{array}$ & $\begin{array}{c}0.003 \\
(0.021) \\
{[0.868]}\end{array}$ & $\begin{array}{c}0.009 \\
(0.025) \\
{[0.719]}\end{array}$ \\
\hline Mean in control & 0.00 & 0.00 & 0.37 & 0.45 \\
\hline Observations & 1221 & 1221 & 1221 & 866 \\
\hline p-value & 0.000 & 0.021 & 0.819 & 0.433 \\
\hline
\end{tabular}

Notes: Table reports OLS estimates. Each dependent variable in columns (1) and (2) is an inverse-covarianceweighted index as described in Anderson (2008) and standardized to a mean of 0 and standard deviation of 1 . Dependent variables in columns (3) and (4) are on a scale of 0 to 1 . COVID-19 vaccine intent was asked during the 2020-2021 flu season only. Outcome variables are described in Section III and in Appendix Section E. The $p$-value in Panel (B) tests the null hypothesis that the acknowledgement signal treatment and layperson treatment effects are equal. The $p$-value in Panel (D) tests the null hypothesis that the concordance treatment effects are the same across Black and White respondents. Stratifying variables (platform and season) are included as controls in the regression but not reported. Robust standard errors are in parentheses. $p$-values are in brackets. 
to receive the flu and COVID-19 vaccination, respectively. ${ }^{13}$

\section{Layperson vs. Expert}

Results comparing concordant non-expert to concordant expert senders are displayed in Panel A of Table 1. Respondents randomized to the layperson condition provide less favorable ratings of the sender, by 0.54 standard deviation units. The large negative effect on the rating of the sender lends credence to respondents paying attention: the measure includes a rating of the sender's qualification to give general medical advice. This finding also accords with the perception that senders wearing a white short-sleeved shirt are less educated and younger than those wearing a white coat (Appendix Table B1 columns (1)-(3)).

Despite perceiving non-expert senders to be of lower expertise, however, respondents assigned to such senders stated no lower intent to receive the flu vaccine, and even significantly increased their intent to receive the COVID19 vaccine by 8.8 percentage points relative to the expert sender condition. Consistent with this finding, the non-expert sender condition significantly increased take-up of the flu vaccine: respondents assigned to lay senders were 15 percentage points more likely in our follow-up survey to report that they and/or another household member received the flu vaccine in the weeks since the baseline survey (a 39\% increase).

Experimenter demand effect is not a reasonable explanation for these patterns since all arms were "treated" in the study and there would need to be higher self-report bias among those viewing a signal from a non-expert versus a health authority figure, which seems very unlikely. Instead, respondents absorbed more information on the flu vaccine from lay senders, as reflected by a sizable positive effect of the lay treatment on signal content recall (0.12 standard deviation units). This finding is consistent with patients experiencing increased anxiety levels when interacting with a doctor (which can sometimes raise blood pressure, a phenomenon in clinical

\footnotetext{
${ }^{13}$ Results pertaining to secondary outcomes are presented in Appendix Table B7.
} 
medicine dubbed "white coat hypertension"), which may in turn impair the ability to retain information. The lower rating of lay sender qualifications, moreover, did not translate into significantly less favorable beliefs or attitudes, such as on the perceived safety of the flu vaccine, interest in a flu vaccine coupon, compared to individuals randomized to an expert sender.

\section{Acknowledgment vs. Standard Message}

Panel B of Table 1 reports the main effect of the acknowledgement signal intervention among Black respondents assigned to White expert senders. On average, Black respondents assigned to the acknowledgement statement condition rate the statement 0.14 standard deviation units higher than the default statement conveyed by the same set of senders. They are also 5.4 percentage points more likely to intend to take up the COVID-19 vaccine. We do not detect statistically significant effects of the acknowledgement statement on flu vaccine intent (and take-up).

\section{Race Concordance vs. Discordance}

For Black respondents (Panel C), race concordance has a positive, sizeable effect on the respondent's ratings of the sender ( 0.18 standard deviation units). Furthermore, relative to the discordant expert baseline signal, a raceconcordant expert sender increases ratings of the signal by approximately the same magnitude as the acknowledgement of past breaches of trust by a race-discordant expert sender (an increase of 0.14 standard deviation units). By contrast, we do not detect concordance effects on sender or signal ratings among White respondents (Panel D).

Concordance is associated with weak positive effects on flu and COVID19 vaccination intent for Black respondents, but these are not statistically significant. ${ }^{14}$ As mentioned in Section IV, White respondents assigned a dis-

\footnotetext{
${ }^{14}$ There may be a concern that Black and White senders may differ along other characteristics besides race (e.g. Heckman 1998 and Pager 2007). We designed this experiment to minimize such concerns, by holding key other dimensions (e.g. sex, age, clothing, setting and script) constant. We also demonstrate that the effect of any given Black sender on most
} 
cordant sender attrited at higher rates, which we view as a relevant outcome. It does, however, suggest that estimates reported in Panel D are biased towards the (reported) null effect of concordance. ${ }^{15}$

\section{Most Effective Treatment, Overall}

Figure 1 displays means of primary outcomes, as well as 95\% confidence bands by treatment condition. Across our key measures of vaccination intention and behavior (including flu vaccine take-up, displayed in Panel (D) of Appendix Figure A8), the layperson treatment condition consistently performs the best among Black respondents (dark blue bars), whereas discordant expert senders fare poorly among Black individuals. White respondent averages (light blue bars) across concordant and discordant treatment conditions do not meaningfully differ. Soberingly, flu and COVID-19 vaccination intent, as well as flu vaccine take-up are substantially lower-by 3 to 6 percentage points-among Black respondents paired with a discordant expert sender than among White respondents paired with a concordant expert sender. As $85 \%$ of White patients in the U.S. have a concordant physician yet nearly $75 \%$ of Black patients do not, such a comparison mirrors the experience of many Black Americans in the U.S. healthcare system (Blewett et al. 2018). We find, however, that layperson senders shift Black respondents to levels of vaccination intent and take-up comparable to White respondents.

An assessment of the overall effect of any one signal on outcomes, relative to no signal at all, is of interest in itself as well. However, since the focus of this study is on testing the differential effectiveness of signal frames aimed at bridging trust gaps relative to a standard signal from a typical expert sender, we did not include a no-signal control group. Therefore, we

of the outcomes is indistinguishable from other Black senders in the concordance arm (see Appendix Table B8 for the rating outcomes). For one outcome (COVID-19 vaccine intent) we do reject the null; however, there are no concordance effects detected for this outcome (see column (4) of Table 1 Panel C). Similarly, we do not detect heterogeneity in the layperson treatment effect by sender (Appendix Table B9).

${ }^{15}$ Individual outcomes that comprise the indices can be found in Appendix Figures A6 and A7. Specifications including LASSO-chosen controls can be found in Appendix Table B10. Estimates with Lee (2009) bounds, available on request, also fail to find an effect. 


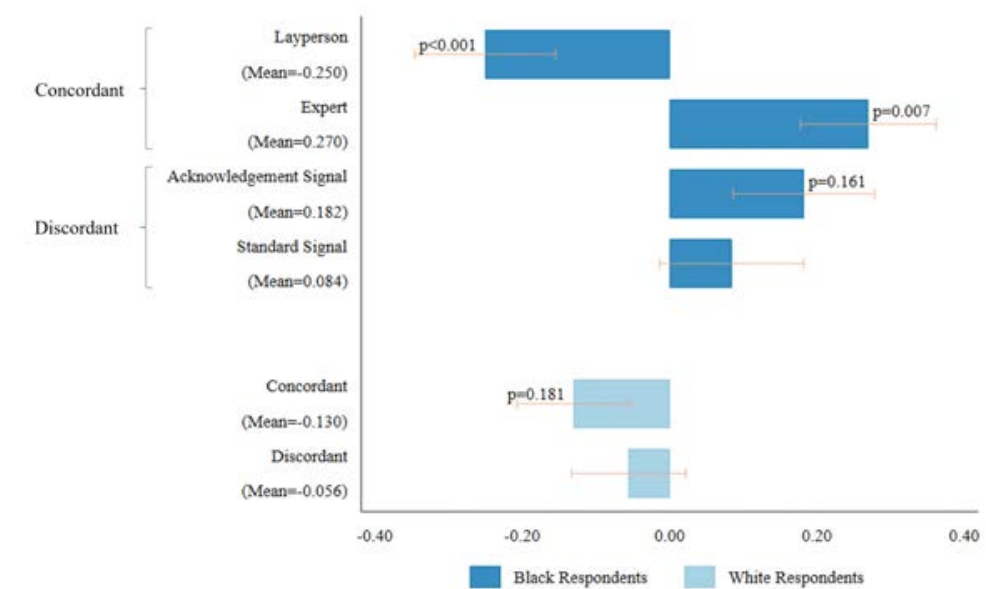

Panel (A): Sender Rating

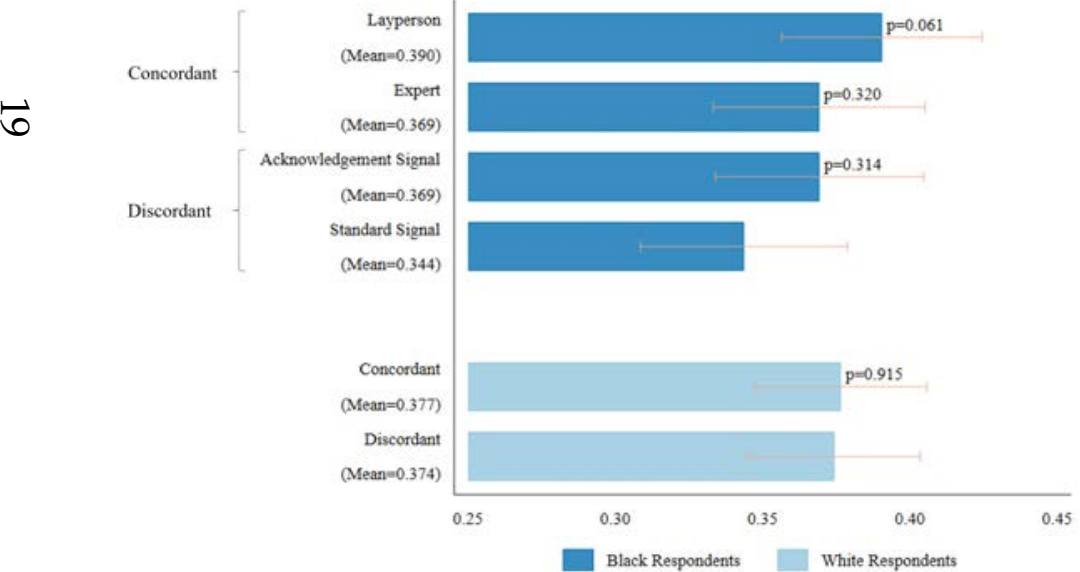

Panel (C): Flu Vaccine Intent

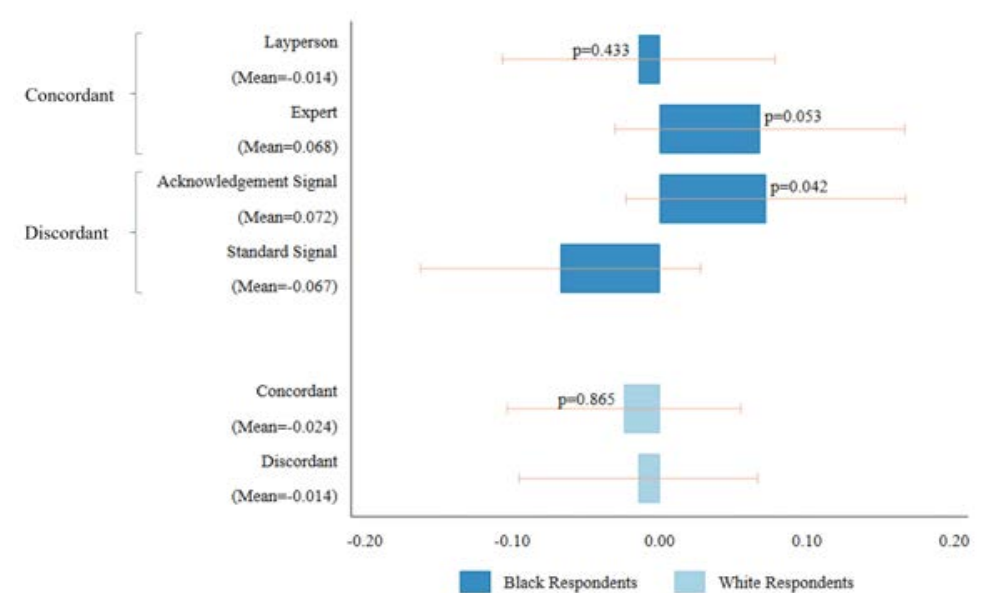

Panel (B): Signal Rating

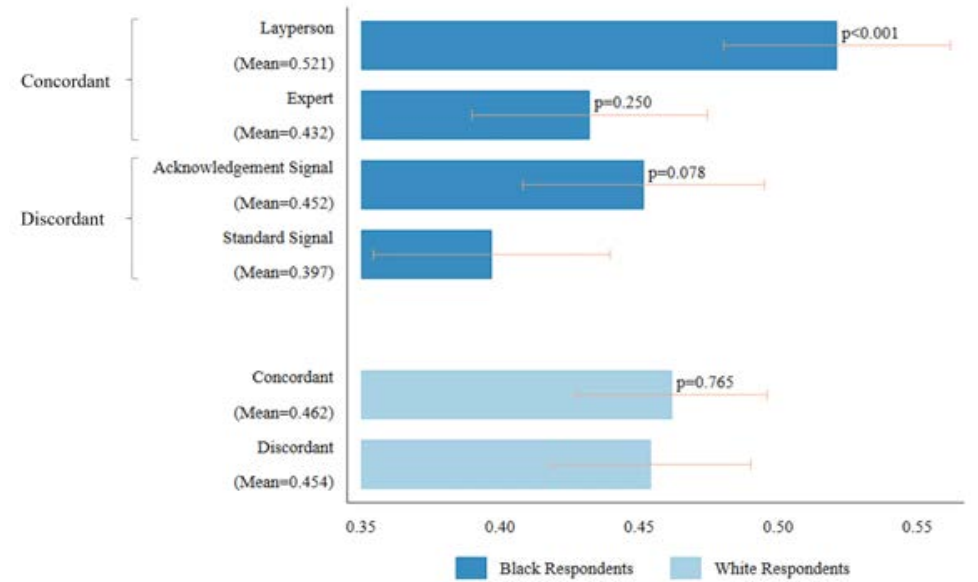

Panel (D): COVID-19 Vaccine Intent

Notes: Figure shows the mean of each primary outcome by treatment condition among the sample of Black respondents (dark blue bars), as well as among the sample of White respondents (light blue bars). Sender and signal rating are inverse-covariance-weighted indices as described in Anderson (2008); flu and COVID-19 vaccine intent have support 0 to 1 . For dark blue bars, $p$-values test the null hypotheses that the concordant expert, concordant non-expert (standard signal condition), and discordant expert (acknowledgement condition) means each differ from the discordant expert (standard signal condition) among Black respondents. For light blue bars, $p$-values test the null hypothesis that the concordant expert (standard signal condition) mean differs from the discordant expert (standard signal condition) among White respondents. 95\% confidence intervals using robust standard errors are shown.

Figure 1: Outcome Means By Treatment Arm 
cannot assess the impact of any one signal relative to a no-signal counterfactual directly, but differences between posterior and prior flu vaccination intent do provide some suggestive evidence (Appendix Figure A9). Reassuringly, we observe an increase or no change in flu vaccine intent among the vast majority (approximately 90\%) of respondents.

\section{B Heterogeneity}

What type of message is most persuasive may depend upon an individual's baseline beliefs about vaccines, which may be shaped by past experience with medical experts and vaccination. Those who elected to receive an influenza vaccine at some point in their lifetime may be less opposed to vaccines than those who never evinced a willingness to do so, all else equal. ${ }^{16}$ We divided the sample into three groups: "most hesitant", "moderate hesitant", and "least hesitant", based on whether the respondent reported never receiving a flu vaccine, receiving a flu vaccine over two years ago (with the majority of these individuals receiving their last vaccine over five years ago), or receiving a flu vaccine recently (within the past two years exclusive of the current season).

We fully interact our treatment effects with the three hesitancy indicator variables and report the results for each study arm in Figure $2 .{ }^{17,18}$ As hypothesized, we find striking heterogeneity in the persuasiveness of interventions across hesitancy groups: the lay signal is most persuasive among the most hesitant, while the acknowledgement and concordance conditions persuade those less hesitant more.

Specifically, panel A shows that non-experts are consistently judged as

\footnotetext{
${ }^{16}$ Indeed, we find that $69 \%$ of those who never received a flu vaccine in the past state prior to the video treatment that they are "not at all likely" to receive the flu vaccine in the current season, compared to $54 \%$ of those who are moderately hesitant and $20 \%$ of those who are least hesitant as measured by past vaccination take-up. Appendix Figure A10 provides a histogram of prior flu vaccine intent by respondent vaccination experience.

${ }^{17}$ We also test the null hypothesis that treatment effects for the most and least hesitant individuals are equal and report results in Appendix Table B11.

${ }^{18}$ We present additional heterogeneity results along other margins in Appendix Figure A11.
} 


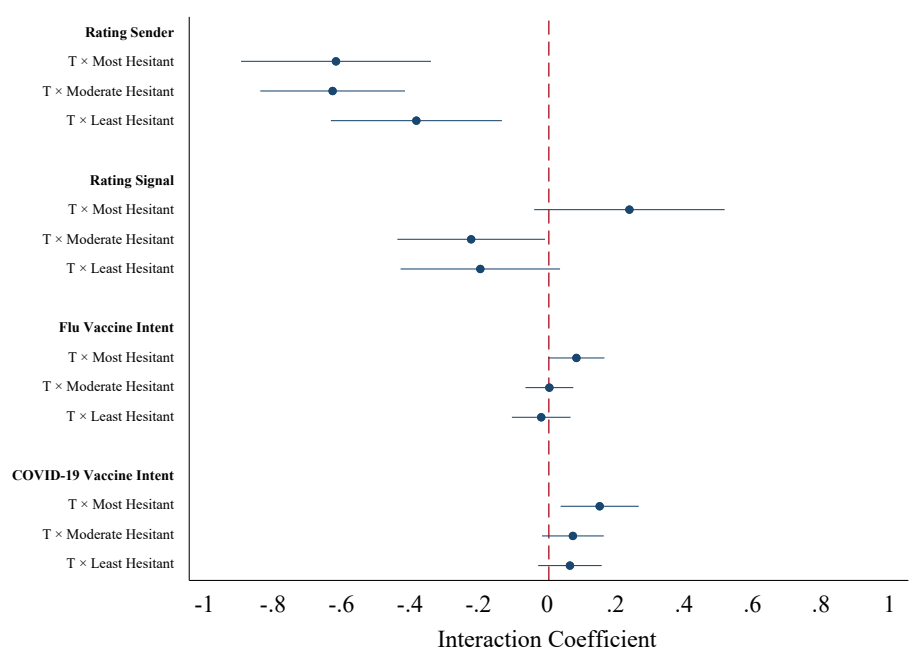

Panel (A): Layperson Treatment

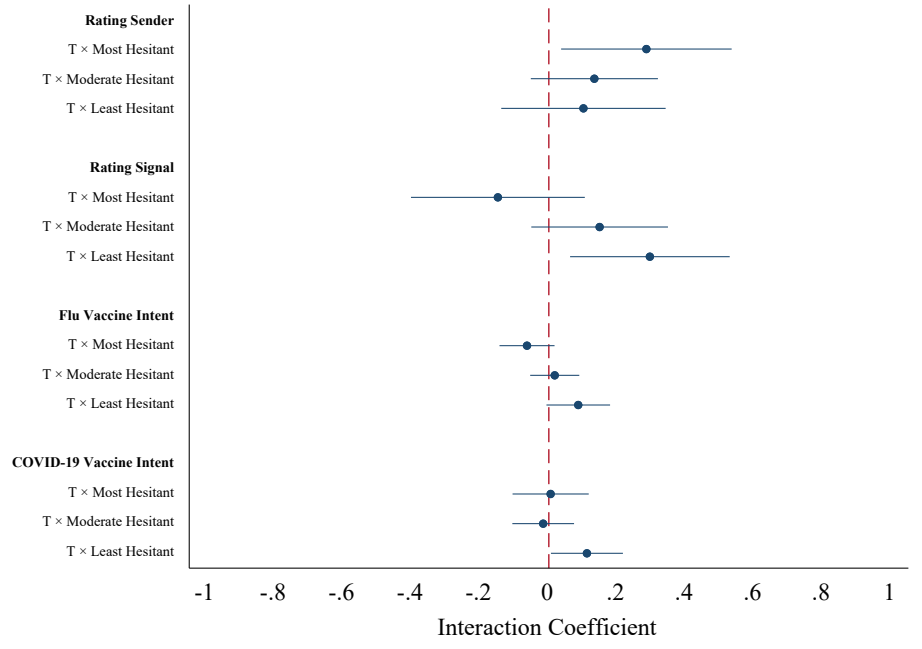

Panel (C): Concordance Treatment - Black Respondents $\gamma_{1}$ Moderate $_{i}+\gamma_{2}$ Least $_{i}+\mu X_{i}+\epsilon_{i}$. Interaction coefficients are shown. Most Hesitant is a binary variable equal to 1 if the respondent has never received the flu shot. Moderate Hesitant is a binary variable equal to 1 if the respondent received the flu shot more than 2 years ago. Least Hesitant is a binary variable equal to 1 if the respondent received the flu shot within the past 2 years, not including the current season. Controls $X_{i}$ include season dummy and survey platform fixed effects. Sender rating and signal rating are inverse-covariance-weighted indices as described in Anderson (2008). 95\% confidence intervals using robust standard errors are shown.

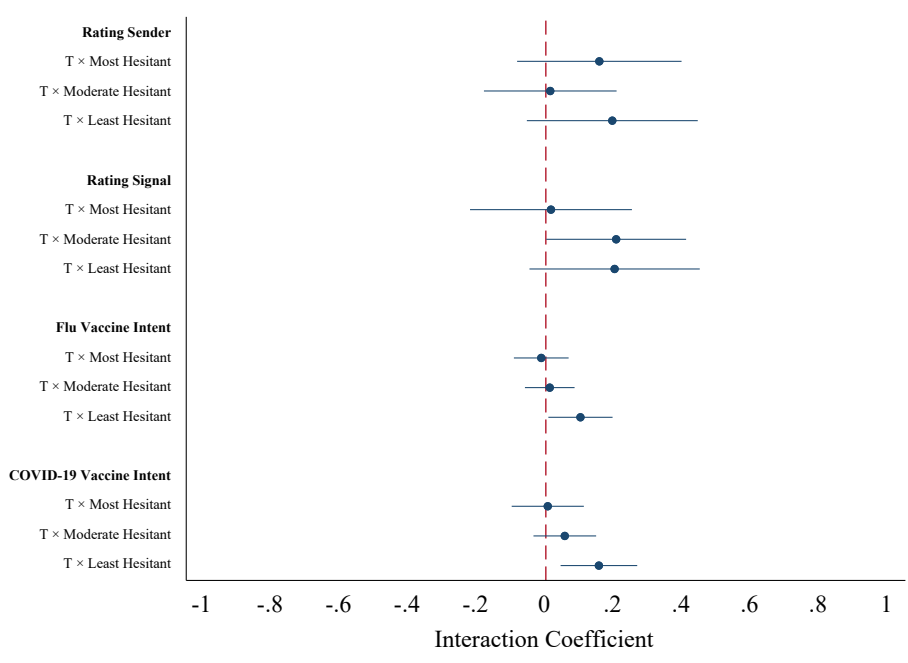

Panel (B): Acknowledgement Signal Treatment

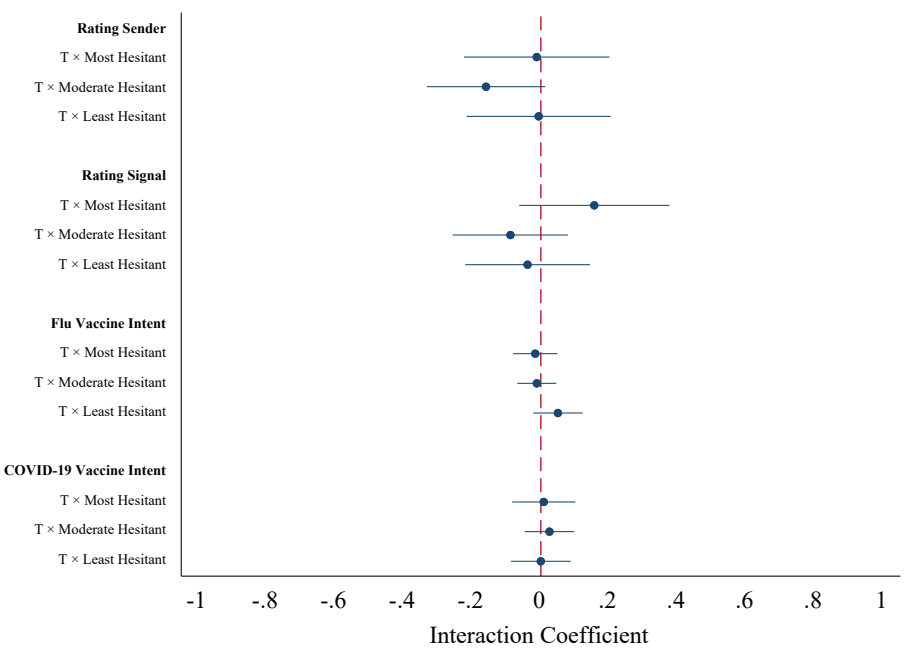

Panel (D): Concordance Treatment - White Respondents

(1)

Figure 2: Heterogeneity by Vaccine Hesitancy 
unqualified to provide medical advice and this does not vary by prior flu vaccination experience. However, the rating of the signal delivered by nonexpert senders is more positive among the most hesitant and this difference is statistically significant at the $10 \%$ level, a result strikingly different from the perception among the least hesitant. Moreover, the effect of non-expert senders on both influenza and COVID-19 vaccine intent is large, significant, and positive for the most hesitant, and in the former case statistically different from those who are least hesitant.

The positive effect of the acknowledgement intervention on signal ratings is driven by those who have ever received a vaccine (i.e. the "moderately hesitant"), with the coefficient estimate among the least hesitant large but imprecise (Panel B). The acknowledgement signal increases flu and COVID19 vaccination intent substantially among the least hesitant of the flu vaccine, while effects on intent among the most hesitant are muted and significantly different from respondents with recent immunization experience.

Panel $\mathrm{C}$ demonstrates that among Black respondents, concordance effects on signal ratings and flu vaccination intent are positive and statistically significant only among those that have recently taken up the vaccine (i.e. the least hesitant). There is no such heterogeneity among White respondents in Panel D.

\section{Contextualizing Findings}

Our findings suggest that two key processes shape how individuals absorb advice about vaccines; they jointly rationalize the central findings of our paper:

I) A patient's trust in medical advice from experts (relative to lay persons) may differ when the advice concerns vaccines or other preventives than when it concerns the treatment of an acute condition; such a dynamic is consistent with two key findings in our data: First, we find that rating of the signal (in terms of its relevance, as well as willingness to share the information provided) is much more predictive of vaccination intention than the 
rating of the sender (which captures respondent's perception of the sender's medical expertise and qualification to provide general medical advice). Second, we find that the non-expert intervention simultaneously performs "worst" with respect to respondents' trust in the medical qualifications of the sender, while performing "best" with respect to vaccination intent and take-up.

II) The decision to follow medical advice on vaccines, among low SES, vaccine-hesitant individuals like the ones in our sample, may not operate through direct updating about the relevant parameters of vaccine safety and effectiveness, but through mental "short-cuts" that operate at a faster and easier level: through assessments of whether the advice giver is perceived as trustworthy when it comes to advice about vaccines. This assessment, in turn, may depend on many factors, such as the sender's social proximity (in age, race, perceived socio-economic status). This hypothesis is in line with our finding that vaccination intent and take-up may increase even though we do not observe updating about, for example, vaccine safety. It also rationalizes why updating differs across intervention arms, even though the information disseminated is precisely held constant.

\section{Conclusion}

Low demand for high-value preventive care is of interest to policymakers and a puzzle for researchers. In this paper, we examine the effect of various sender and signal combinations on vaccination outcomes in a sample of low SES men. Although race-concordant expert senders and race-discordant expert senders acknowledging past medical injustice earned higher ratings from Black individuals, we find that signals on vaccination delivered by a race-concordant layperson led to the greatest increases in intent to be vaccinated against influenza and COVID-19, and take-up of the flu vaccine. The effects of non-expert senders were concentrated among respondents with no prior experience with flu vaccination, a group that may be particularly difficult to persuade, whereas experts move vaccination intent most among those immunized in recent years. 
These results are important in understanding how best to improve vaccination take-up rates and reduce health inequality. The effectiveness of non-expert senders relates to work by Larson (2020), who notes that individuals reluctant to vaccinate may be more moved by "heard truths" from proximate community members than elite experts. An alternative explanation is that medical doctors discussing the benefits of vaccination are viewed as agents not solely of the individual patient, but also of broader social interests or private interests such as insurers or pharmaceutical companies. ${ }^{19}$ Through such a lens, professionals, though qualified, may also appear conflicted, whereas laypersons do not. More broadly, our results suggest a role for communicating information on preventive care through senders diverse both in racial background as well as level of expertise.

\footnotetext{
${ }^{19}$ One such comment from respondents was "Medical industry using mind games to get people to buy their nonsense." We thank Keith Ericson for the interpretation of doctors as agents acting on behalf of potentially multiple principals.
} 


\section{References}

Alatas, Vivi, Arun G Chandrasekhar, Markus Mobius, Benjamin A Olken, and Cindy Paladines. 2019. "When Celebrities Speak: A Nationwide Twitter Experiment Promoting Vaccination In Indonesia." National Bureau of Economic Research, 1-54. Working Paper 25589.

Alsan, Marcella, and Marianne Wanamaker. 2018. "Tuskegee and the Health of Black Men." The Quarterly Journal of Economics, 133(1): 407-455.

Alsan, Marcella, Fatima Cody Stanford, Abhijit Banerjee, Emily Breza, Arun Chandrasekhar, Sarah Eichmeyer, Paul Goldsmith-Pinkham, Lucy Obgu-Nwobodo, Benjamin Olken, Carlos Torres, Anirudh Sankar, Pierre-Luc Vautrey, and Esther Duflo. 2020. “Comparison of Knowledge and Information-Seeking Behavior After General COVID-19 Public Health Messages and Messages Tailored for Black and Latinx Communities : A Randomized Controlled Trial." Annals of Internal Medicine, $1-13$.

Alsan, Marcella, Owen Garrick, and Grant Graziani. 2019. “Does Diversity Matter for Health? Experimental Evidence from Oakland." American Economic Review, 109(12): 4071-4111.

American Association of Medical Colleges. 2019. "Diversity in Medicine: Facts and Figures 2019 - Figure 20. Percentage of physicians by sex and race/ethnicity, 2018." https://www.aamc.org/datareports/workforce/interactive-data/figure-20-percentage-physicianssex-and-race/ethnicity-2018 (accessed March 10, 2021).

Anderson, Michael L. 2008. "Multiple Inference and Gender Differences in the Effects of Early Intervention: A Reevaluation of the Abecedarian, Perry Preschool, and Early Training Projects." Journal of the American Statistical Association, 103(484): 1481-1495. 
Bajaj, Simar Singh, and Fatima Cody Stanford. 2021. "Beyond Tuskegee Vaccine Distrust and Everyday Racism." New England Journal of Medicine, 384: e12.

Banerjee, Abhijit Vinayak, Esther Duflo, Rachel Glennerster, and Dhruva Kothari. 2010. "Improving immunisation coverage in rural India: clustered randomised controlled evaluation of immunisation campaigns with and without incentives." BMJ, 340: 1-9.

Bhargava, Saurabh, George Loewenstein, and Shlomo Benartzi. 2017. "The costs of poor health (plan choices) \& prescriptions for reform." Behavioral Science and Policy, 3(1): 1-12.

Blendon, Robert J, John M Benson, and Joachim O Hero. 2014. "Public Trust in Physicians - U.S. Medicine in International Perspective." New England Journal of Medicine, 371(17): 1570-1572.

Blewett, Lynn A., Julia A. Rivera Drew, Risa Griffin, Jari C.W. Williams, and Daniel Backman. 2018. "IPUMS Health Surveys: Medical Expenditure Panel Survey, Version 1.0 [Medical Expenditure Panel Survey, 2005-2015]." Minneapolis, MN: IPUMS. https://ipums.org/projects/ ipums-health-surveys/d071.v1.0 (accessed March 10, 2021).

Brandt, Allan M. 1978. "Racism and Research: The Case of the Tuskegee Syphilis Study." The Hastings Center Report, 8(6): 21-29.

Brewer, Noel T., Gretchen B. Chapman, Alexander J. Rothman, Julie Leask, and Allison Kempe. 2017. "Increasing Vaccination: Putting Psychological Science Into Action." Psychological Science in the Public Interest, 18(3): 149-207.

Brot-Goldberg, Zarek C., Amitabh Chandra, Benjamin R. Handel, and Jonathan T. Kolstad. 2017. "What does a Deductible Do? The Impact of Cost-Sharing on Health Care Prices, Quantities, and Spending Dynamics." The Quarterly Journal of Economics, 132(3): 1261-1318. 
Centers for Disease Control and Prevention. 2018. "Behavioral Risk Factor Surveillance System 2017 (BRFSS 2017)." Centers for Disease Control and Prevention. https://www.cdc.gov/brfss/annual_data/annual_2017. html (accessed May 31, 2019).

Centers for Disease Control and Prevention. 2020. "Past Seasons Estimated Influenza Disease Burden Averted by Vaccination." https://www.cdc. gov/flu/vaccines-work/past-burden-averted-est.html (accessed February 25,2021$)$.

Centers for Disease Control and Prevention. 2021a. "Results for General Population Influenza Vaccination Coverage." https://www.cdc.gov/flu/ fluvaxview/interactive-general-population.htm (accessed February 25, 2021).

Centers for Disease Control and Prevention. 2021b. "Weekly Cumulative Doses (in Millions) of Influenza Vaccines Distributed, United States, 20162021." https://www.cdc.gov/flu/fluvaxview/dashboard/vaccinationdoses-distributed.html (accessed February 25, 2021).

Centers for Medicare and Medicaid Services. 2010. "Background: The Affordable Care Act's New Rules on Preventive Care." https: //www.cms.gov/CCIIO/Resources/Fact-Sheets-and-FAQs/preventivecare-background (accessed February 25, 2021).

Chandra, Amitabh, Evan Flack, and Ziad Obermeyer. 2021. "The Health Costs of Cost Sharing." National Bureau of Economic Research, 1-55. Working Paper 28439.

Cooper, Lisa A., Debra L. Roter, Rachel L. Johnson, Daniel E. Ford, Donald M. Steinwachs, and Neil R. Powe. 2003. "Patient-Centered Communication, Ratings of Care, and Concordance of Patient and Physician Race." Annals of Internal Medicine, 139(11): 907-915.

Cooper-Patrick, Lisa, Joseph J. Gallo, Junius J. Gonzales, Hong Thi Vu, Neil R. Powe, Christine Nelson, and Daniel E. Ford. 1999. “Race, Gen- 
der, and Partnership in the Patient-Physician Relationship." Journal of the American Medical Association, 282(6): 583-589.

DellaVigna, Stefano, and Devin Pope. 2018. "Predicting Experimental Results: Who Knows What?" Journal of Political Economy, 126(6): 2410-2456.

Eichengreen, Barry, Cevat Giray Aksoy, and Orkun Saka. 2021. "Revenge of the Experts: Will COVID-19 Renew or Diminish Public Trust in Science?" Journal of Public Economics, 193: 104343.

Ericson, Keith Marzilli, and Justin Sydnor. 2017. "The Questionable Value of Having a Choice of Levels of Health Insurance Coverage." Journal of Economic Perspectives, 31(4): 51-72.

Gallegos, Alicia. 2016. "AAMC Report Shows Decline of Black Males in Medicine." Association of American Medical Colleges. https://www.aamc.org/news-insights/aamc-report-shows-declineblack-males-medicine (accessed March 10, 2021).

Gauchat, Gordon. 2012. "Politicization of Science in the Public Sphere: A Study of Public Trust in the United States, 1974 to 2010." American Sociological Review, 77(2): 167-187.

Greenwood, Brad N., Rachel R. Hardeman, Laura Huang, and Aaron Sojourner. 2020. "Physician-patient racial concordance and disparities in birthing mortality for newborns." Proceedings of the National Academy of Sciences of the United States of America, 117(35): 21194-21200.

Greenwood, Brad N., Seth Carnahan, and Laura Huang. 2018. "Patient-physician gender concordance and increased mortality among female heart attack patients." Proceedings of the National Academy of Sciences of the United States of America, 115(34): 8569-8574.

Hammond, Wizdom Powell, Derrick Matthews, Dinushika Mohottige, Amma Agyemang, and Giselle Corbie-Smith. 2010. "Association of Patient Perceptions of Cardiovascular Risk and Beliefs on Statin Drugs 
with Racial Differences in Statin Use: Insights From the Patient and Provider Assessment of Lipid Management Registry." JAMA Cardiology, 25(12): 1300-08.

Handel, Benjamin R., and Jonathan T. Kolstad. 2015. "Health Insurance for "Humans": Information Frictions, Plan Choice, and Consumer Welfare." American Economic Review, 105(8): 2449-2500.

Handel, Benjamin R., and Joshua Schwartzstein. 2018. “Frictions or Mental Gaps: What's Behind the Information We (Don't) Use and When Do We Care?" Journal of Economic Perspectives, 32(1): 155-178.

Harris, Katherine M., Jürgen Maurer, and Lori Uscher-Pines. 2010. "Seasonal Influenza Vaccine Use by Adults in the U.S: A Snapshot from the End of the 2009-2010 Vaccination Season." RAND Corporation, 1-3. Document OP-311-GSK.

Health Day News. 2021. "Poll: Education level a prime driver of COVID-19 vaccine hesitancy." Untied Press International. https: //www.upi.com/Health_News/2021/02/27/coronavirus-vaccinehesitation-education-level/3001614375413/ (accessed February 27, 2021).

Heckman, James J. 1998. “Detecting discrimination." Journal of economic perspectives, 12(2): 101-116.

Hester, Neil, and Kurt Gray. 2018. "For Black men, being tall increases threat stereotyping and police stops." Proceedings of the National Academy of Sciences of the United States of America, 115(11): 2711-2715.

Hill, Andrew, Daniel Jones, and Lindsey Woodworth. 2020. "PhysicianPatient Race-Match Reduces Patient Mortality." Social Science Research Network, 1-44. Working Paper.

Idan, Edna, Anlu Xing, Javarcia Ivory, and Marcella Alsan. 2020. “Sociodemographic Correlates of Medical Mistrust among African American Men 
Living in the East Bay." Journal of Health Care for the Poor and Underserved, 31(1): 115-127.

Kamenica, Emir, and Matthew Gentzkow. 2011. "Bayesian Persuasion." American Economic Review, 101(6): 2590-2615.

Kinlock, Ballington, Lauren J. Parker, Janice V. Bowie, Daniel L. Howard, Thomas A. Laveist, and Roland J. Thorp Jr. 2017. “High Levels of Medical Mistrust Are Associated with Low Quality of Life among Black and White Men with Prostate Cancer." Cancer Control, 24(1): 72-77.

Larson, Heidi J. 2020. Stuck: How Vaccine Rumors Start - and Why They Don't Go Away. New York, NY:Oxford University Press.

Lee, David S. 2009. "Training, Wages, and Sample Selection: Estimating Sharp Bounds on Treatment Effects." The Review of Economic Studies, 76(3): 1071-1102.

Milkman, Katherine L, John Beshears, James J Choi, David Laibson, and Brigitte C Madrian. 2011. "Using implementation intentions prompts to enhance influenza vaccination rates." Proceedings of the National Academy of Sciences of the United States of America, 108(26): 10415-10420.

Nanna, Michael G., Ann Marie Navar, Pearl Zakroysky, Qun Xiang, Anne C. Goldberg, Jennifer Robinson, Veronique L. Roger, and et al. 2018. "Association of Patient Perceptions of Cardiovascular Risk and Beliefs on Statin Drugs with Racial Differences in Statin Use: Insights From the Patient and Provider Assessment of Lipid Management Registry." JAMA Cardiology, 3(3): 739-48.

Newhouse, Joseph P. 2020. "An Ounce of Prevention." National Bureau of Economic Research, 1-20. Working Paper 27553.

Newhouse, Joseph P., and Insurance Experiment Group. 1993. Free for All? Lessons from the RAND Health Insurance Experiment. Cambridge, MA:Harvard University Press. 
Nichol, Kristin L., Kenneth P. Mallon, and Paul M. Mendelman. 2003. "Cost benefit of influenza vaccination in healthy, working adults: an economic analysis based on the results of a clinical trial of trivalent live attenuated influenza virus vaccine." Vaccine, 21(17-18): 2207-2217.

Oliver, Mary Beth. 2003. "African American Men as "Criminal and Dangerous": Implications of Media Portrayals of Crime on the "Criminalization" of African American Men." Journal of African American Studies, 3-18.

Opel, Douglas J., Bernard Lo, and Monica E. Peek. 2021. "Addressing Mistrust About COVID-19 Vaccines Among Patients of Color." Annals of Internal Medicine, 1-4.

Pager, Devah. 2007. "The use of field experiments for studies of employment discrimination: Contributions, critiques, and directions for the future." The Annals of the American Academy of Political and Social Science, 609(1): 104-133.

Petrilli, Christopher M., Sanjay Saint, Joseph J. Jennings, Andrew Caruso, Latoya Kuhn, Ashley Snyder, and Vineet Chopra. 2018. “Understanding patient preference for physician attire: a cross-sectional observational study of 10 academic medical centres in the USA." BMJ Open, 8(5).

Ries, Tonia. 2016. "The Inversion of Influence." Edelman. https://www. edelman.com/post/inversion-of-influence.

Sapienza, Paola, and Luigi Zingales. 2013. "Economic Experts versus Average Americans." American Economic Review: Papers \& Proceedings, 103(3): 636-642.

Street, Richard L., Kimberly J. O'Malley, Lisa A. Cooper, and Paul Haidet. 2008. "Understanding Concordance in Patient-Physician Relationships: Personal and Ethnic Dimensions of Shared Identity." The Annals of Family Medicine, 6(3): 198-205. 
Sun, Michael, Tomasz Oliwa, Monica E. Peek, and Elizabeth L. Tung. 2022. "Negative Patient Descriptors: Documenting Racial Bias In The Electronic Health Record." Health Affairs, 41(2).

Torres, Carlos, Lucy Ogbu-Nwobodo, Marcella Alsan, Fatima Cody Stanford, Abhijit Banerjee, Emily Breza, Arun G. Chandrasekhar, Sarah Eichmeyer, Mohit Karnani, Tristan Loisel, Paul Goldsmith-Pinkham, Benjamin A. Olken, Pierre-Luc Vautrey, Erica Warner, Esther Duflo, and the COVID-19 Working Group. 2021. "Comparison of Knowledge and Behavior Following Physician-delivered COVID-19 Public Health Messages and Messages Acknowledging Racial Inequity: A Randomized Clinical Trial." Unpublished.

Varnado-Sullivan, Paula, Michele Larzelere, Kaly Solek, Shalinder Gupta, Jackson E. Hatfield, Mohammad H. Cheema, and Matthew Delfino. 2019. "The Impact of Physician Demographic Characteristics on Perceptions of Their Attire." Familiy Medicine, 51(9).

Williams, David R, and Toni D Rucker. 2000. "Understanding and addressing racial disparities in health care." Health care financing review, 21(4): 75. 


\section{Appendix}

\section{Table of Contents}
A Appendix Figures
A. 2
B Appendix Tables
A.13
C Baseline Survey Questionnaire
A.24
D Videos and Scripts
A. 25

E Outcome Measures: Question Wording 


\section{A Appendix Figures}

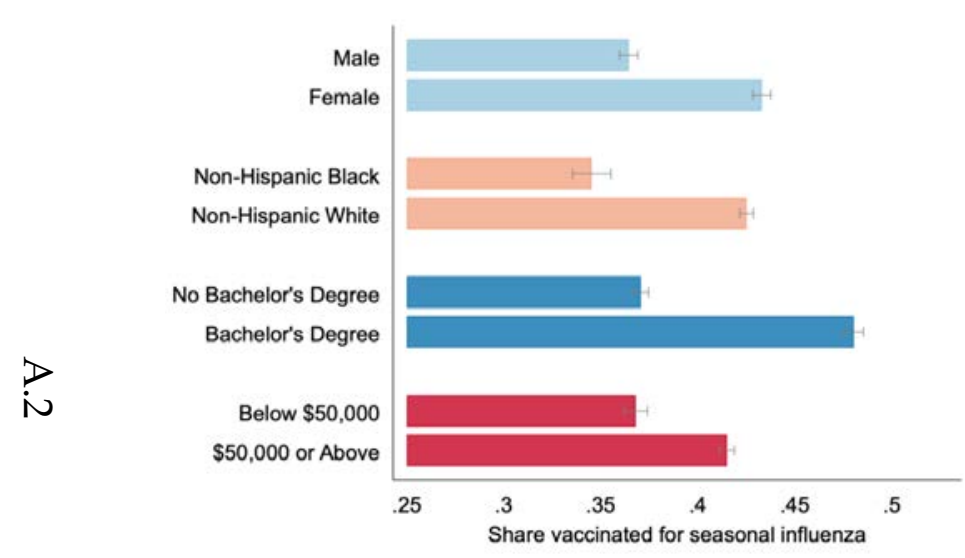

Panel (A): By Sex, Race, Education and Household Income

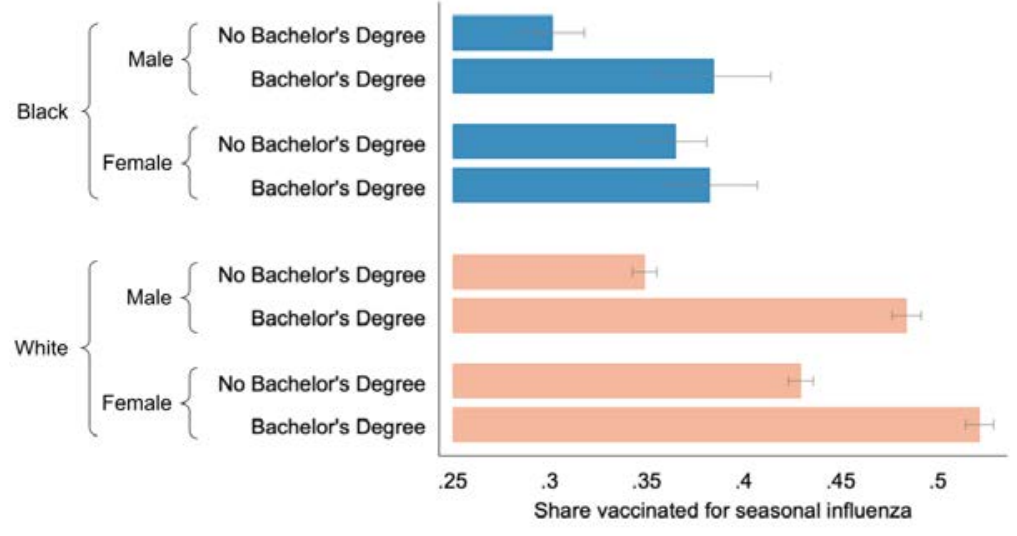

Panel (B): Intersectionality of Race, Sex and Education

Notes: Figure is based on data from the 2017 Behavioral Risk Factor Surveillance System survey (Centers for Disease Control and Prevention 2018). Panel (A) reports means by sex, race, education level, and household income. Panel (B) reports the intersectionality of race, sex and education. Observations are weighted using survey sample weights. $95 \%$ confidence intervals are shown.

Appendix Figure A1: Seasonal Flu Vaccination Rates 


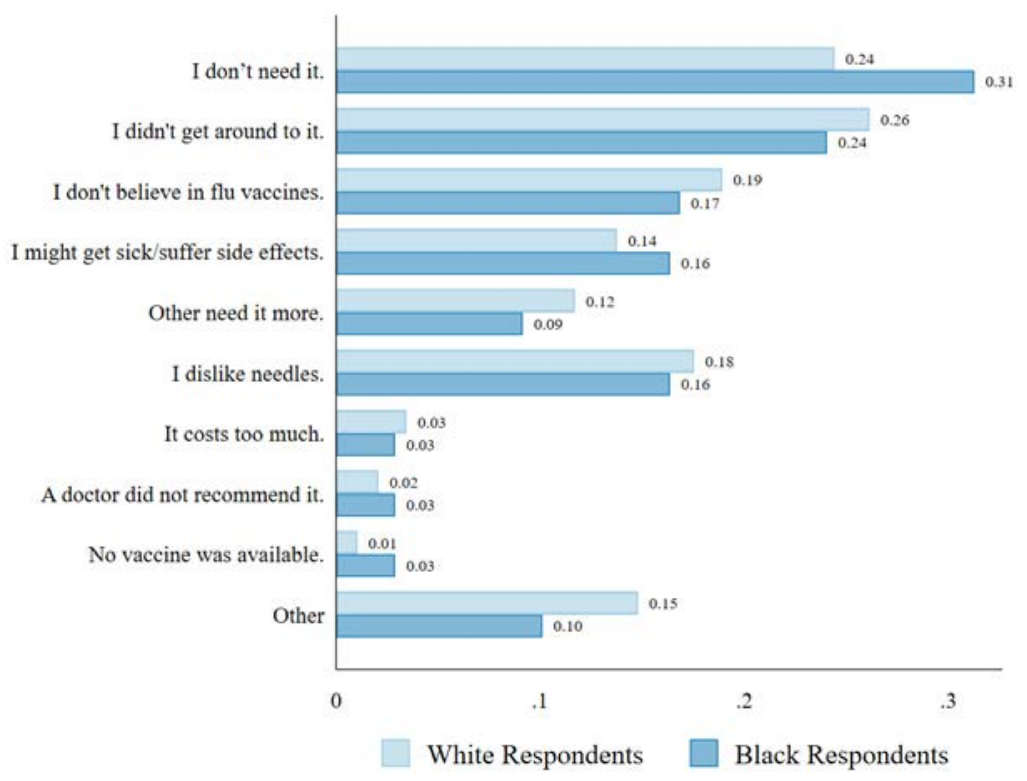

Notes: Figure is based on the follow-up survey sample, restricting to the respondents who indicated that they had not received a flu vaccine since the baseline survey $(\mathrm{N}=499)$. Respondents were asked the following question: "You said that you did not get the flu shot. Why is that? Please see list below and check all reasons that apply." The question on and list of reasons for not wanting an influenza vaccination were adopted from a 2010 RAND survey (Harris, Maurer and Uscher-Pines 2010).

\section{Appendix Figure A2: Reasons for Not Vaccinating}




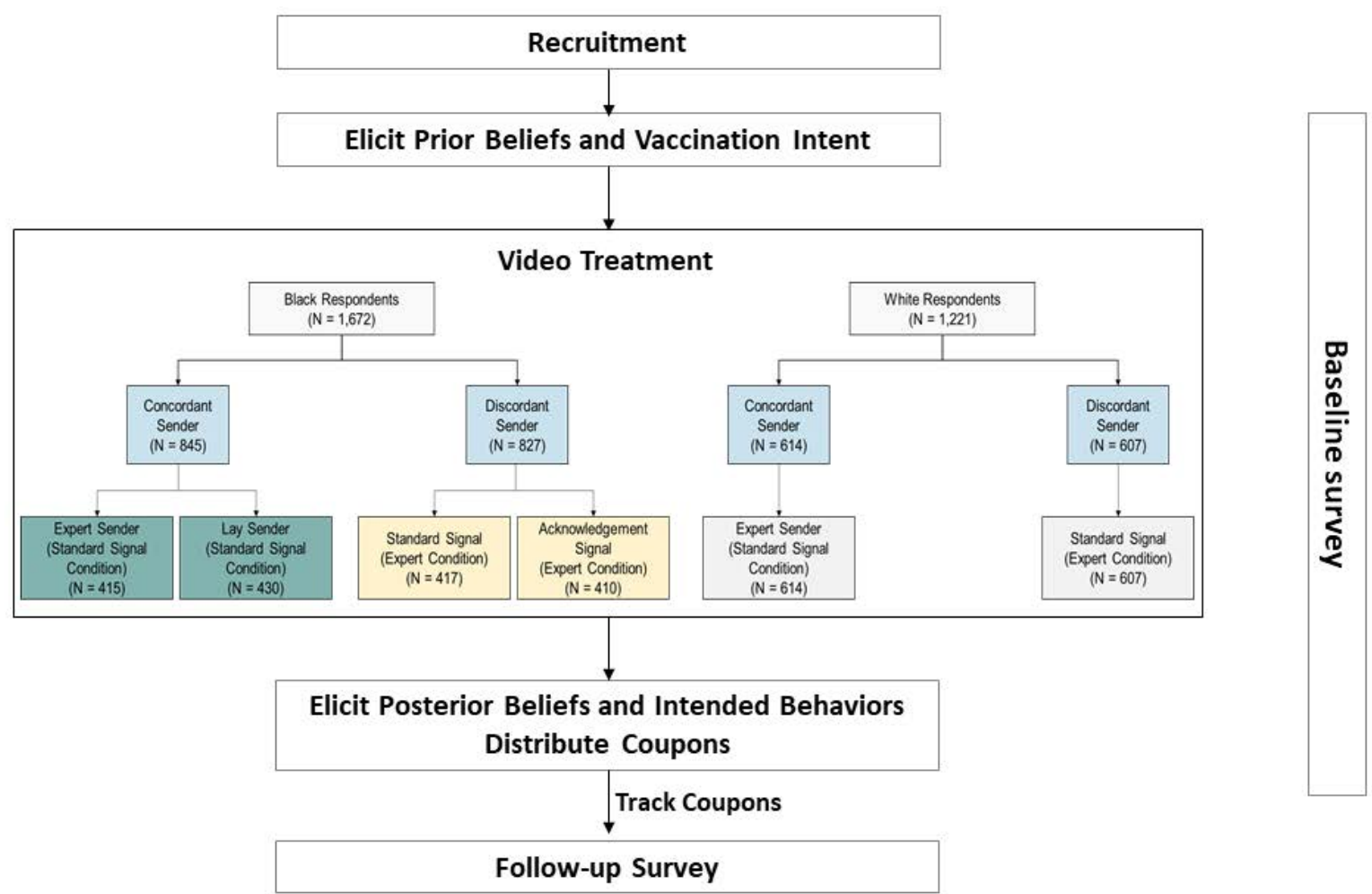

Appendix Figure A3: Study Design 


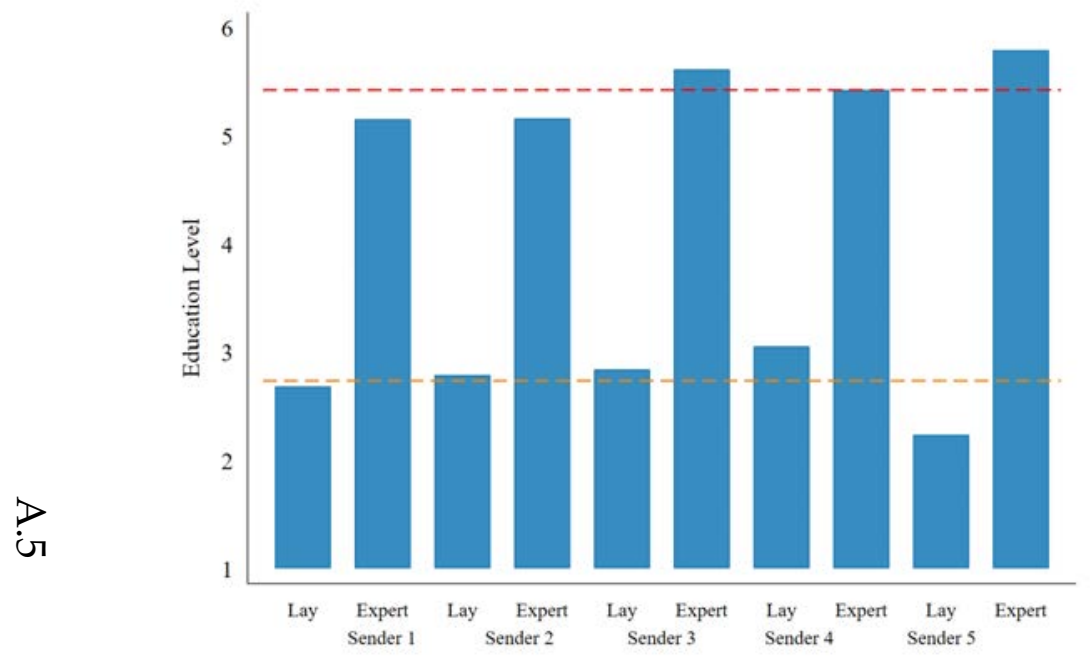

Panel (A): Black Senders

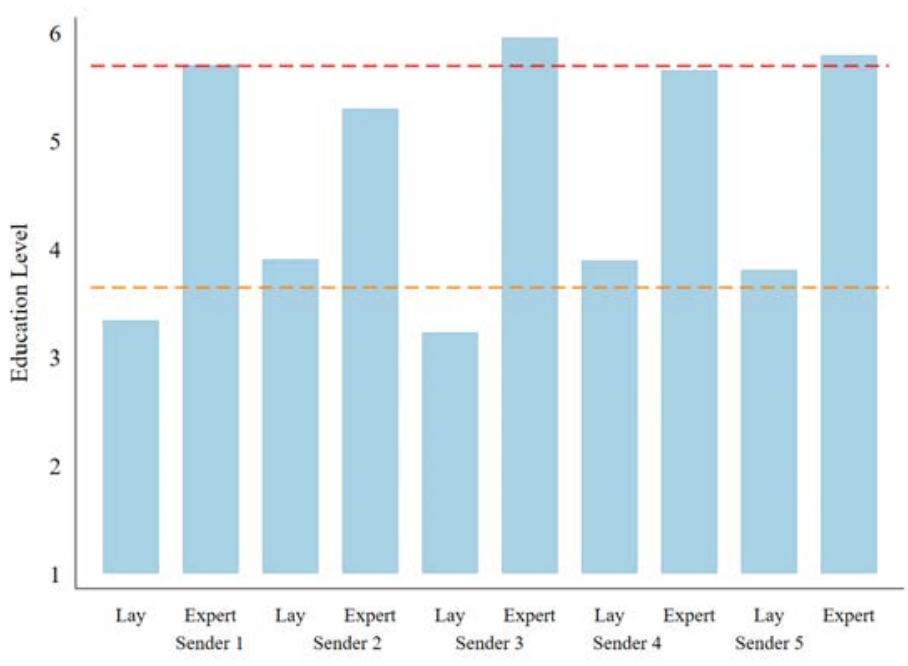

Panel (B): White Senders

Notes: Figure displays the mean of MTurkers' ratings of sender education by race and role of senders based on a sample of $381 \mathrm{Mturkers.} \mathrm{Each} \mathrm{sender} \mathrm{was} \mathrm{rated} \mathrm{on}$ their level of education on a scale of 1 (lowest; less than high school education) to 6 (highest; a graduate degree), in both a layperson and expert role. The red lines represent the mean education rating in an expert role for all Black senders (Panel (A)) and White senders (Panel (B)). The orange lines represent the mean education rating in a layperson role for all Black senders (Panel (A)) and White senders (Panel (B)).

\section{Appendix Figure A4: MTurkers' Ratings of Black and White Senders}




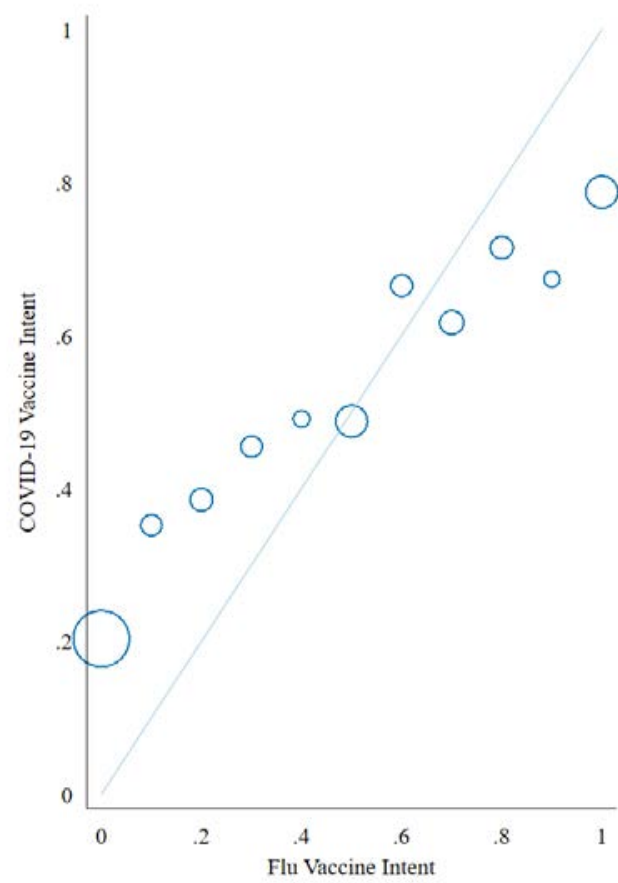

Panel (A): Black Respondents

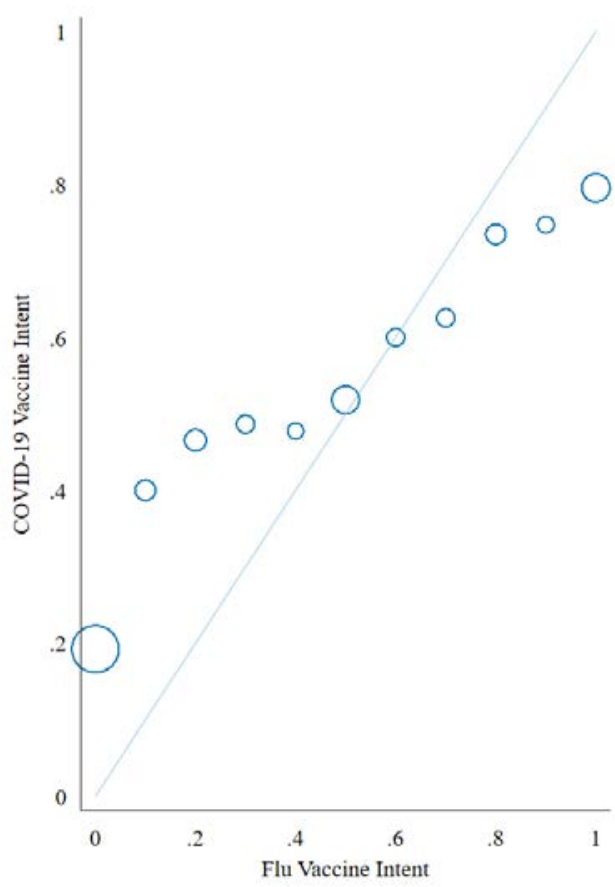

Panel (B): White Respondents

Notes: Figure shows the relationship between Flu Vaccine Intent (on a scale of 0 to 1 ) and COVID-19 Vaccine Intent (on a scale of 0 to 1 ). The size of dots represents the number of respondents in each bin of Flu Vaccine Intent. The figure is based on the sample of respondents from the 2020-2021 flu season, as the question about COVID-19 Vaccine Intent was not asked during the 2019-2020 flu season.

\section{Appendix Figure A5: Relationship Between Flu Vaccine Intent and COVID-19 Vaccine Intent}




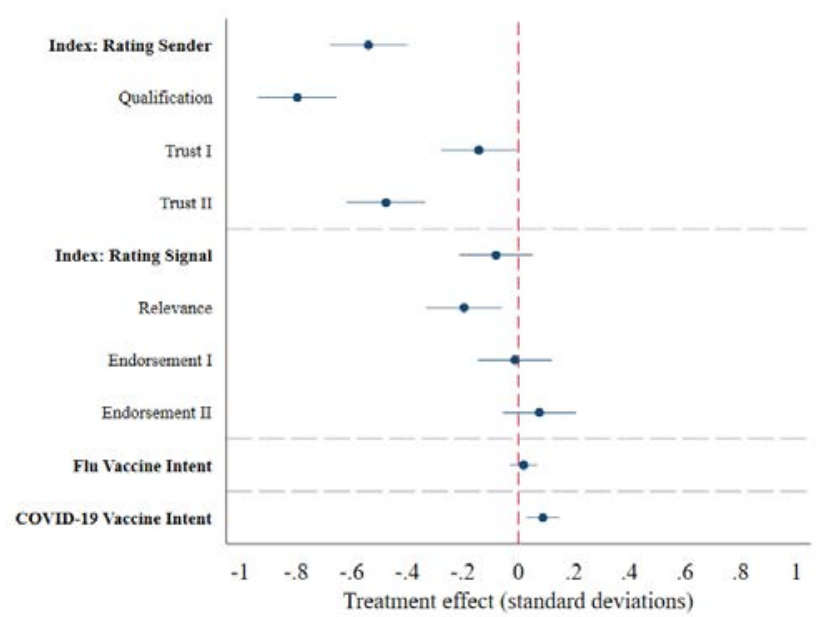

Panel (A): Layperson Treatment

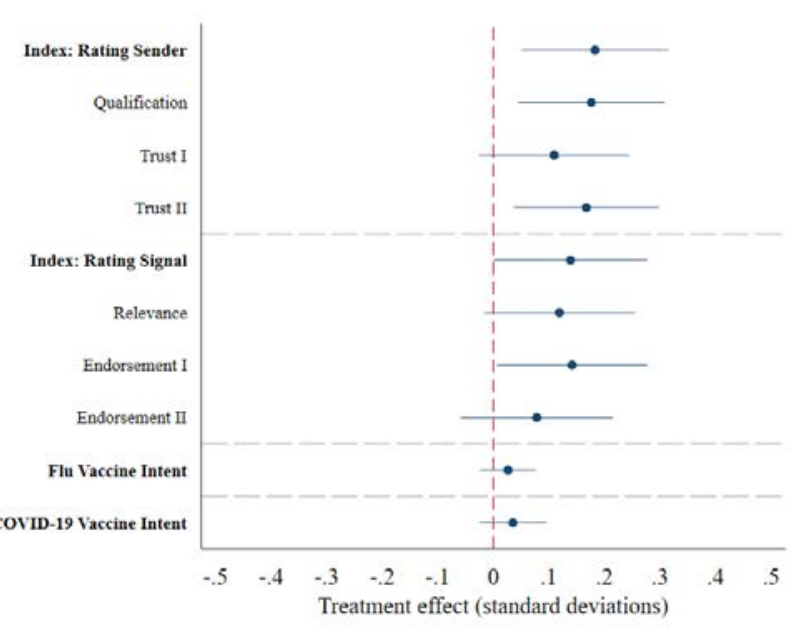

Panel (C): Concordance Treatment - Black Respondents

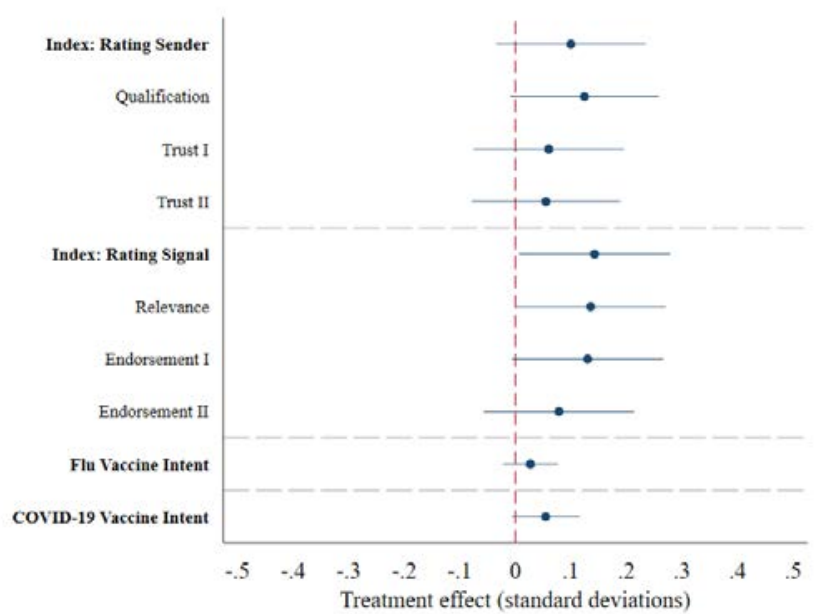

Panel (B): Acknowledgement Signal Treatment

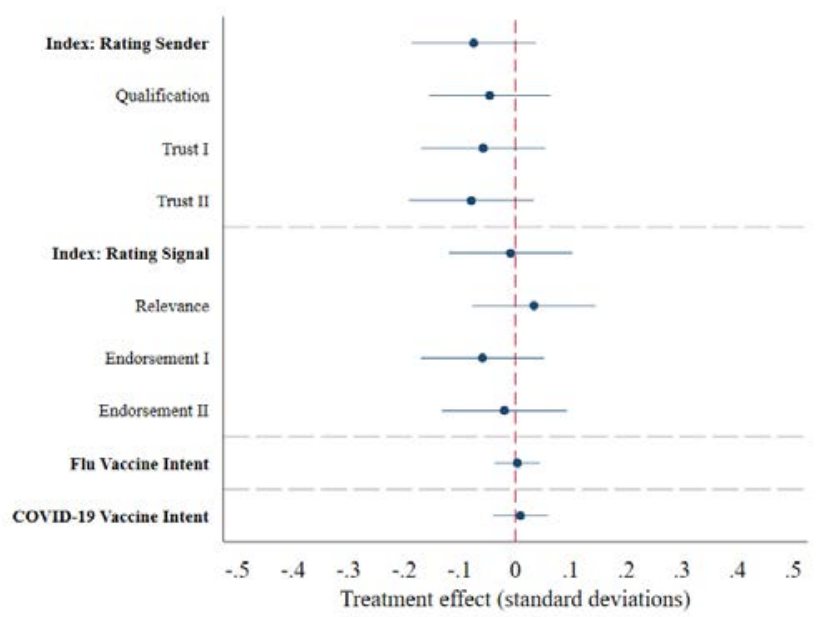

Panel (D): Concordance Treatment - White Respondents Notes: Figure shows treatment effects on each individual outcome that enters a primary outcome index, for each treatment comparison (A: layperson vs. expert sender; B: acknowledgement vs. standard message; C and D: concordant vs. discordant sender). Outcomes are described in Section III and in Appendix Section E. Outcomes are standardized, except flu vaccine and COVID-19 vaccination intent. Dots represent coefficient estimates obtained from OLS regressions of each outcome of interest on the treatment indicator variable. Stratifying variables (platform and season) are included as controls in the regression but not reported. $95 \%$ confidence intervals using robust standard errors are shown.

\section{Appendix Figure A6: Treatment Effects For Each Component of the Primary Outcomes}




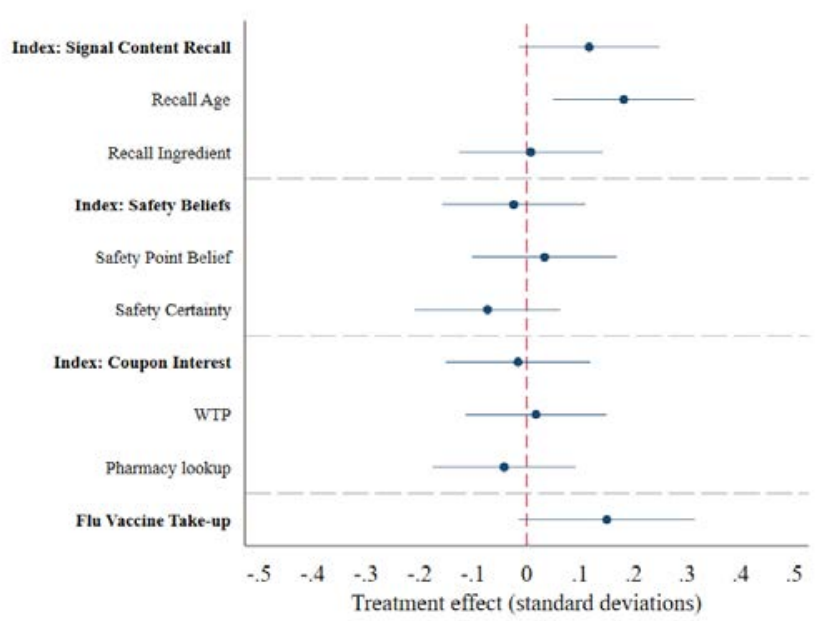

Panel (A): Layperson Treatment

$\stackrel{D}{\infty}$

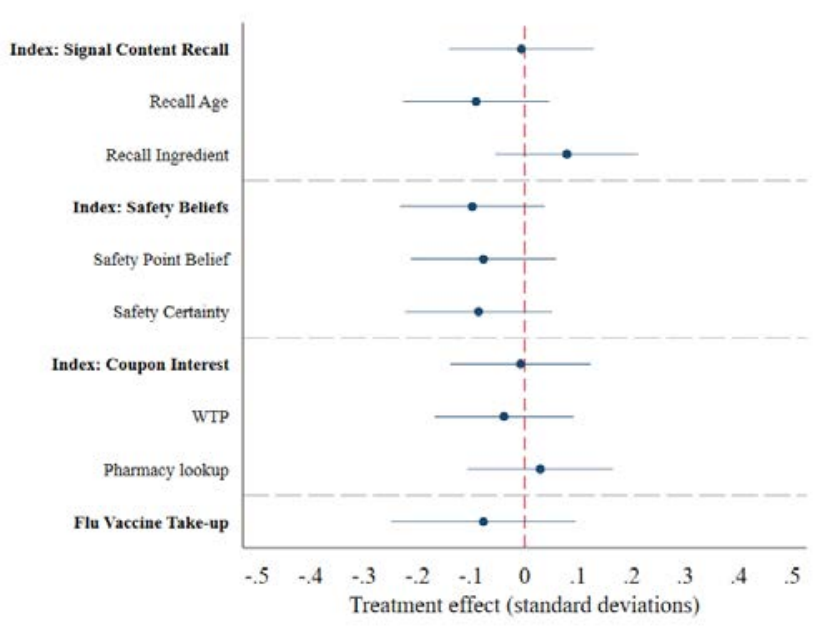

Panel (C): Concordance Treatment - Black Respondents Notes: Figure E. Outcomes are standardized, except flu vaccine take-up. Dots represent coefficient estimates obtained from OLS regressions of each outcome of interest on the treatment indicator variable. Stratifying variables (platform and season) are included as controls in the regression but not reported; an additional stratifying variable (an indicator $(=1)$ if the respondent is married) is included in the regression of the take-up outcome. 95\% confidence intervals using robust standard errors are shown.

\section{Appendix Figure A7: Treatment Effects For Each Component of the Secondary Outcomes}

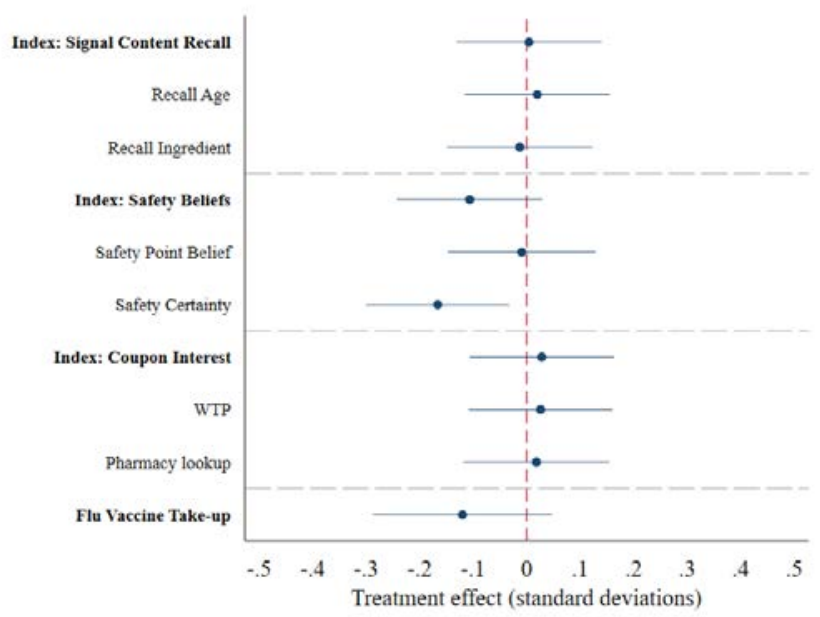

Panel (B): Acknowledgement Signal Treatment

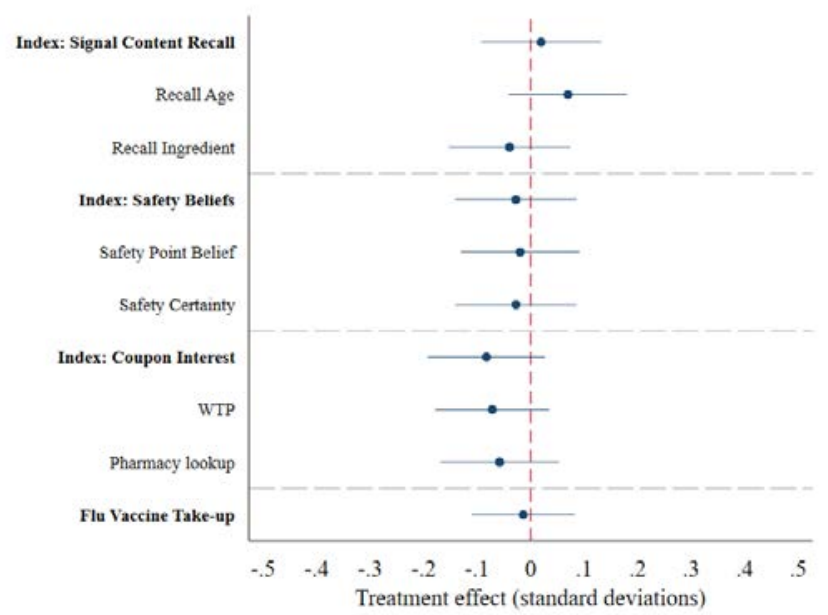

Panel (D): Concordance Treatment - White Respondents 

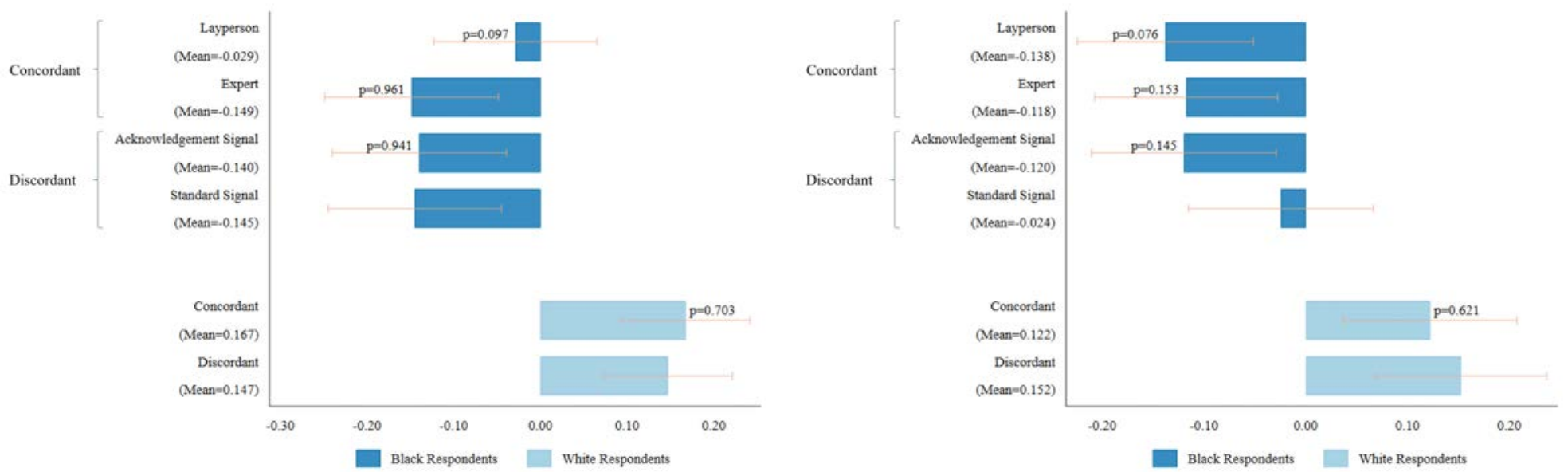

Panel (A): Signal Content Recall

Panel (B): Safety Beliefs
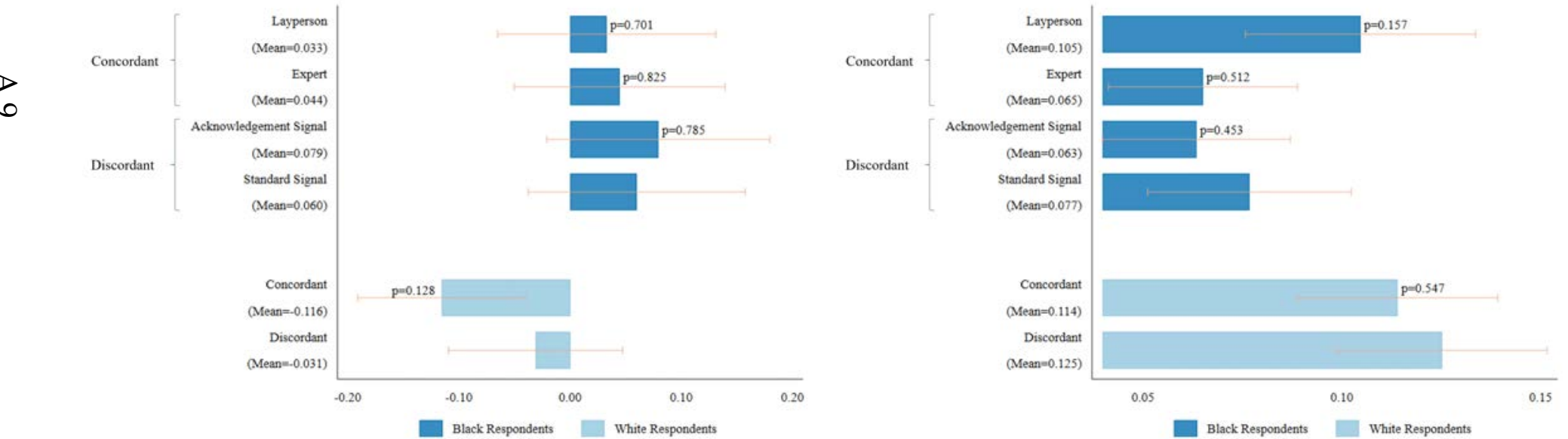

Panel (C): Coupon Interest

Panel (D): Flu Vaccine Take-Up

Notes: Figure shows the mean of each secondary outcome by treatment condition among the sample of Black respondents (dark blue bars), as well as among the sample of White respondents (light blue bars). Signal content recall, safety beliefs and coupon interest are inverse-covariance-weighted indices as described in Anderson (2008), while flu vaccine take-up is binary. For dark blue bars, $p$-values test the null hypotheses that the concordant expert, concordant non-expert (standard signal condition), and discordant expert (acknowledgement condition) means each differ from the discordant expert (standard signal condition) among Black respondents. For light blue bars, $p$-values test the null hypothesis that the concordant expert (standard signal condition) mean differs from the discordant expert (standard signal condition) among White respondents. 95\% confidence intervals using robust standard errors are shown.

\section{Appendix Figure A8: Secondary Outcome Means By Treatment Arm}



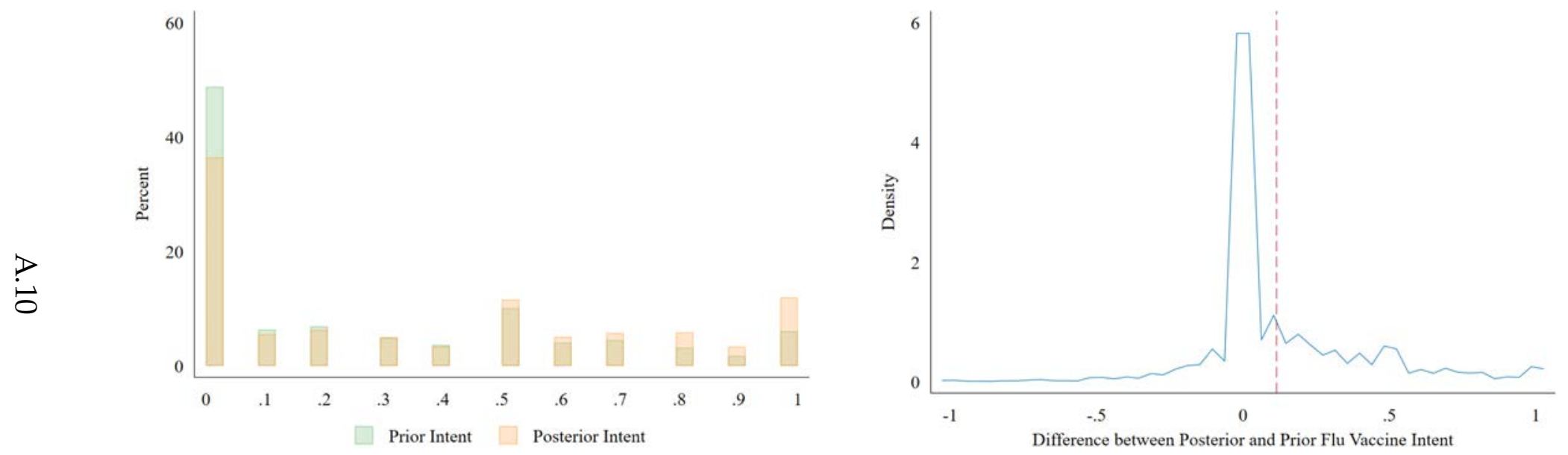

Panel (A): Histogram

Panel (B): Distribution of Difference

Notes: Panel (A) shows a histogram of prior and posterior flu vaccine intent. Panel (B) plots the histogram of the individual-level difference. See Appendix Section E for definitions.

\section{Appendix Figure A9: Prior and Posterior Flu Vaccine Intent}




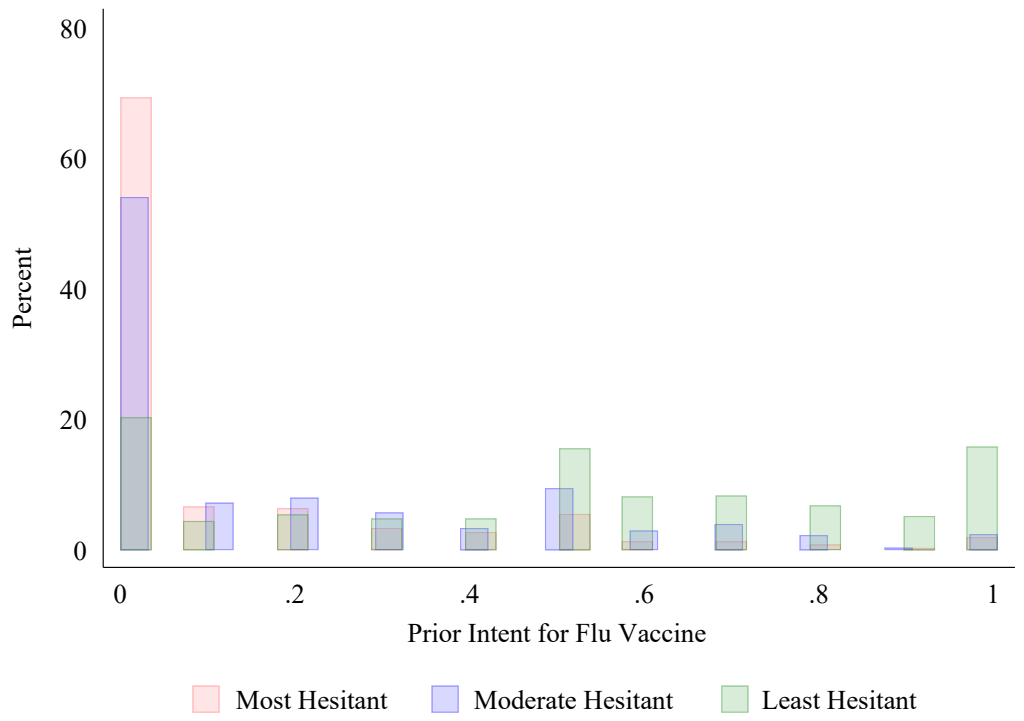

Notes: Figure shows the distribution of the variable Prior Intent for Flu Vaccine among the most hesitant, moderately hesitant, and least hesitant to take the flu vaccine. Most hesitant encompasses individuals who reported having never received the flu vaccine. The moderate hesitant category encompasses respondents who reported having received their last flu vaccination over two years ago. Least hesitant include respondents who reported having received their last flu vaccination within the past two years but not in the current influenza season.

\section{Appendix Figure A10: Histogram of Prior Flu Vaccine Intent by Vaccination Experience}

\section{A.11}




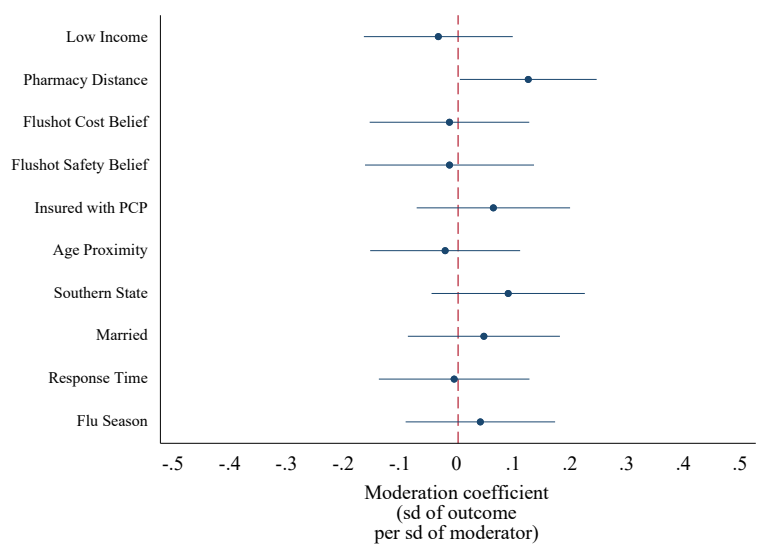

Panel (A): Layperson Treatment Heterogeneity

$\stackrel{D}{N}$
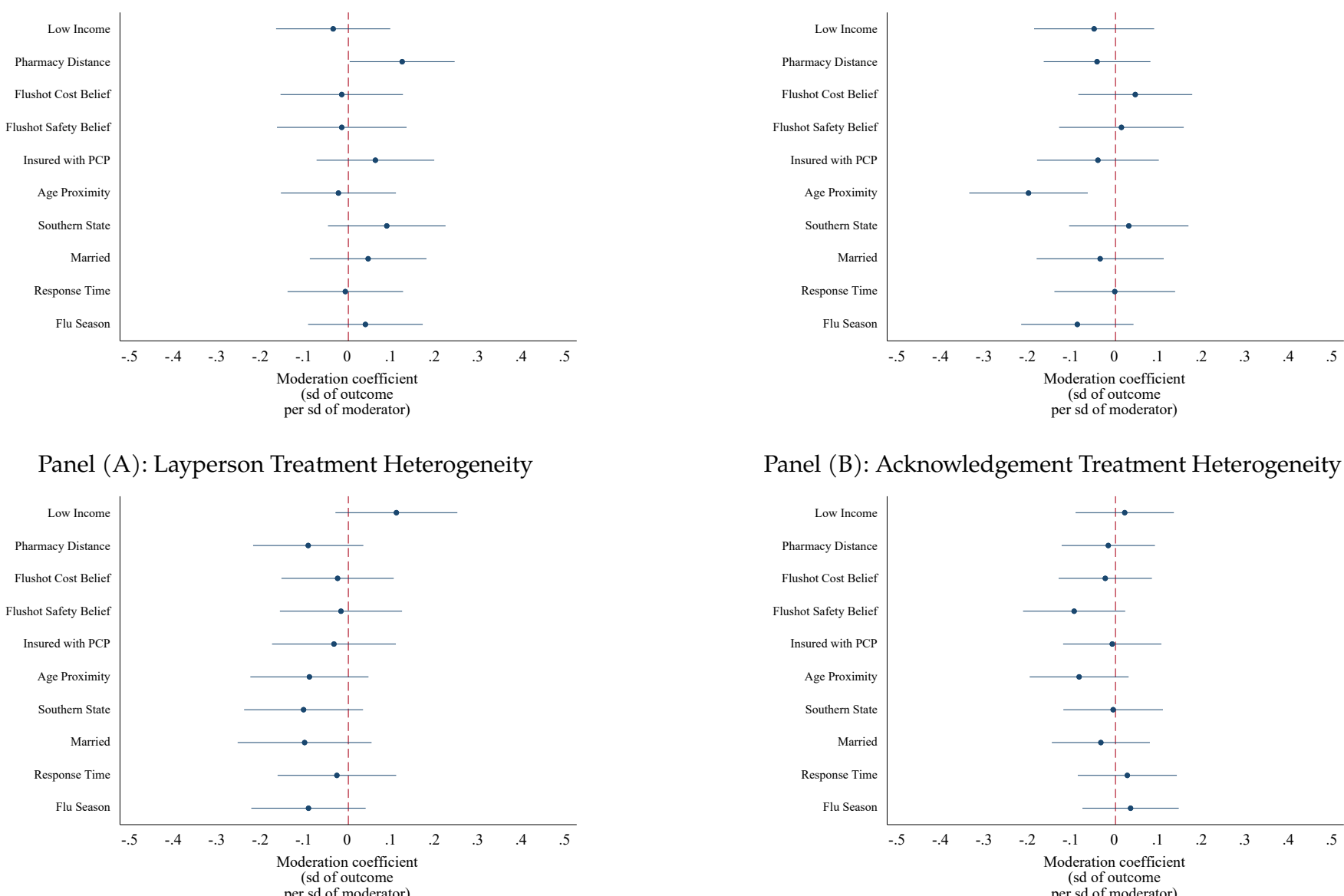

Panel (B): Acknowledgement Treatment Heterogeneity

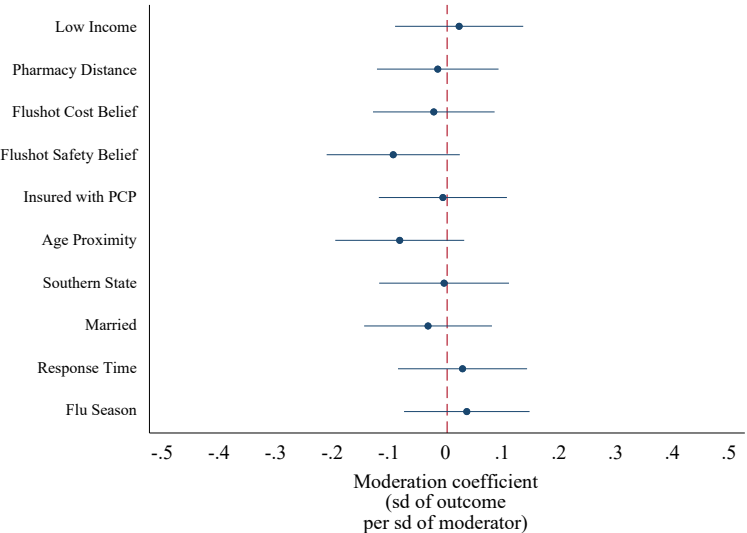

Panel (C): Concordance Treatment Heterogeneity - Black Respondents Panel (D): Concordance Treatment Heterogeneity - White Respondents

Notes: Figure reports heterogeneity in treatment effects for each treatment comparison (A: layperson vs. expert sender; B: acknowledgement vs. standard message; C and D: concordant vs. discordant sender). Estimates are obtained from a regression of the variable Flu Vaccine Intent on the treatment indicator, moderator, and their interaction. Both the outcome and the moderator are standardized to a mean of 0 and standard deviation of 1 . Dots represent coefficient estimates on the interaction coefficient. Stratifying variables (platform and season) are included as controls in the regression but not reported. Moderators (before standardization) are defined as: Low Income $=1$ if the respondent's self-reported household income is less than or equal to the median income among Black respondents in the sample (= $\$ 30 \mathrm{k})$; as: Low Income $=1$ if the respondent's self-reported household income is less than or equal to the median income among Black respondents in the sample ( $=\$ 30 \mathrm{k})$;
Pharmacy Distance = distance to nearest pharmacy in miles; Flushot Cost Belief = belief about own out-of-pocket cost for the flu shot in USD; Flushot Safety Belief Pharmacy Distance $=$ distance to nearest pharmacy in miles; Flushot Cost Belief = belief about own out-of-pocket cost for the flu shot in USD; Flushot Safety Belief
$=$ prior belief of fraction of individuals who get the flu from the flu shot; Insured with PCP = dummy for having a primary care provider and health insurance; Age = prior belief of fraction of individuals who get the flu from the flu shot; Insured with PCP = dummy for having a primary care provider and health insurance; Age
Proximity = dummy equal to one if sender and receiver age difference is no more than ten years; Southern State = dummy for residence in the U.S. South; Married $=$ dummy for being married; Response Time $=\log$ of time in seconds that the respondent spent on the survey up to (but excluding) the video treatment screen; Flu Season $=$ dummy that equals one for observations that fall into the flu season 2020-21 (as opposed to the flu season 2019-20). 95\% confidence intervals using robust standard errors are shown.

Appendix Figure A11: Additional Results On Treatment Effect Heterogeneity 


\section{B Appendix Tables}

\section{Appendix Table B1: Sender Ratings by Study Arm}

\begin{tabular}{|c|c|c|c|c|c|c|c|c|c|}
\hline & \multicolumn{3}{|c|}{ Layperson vs. Expert - Black Rs } & \multicolumn{3}{|c|}{ Concordant vs. Discordant - Black Rs } & \multicolumn{3}{|c|}{ Concordant vs. Discordant - White Rs } \\
\hline & (1) & (2) & (3) & (4) & (5) & (6) & (7) & (8) & (9) \\
\hline & Age & Education & Attractiveness & & Education & Attractiveness & & Education & Attractiveness \\
\hline Layperson Role & $\begin{array}{l}-0.300 \\
(0.174) \\
{[0.088]}\end{array}$ & $\begin{array}{c}-1.743 \\
(0.185) \\
{[0.000]}\end{array}$ & $\begin{array}{c}-0.584 \\
(0.219) \\
{[0.009]}\end{array}$ & & & & & & \\
\hline Black Sender & & & & $\begin{array}{c}0.019 \\
(0.189) \\
{[0.918]}\end{array}$ & $\begin{array}{c}-0.153 \\
(0.233) \\
{[0.512]}\end{array}$ & $\begin{array}{c}0.349 \\
(0.162) \\
{[0.034]}\end{array}$ & $\begin{array}{l}-0.527 \\
(0.202) \\
{[0.010]}\end{array}$ & $\begin{array}{l}-2.841 \\
(1.045) \\
{[0.008]}\end{array}$ & $\begin{array}{c}-0.339 \\
(0.218) \\
{[0.124]}\end{array}$ \\
\hline Mean & 0.00 & 0.00 & 0.00 & 0.00 & 0.00 & 0.00 & 0.00 & 0.00 & 0.00 \\
\hline Observations & 102 & 102 & 102 & 103 & 103 & 103 & 89 & 89 & 89 \\
\hline
\end{tabular}

Notes: Table reports OLS estimates based on the MTurk sample. Dependent variables are perceptions of age, education and attractiveness. The outcomes are described in Appendix Section $\mathrm{E}$ and standardized to a mean of 0 and a standard deviation of 1 . Columns (1) to (6) include ratings from Black Mturk respondents only. Columns (1) to (3) include sender fixed effects, thus comparing MTurkers' ratings of the same sender, assuming a different identity (lay vs. expert). Columns (4) to (9) compare MTurkers' ratings of Black vs. White experts. Columns (7) to (9) include ratings from White Mturk respondents only. The mean of each dependent variable for the omitted group is shown. Robust standard errors are in parentheses, and $p$-values are in brackets. 


\section{Appendix Table B2: Treatment Effects on Flu Vaccine Take-up: Alternative Measures and Specification Checks}

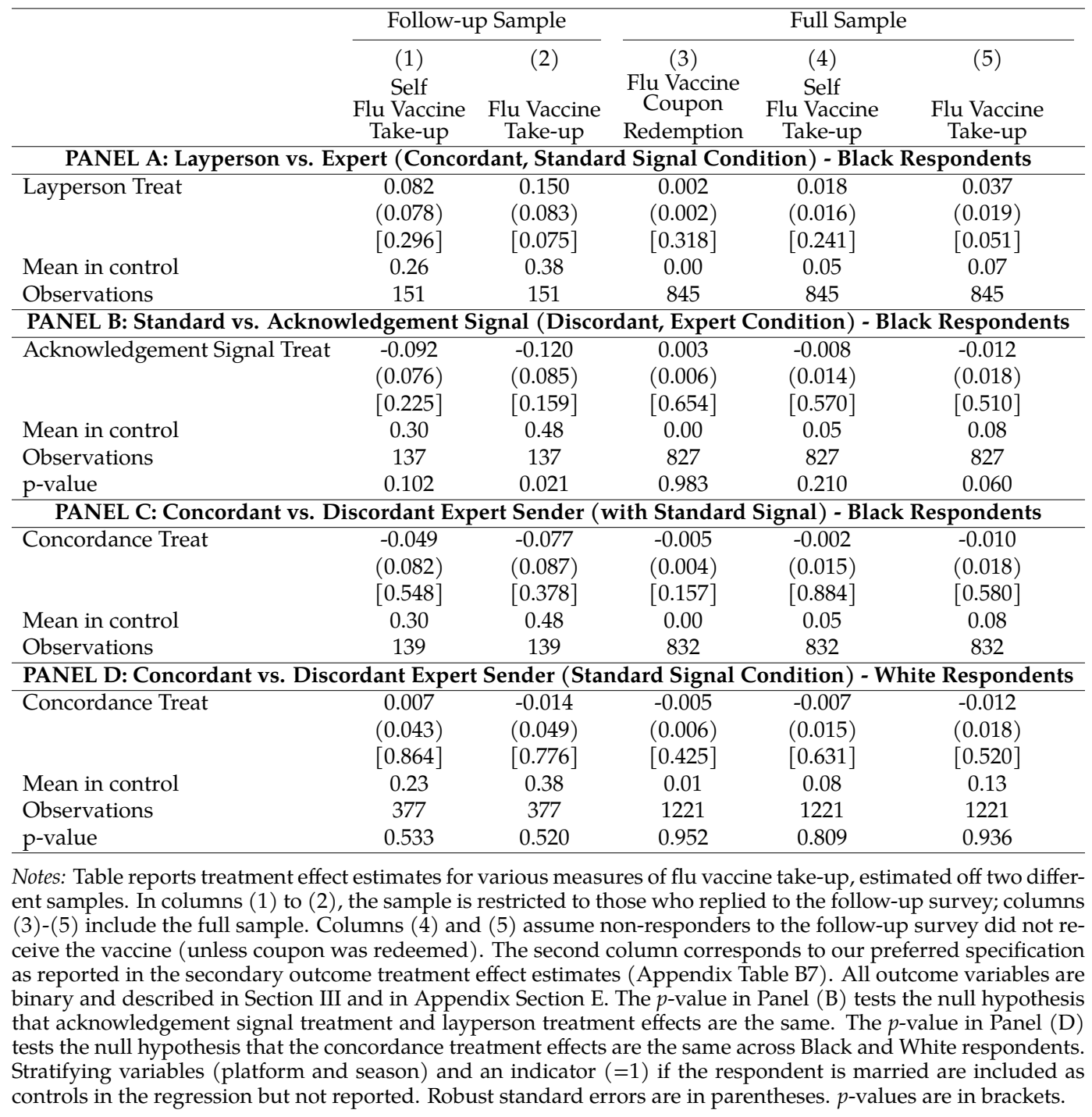




\section{Appendix Table B3: Attrition from Baseline and Between Baseline and Follow-up Surveys}

\begin{tabular}{|c|c|c|c|c|}
\hline & \multicolumn{2}{|c|}{ Attrition from BL } & \multicolumn{2}{|c|}{ Attrition between BL and EL } \\
\hline & (1) & (2) & (3) & (4) \\
\hline & Black Respondents & White Respondents & Black Respondents & White Respondents \\
\hline \multirow[t]{3}{*}{ Expert Discordant } & -0.006 & 0.023 & 0.013 & -0.018 \\
\hline & $(0.022)$ & $(0.014)$ & $(0.026)$ & $(0.026)$ \\
\hline & {$[0.765]$} & {$[0.088]$} & {$[0.621]$} & [0.490] \\
\hline \multirow[t]{3}{*}{ Layperson Concordant } & -0.000 & & -0.010 & \\
\hline & $(0.022)$ & & $(0.026)$ & \\
\hline & {$[0.990]$} & & [0.698] & \\
\hline \multirow[t]{3}{*}{ Acknowledgement Signal Discordant } & 0.021 & & 0.003 & \\
\hline & $(0.022)$ & & $(0.026)$ & \\
\hline & [0.341] & & {$[0.916]$} & \\
\hline $\mathrm{p}$-value & 0.627 & n.a. & 0.849 & n.a. \\
\hline Mean & 0.13 & 0.05 & 0.83 & 0.70 \\
\hline Observations & 1938 & 1307 & 1672 & 1221 \\
\hline
\end{tabular}

Notes: Table reports OLS estimates obtained from a regression of an attrition dummy on treatment indicators, with the "Expert Concordant" treatment arm being the left-out category. The dependent variable in columns (1) and (3) is attrition from the baseline survey, which is an indicator variable equal to 1 if the respondent was randomized but did not complete the baseline survey and 0 otherwise. The dependent variable in columns (2) and (4) is attrition between baseline and follow-up survey, which is an indicator variable equal to 1 if the respondent completed the baseline survey but did not complete the follow-up survey and 0 otherwise. Columns (1) and (3) correspond to the sample of Black respondents. Columns (2) and (4) corresponds to the sample of White respondents. "Mean" refers to the mean of the attrition outcome in the left-out category. The reported $p$-value at the bottom of the table tests the null hypothesis that the effect of all four treatments on attrition, among Black respondents, is the same. Stratifying variables (platform and season) are included as controls in the regression but not reported. Robust standard errors are in parentheses. $p$-values are in brackets. 


\section{Appendix Table B4: Summary Statistics}

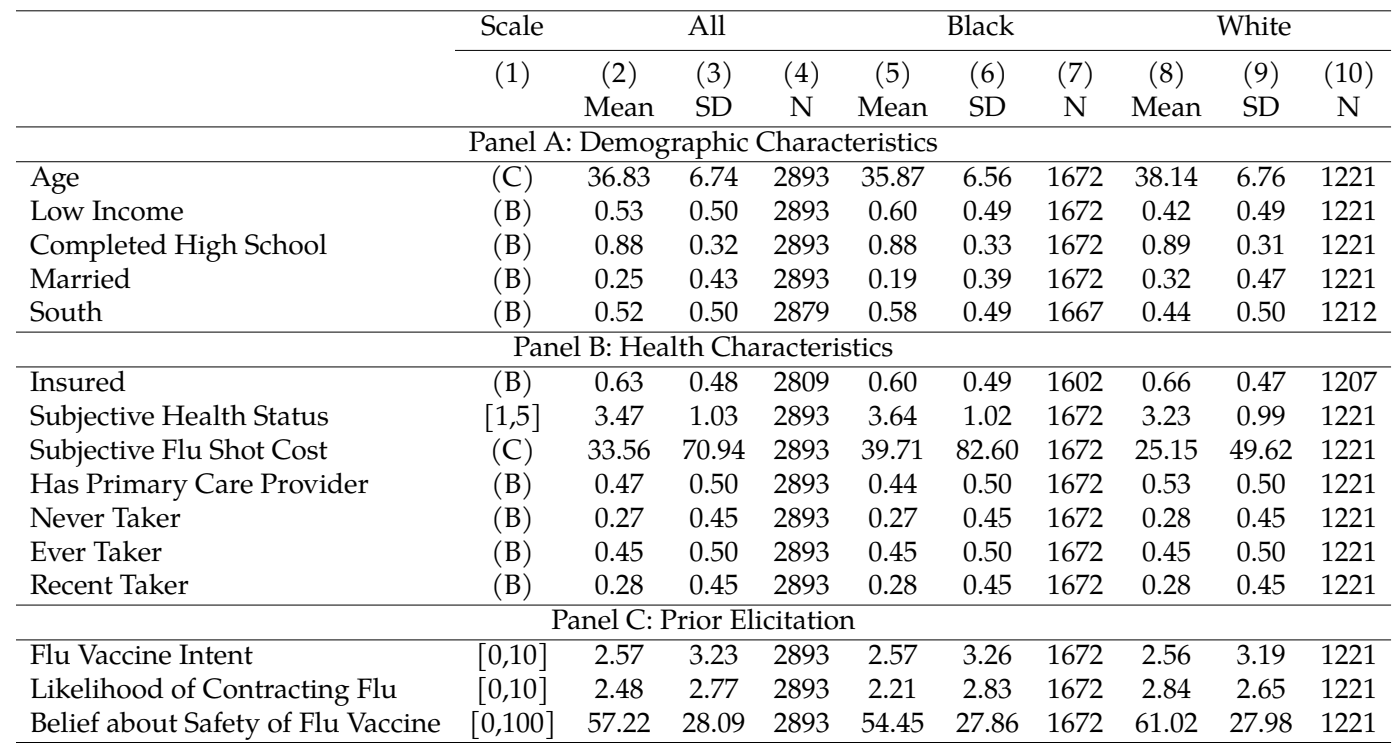

Notes: Columns (2)-(4) show the mean, standard deviation, and sample size for all respondents. Columns (5)-(7) restrict the sample to Black respondents, and columns (8)-(10) restrict the sample to White respondents. Low Income is a binary variable equal to 1 if the respondent's self-reported household income is less than or equal to the median income of Black respondents in the sample $(=\$ 30 \mathrm{k})$. Subjective Health Status is measured on a 5point Likert scale (where 1 is poor and 5 is excellent). Subjective Flu Shot Cost is in US\$; the values above the 99th percentile are set to the 99th percentile value. Most Hesitant is a binary variable equal to 1 if the respondent has never received the flu shot. Moderate Hesitant is a binary variable equal to 1 if the respondent has received the flu shot more than 2 years ago. Least Hesitant is a binary variable equal to 1 if the respondent has received the flu shot within the past 2 years. Flu Vaccine Intent is the respondent's prior intent to receive the flu vaccine before the end of the flu season elicited on an 11-point Likert scale. Likelihood of Contracting Flu is the respondent's subjective likelihood of contracting flu before the end of the flu season elicited on an 11-point Likert scale. Belief about Safety of Flu Vaccine is belief over how many individuals out of 100 will not contract the flu from the flu shot. (C) indicates that the variable is continuous; (B) indicates that the variable is binary. In cases when the variable is not binary or continuous, the scale of the raw variable is provided. 


\section{Appendix Table B5: Balance Table for Baseline Survey Sample}

\begin{tabular}{|c|c|c|c|c|c|c|c|c|c|c|c|c|c|}
\hline & \multicolumn{3}{|c|}{$\begin{array}{c}\text { Black Rs: } \\
\text { Lay vs Expert }\end{array}$} & \multicolumn{3}{|c|}{$\begin{array}{c}\text { Black Rs: } \\
\text { Acknow. vs Standard }\end{array}$} & \multicolumn{3}{|c|}{$\begin{array}{c}\text { Black Rs: } \\
\text { Concor. vs Discor. }\end{array}$} & \multicolumn{3}{|c|}{$\begin{array}{c}\text { White Rs: } \\
\text { Concor. vs Discor. }\end{array}$} & \multirow[b]{2}{*}{$\begin{array}{c}\text { F-stat. } \\
(13)\end{array}$} \\
\hline & $\begin{array}{l}\text { Coeff. } \\
(1)\end{array}$ & $\begin{array}{l}\text { Mean } \\
(2)\end{array}$ & $\begin{array}{l}\mathrm{N} \\
(3)\end{array}$ & $\begin{array}{l}\text { Coeff. } \\
(4)\end{array}$ & $\begin{array}{c}\text { Mean } \\
(5)\end{array}$ & $\begin{array}{l}N \\
(6)\end{array}$ & $\begin{array}{c}\text { Coeff. } \\
(7)\end{array}$ & $\begin{array}{c}\text { Mean } \\
(8)\end{array}$ & $\begin{array}{l}\mathrm{N} \\
(9)\end{array}$ & $\begin{array}{l}\text { Coeff. } \\
(10)\end{array}$ & $\begin{array}{c}\text { Mean } \\
(11)\end{array}$ & $\begin{array}{c}\mathrm{N} \\
(12)\end{array}$ & \\
\hline \multicolumn{14}{|c|}{ Panel A: Demographic Characteristics } \\
\hline Age & $\begin{array}{l}-0.381 \\
(0.438) \\
{[0.385]}\end{array}$ & 35.920 & 845 & $\begin{array}{c}-0.276 \\
(0.458) \\
{[0.547]}\end{array}$ & 36.125 & 827 & $\begin{array}{l}-0.258 \\
(0.452) \\
{[0.568]}\end{array}$ & 36.125 & 832 & $\begin{array}{c}-0.008 \\
(0.353) \\
{[0.982]}\end{array}$ & 38.165 & 1221 & $\begin{array}{c}0.766 \\
{[0.513]}\end{array}$ \\
\hline Low Income & $\begin{array}{l}-0.028 \\
(0.034) \\
{[0.411]}\end{array}$ & 0.627 & 845 & $\begin{array}{c}0.021 \\
(0.034) \\
{[0.543]}\end{array}$ & 0.580 & 827 & $\begin{array}{c}0.046 \\
(0.034) \\
{[0.179]}\end{array}$ & 0.580 & 832 & $\begin{array}{c}-0.015 \\
(0.028) \\
{[0.597]}\end{array}$ & 0.432 & 1221 & $\begin{array}{c}0.639 \\
{[0.590]}\end{array}$ \\
\hline Completed High School & $\begin{array}{c}0.019 \\
(0.023) \\
{[0.416]}\end{array}$ & 0.865 & 845 & $\begin{array}{l}-0.031 \\
(0.023) \\
{[0.167]}\end{array}$ & 0.897 & 827 & $\begin{array}{l}-0.032 \\
(0.022) \\
{[0.157]}\end{array}$ & 0.897 & 832 & $\begin{array}{c}0.024 \\
(0.018) \\
{[0.176]}\end{array}$ & 0.878 & 1221 & $\begin{array}{c}0.939 \\
{[0.421]}\end{array}$ \\
\hline Married & $\begin{array}{l}-0.027 \\
(0.030) \\
{[0.370]}\end{array}$ & 0.754 & 845 & $\begin{array}{c}0.021 \\
(0.031) \\
{[0.509]}\end{array}$ & 0.715 & 827 & $\begin{array}{c}0.040 \\
(0.031) \\
{[0.187]}\end{array}$ & 0.715 & 832 & $\begin{array}{l}-0.009 \\
(0.028) \\
{[0.755]}\end{array}$ & 0.593 & 1221 & $\begin{array}{c}0.629 \\
{[0.596]}\end{array}$ \\
\hline South & $\begin{array}{c}0.099 \\
(0.034) \\
{[0.004]}\end{array}$ & 0.522 & 843 & $\begin{array}{c}0.031 \\
(0.034) \\
{[0.369]}\end{array}$ & 0.570 & 824 & $\begin{array}{l}-0.049 \\
(0.035) \\
{[0.156]}\end{array}$ & 0.570 & 828 & $\begin{array}{l}-0.019 \\
(0.028) \\
{[0.499]}\end{array}$ & 0.450 & 1212 & $\begin{array}{c}3.166 \\
{[0.024]}\end{array}$ \\
\hline \multicolumn{14}{|c|}{ Panel B: Health Characteristics } \\
\hline Insured & $\begin{array}{c}0.014 \\
(0.035) \\
{[0.695]}\end{array}$ & 0.591 & 812 & $\begin{array}{c}0.003 \\
(0.035) \\
{[0.939]}\end{array}$ & 0.611 & 790 & $\begin{array}{l}-0.020 \\
(0.035) \\
{[0.566]}\end{array}$ & 0.611 & 797 & $\begin{array}{c}0.010 \\
(0.027) \\
{[0.719]}\end{array}$ & 0.653 & 1207 & $\begin{array}{c}0.174 \\
{[0.914]}\end{array}$ \\
\hline Subjective Health Status & $\begin{array}{c}0.225 \\
(0.069) \\
{[0.001]}\end{array}$ & 3.523 & 845 & $\begin{array}{c}0.012 \\
(0.072) \\
{[0.870]}\end{array}$ & 3.643 & 827 & $\begin{array}{l}-0.117 \\
(0.070) \\
{[0.094]}\end{array}$ & 3.643 & 832 & $\begin{array}{c}-0.017 \\
(0.057) \\
{[0.771]}\end{array}$ & 3.237 & 1221 & $\begin{array}{c}3.637 \\
{[0.012]}\end{array}$ \\
\hline Subjective Flu Shot Cost & $\begin{array}{c}0.615 \\
(3.425) \\
{[0.857]}\end{array}$ & 30.707 & 822 & $\begin{array}{l}-2.866 \\
(3.035) \\
{[0.345]}\end{array}$ & 28.691 & 811 & $\begin{array}{l}2.015 \\
(3.378) \\
{[0.551]}\end{array}$ & 28.691 & 811 & $\begin{array}{l}-1.270 \\
(2.111) \\
{[0.548]}\end{array}$ & 23.452 & 1215 & $\begin{array}{c}1.381 \\
{[0.247]}\end{array}$ \\
\hline Has Primary Care Provider & $\begin{array}{l}-0.043 \\
(0.034) \\
{[0.212]}\end{array}$ & 0.455 & 845 & $\begin{array}{l}-0.043 \\
(0.034) \\
{[0.215]}\end{array}$ & 0.460 & 827 & $\begin{array}{l}-0.004 \\
(0.035) \\
{[0.904]}\end{array}$ & 0.460 & 832 & $\begin{array}{l}-0.009 \\
(0.029) \\
{[0.762]}\end{array}$ & 0.532 & 1221 & $\begin{array}{c}1.080 \\
{[0.356]}\end{array}$ \\
\hline Never Taker & $\begin{array}{l}-0.029 \\
(0.030) \\
{[0.322]}\end{array}$ & 0.263 & 845 & $\begin{array}{c}0.033 \\
(0.032) \\
{[0.305]}\end{array}$ & 0.281 & 827 & $\begin{array}{l}-0.019 \\
(0.031) \\
{[0.528]}\end{array}$ & 0.281 & 832 & $\begin{array}{c}0.004 \\
(0.026) \\
{[0.867]}\end{array}$ & 0.275 & 1221 & $\begin{array}{c}2.444 \\
{[0.062]}\end{array}$ \\
\hline Ever Taker & $\begin{array}{c}0.026 \\
(0.034) \\
{[0.455]}\end{array}$ & 0.443 & 845 & $\begin{array}{l}-0.045 \\
(0.035) \\
{[0.196]}\end{array}$ & 0.468 & 827 & $\begin{array}{c}-0.024 \\
(0.035) \\
{[0.486]}\end{array}$ & 0.468 & 832 & $\begin{array}{l}-0.003 \\
(0.028) \\
{[0.902]}\end{array}$ & 0.446 & 1221 & $\begin{array}{c}0.816 \\
{[0.485]}\end{array}$ \\
\hline Recent Taker & $\begin{array}{c}0.004 \\
(0.031) \\
{[0.899]}\end{array}$ & 0.294 & 845 & $\begin{array}{c}0.012 \\
(0.030) \\
{[0.690]}\end{array}$ & 0.252 & 827 & $\begin{array}{c}0.044 \\
(0.031) \\
{[0.156]}\end{array}$ & 0.252 & 832 & $\begin{array}{l}-0.001 \\
(0.026) \\
{[0.976]}\end{array}$ & 0.278 & 1221 & $\begin{array}{c}1.144 \\
{[0.330]}\end{array}$ \\
\hline \multicolumn{14}{|c|}{ Panel C: Prior Elicitation } \\
\hline Flu Vaccine Intent & $\begin{array}{c}0.213 \\
(0.224) \\
{[0.342]}\end{array}$ & 2.554 & 845 & $\begin{array}{c}0.049 \\
(0.223) \\
{[0.825]}\end{array}$ & 2.446 & 827 & $\begin{array}{c}0.118 \\
(0.225) \\
{[0.600]}\end{array}$ & 2.446 & 832 & $\begin{array}{c}0.083 \\
(0.181) \\
{[0.648]}\end{array}$ & 2.529 & 1221 & $\begin{array}{c}0.859 \\
{[0.462]}\end{array}$ \\
\hline Likelihood of Contracting Flu & $\begin{array}{l}-0.279 \\
(0.194) \\
{[0.150]}\end{array}$ & 2.342 & 845 & $\begin{array}{c}0.167 \\
(0.197) \\
{[0.397]}\end{array}$ & 2.144 & 827 & $\begin{array}{c}0.202 \\
(0.196) \\
{[0.303]}\end{array}$ & 2.144 & 832 & $\begin{array}{l}-0.146 \\
(0.151) \\
{[0.334]}\end{array}$ & 2.913 & 1221 & $\begin{array}{c}0.949 \\
{[0.416]}\end{array}$ \\
\hline Belief about Safety of Flu Vaccine & $\begin{array}{c}1.704 \\
(1.898) \\
{[0.370]} \\
\end{array}$ & 44.978 & 845 & $\begin{array}{c}2.228 \\
(1.950) \\
{[0.254]}\end{array}$ & 44.180 & 827 & $\begin{array}{c}0.896 \\
(1.976) \\
{[0.650]}\end{array}$ & 44.180 & 832 & $\begin{array}{l}1.882 \\
(1.592) \\
{[0.237]}\end{array}$ & 38.021 & 1221 & $\begin{array}{c}0.802 \\
{[0.493]}\end{array}$ \\
\hline \multicolumn{14}{|c|}{ Panel D: Follow-up Survey } \\
\hline Completed Follow-up Survey & $\begin{array}{c}0.010 \\
(0.026) \\
{[0.714]}\end{array}$ & 0.173 & 845 & $\begin{array}{c}0.010 \\
(0.026) \\
{[0.701]}\end{array}$ & 0.161 & 827 & $\begin{array}{c}0.012 \\
(0.026) \\
{[0.630]}\end{array}$ & 0.161 & 832 & $\begin{array}{c}-0.016 \\
(0.026) \\
{[0.536]}\end{array}$ & 0.318 & 1221 & $\begin{array}{c}0.238 \\
{[0.870]}\end{array}$ \\
\hline
\end{tabular}

Notes: Table reports estimates obtained from OLS regressions of each respondent characteristic (rows) on treatment variables by study arm. Columns (1) to (3) test the effects of the concordant non-expert (vs. concordant expert) treatment with the standard signal, among the sample of Black respondents. Columns (4) to (6) test the effects of the acknowledgement (vs. standard) signal treatment with discordant, expert senders, among the sample of Black respondents. Columns (7) to (9) test the effects of the concordant (vs. discordant) expert treatment with the standard signal, among the sample of Black respondents. Columns (10) to (12) test the effects of concordant (vs. discordant) expert treatment with the standard signal, among the sample of White respondents. See table notes of Appendix Table B4 for the definitions of each respondent characteristic. Total respondents completing the follow-up survey by experimental condition are as follows: 72 for concordant-Black respondents; 67 for discordant-Black respondents; 184 for concordant-White respondents; 193 for discordant-White respondents; 70 for acknowledgement signal treatment; 67 for standard signal treatment; 79 for non-expert treatment; and 72 for expert treatment. Stratifying variables (platform and season) are included as controls in the regression but not reported. The reported F-statistics in Column (13) test the null hypothesis that the effects of all four treatments (i.e. concordant expert, discordant expert (standard signal), concordant non-expert, and discordant expert (acknowledgement signal) are the same, among the sample of Black respondents. Robust standard errors are in parentheses. $p$-values are shown in brackets. 


\section{Appendix Table B6: Balance Table for Follow-up Survey Sample}

\begin{tabular}{|c|c|c|c|c|c|c|c|c|c|c|c|c|c|}
\hline & \multicolumn{3}{|c|}{$\begin{array}{c}\text { Black Rs: } \\
\text { Lay vs Expert }\end{array}$} & \multicolumn{3}{|c|}{$\begin{array}{c}\text { Black Rs: } \\
\text { Acknow. vs Standard }\end{array}$} & \multicolumn{3}{|c|}{$\begin{array}{c}\text { Black Rs: } \\
\text { Concor. vs Discor. }\end{array}$} & \multicolumn{3}{|c|}{$\begin{array}{c}\text { White Rs: } \\
\text { Concor. vs Discor. }\end{array}$} & \multirow[b]{2}{*}{$\begin{array}{c}\text { F-stat. } \\
(13)\end{array}$} \\
\hline & $\begin{array}{l}\text { Coeff. } \\
(1)\end{array}$ & $\begin{array}{l}\text { Mean } \\
(2)\end{array}$ & $\begin{array}{l}\mathrm{N} \\
(3)\end{array}$ & $\begin{array}{l}\text { Coeff. } \\
(4)\end{array}$ & $\begin{array}{l}\text { Mean } \\
(5)\end{array}$ & $\begin{array}{l}\mathrm{N} \\
(6)\end{array}$ & $\begin{array}{c}\text { Coeff. } \\
(7)\end{array}$ & $\begin{array}{c}\text { Mean } \\
(8)\end{array}$ & $\begin{array}{l}\mathrm{N} \\
(9)\end{array}$ & $\begin{array}{l}\text { Coeff. } \\
(10)\end{array}$ & $\begin{array}{c}\text { Mean } \\
(11)\end{array}$ & $\begin{array}{c}\mathrm{N} \\
(12)\end{array}$ & \\
\hline \multicolumn{14}{|c|}{ Panel A: Demographic Characteristics } \\
\hline Age & $\begin{array}{l}-0.313 \\
(0.978) \\
{[0.749]}\end{array}$ & 36.653 & 151 & $\begin{array}{c}-1.460 \\
(1.169) \\
{[0.214]}\end{array}$ & 37.597 & 137 & $\begin{array}{l}-0.926 \\
(1.103) \\
{[0.403]}\end{array}$ & 37.597 & 139 & $\begin{array}{c}0.033 \\
(0.634) \\
{[0.959]}\end{array}$ & 39.518 & 377 & $\begin{array}{c}0.627 \\
{[0.598]}\end{array}$ \\
\hline Low Income & $\begin{array}{c}0.000 \\
(0.082) \\
{[0.995]}\end{array}$ & 0.583 & 151 & $\begin{array}{c}0.020 \\
(0.086) \\
{[0.819]}\end{array}$ & 0.493 & 137 & $\begin{array}{c}0.095 \\
(0.085) \\
{[0.267]}\end{array}$ & 0.493 & 139 & $\begin{array}{l}-0.003 \\
(0.052) \\
{[0.960]}\end{array}$ & 0.472 & 377 & $\begin{array}{c}0.625 \\
{[0.599]}\end{array}$ \\
\hline Completed High School & $\begin{array}{c}0.022 \\
(0.050) \\
{[0.653]}\end{array}$ & 0.889 & 151 & $\begin{array}{c}0.019 \\
(0.054) \\
{[0.720]}\end{array}$ & 0.881 & 137 & $\begin{array}{c}0.009 \\
(0.056) \\
{[0.869]}\end{array}$ & 0.881 & 139 & $\begin{array}{c}0.009 \\
(0.032) \\
{[0.772]}\end{array}$ & 0.891 & 377 & $\begin{array}{c}0.147 \\
{[0.932]}\end{array}$ \\
\hline Married & $\begin{array}{l}-0.090 \\
(0.076) \\
{[0.239]}\end{array}$ & 0.736 & 151 & $\begin{array}{l}-0.002 \\
(0.082) \\
{[0.983]}\end{array}$ & 0.657 & 137 & $\begin{array}{c}0.078 \\
(0.078) \\
{[0.316]}\end{array}$ & 0.657 & 139 & $\begin{array}{l}-0.064 \\
(0.051) \\
{[0.210]}\end{array}$ & 0.627 & 377 & $\begin{array}{c}0.592 \\
{[0.621]}\end{array}$ \\
\hline South & $\begin{array}{l}-0.088 \\
(0.082) \\
{[0.287]}\end{array}$ & 0.606 & 150 & $\begin{array}{c}0.127 \\
(0.085) \\
{[0.141]}\end{array}$ & 0.463 & 137 & $\begin{array}{c}0.136 \\
(0.085) \\
{[0.110]}\end{array}$ & 0.463 & 138 & $\begin{array}{l}-0.005 \\
(0.051) \\
{[0.927]}\end{array}$ & 0.398 & 375 & $\begin{array}{c}1.186 \\
{[0.315]}\end{array}$ \\
\hline \multicolumn{14}{|c|}{ Panel B: Health Characteristics } \\
\hline Insured & $\begin{array}{c}0.136 \\
(0.075) \\
{[0.073]}\end{array}$ & 0.625 & 151 & $\begin{array}{c}0.025 \\
(0.078) \\
{[0.746]}\end{array}$ & 0.723 & 132 & $\begin{array}{l}-0.100 \\
(0.081) \\
{[0.221]}\end{array}$ & 0.723 & 137 & $\begin{array}{l}-0.004 \\
(0.048) \\
{[0.927]}\end{array}$ & 0.689 & 373 & $\begin{array}{c}1.216 \\
{[0.304]}\end{array}$ \\
\hline Subjective Health Status & $\begin{array}{c}0.119 \\
(0.157) \\
{[0.449]}\end{array}$ & 3.569 & 151 & $\begin{array}{l}-0.108 \\
(0.188) \\
{[0.567]}\end{array}$ & 3.582 & 137 & $\begin{array}{l}-0.003 \\
(0.179) \\
{[0.985]}\end{array}$ & 3.582 & 139 & $\begin{array}{c}0.002 \\
(0.105) \\
{[0.982]}\end{array}$ & 3.119 & 377 & $\begin{array}{c}0.562 \\
{[0.641]}\end{array}$ \\
\hline Subjective Flu Shot Cost & $\begin{array}{l}-10.972 \\
(5.478) \\
{[0.047]}\end{array}$ & 27.782 & 146 & $\begin{array}{l}-3.985 \\
(6.939) \\
{[0.567]}\end{array}$ & 28.136 & 135 & $\begin{array}{c}0.490 \\
(7.334) \\
{[0.947]}\end{array}$ & 28.136 & 135 & $\begin{array}{l}-2.353 \\
(2.668) \\
{[0.378]}\end{array}$ & 19.380 & 374 & $\begin{array}{c}2.116 \\
{[0.098]}\end{array}$ \\
\hline Has Primary Care Provider & $\begin{array}{c}0.260 \\
(0.079) \\
{[0.001]}\end{array}$ & 0.375 & 151 & $\begin{array}{c}0.123 \\
(0.083) \\
{[0.143]}\end{array}$ & 0.448 & 137 & $\begin{array}{l}-0.071 \\
(0.084) \\
{[0.399]}\end{array}$ & 0.448 & 139 & $\begin{array}{l}-0.065 \\
(0.051) \\
{[0.206]}\end{array}$ & 0.575 & 377 & $\begin{array}{c}4.356 \\
{[0.005]}\end{array}$ \\
\hline Never Taker & $\begin{array}{l}-0.079 \\
(0.073) \\
{[0.279]}\end{array}$ & 0.306 & 151 & $\begin{array}{l}0.066 \\
(0.077) \\
{[0.391]}\end{array}$ & 0.239 & 137 & $\begin{array}{c}0.069 \\
(0.075) \\
{[0.363]}\end{array}$ & 0.239 & 139 & $\begin{array}{c}0.016 \\
(0.046) \\
{[0.735]}\end{array}$ & 0.269 & 377 & $\begin{array}{c}0.666 \\
{[0.574]}\end{array}$ \\
\hline Ever Taker & $\begin{array}{l}-0.001 \\
(0.080) \\
{[0.986]}\end{array}$ & 0.417 & 151 & $\begin{array}{l}-0.144 \\
(0.083) \\
{[0.087]}\end{array}$ & 0.463 & 137 & $\begin{array}{l}-0.043 \\
(0.085) \\
{[0.615]}\end{array}$ & 0.463 & 139 & $\begin{array}{c}0.042 \\
(0.051) \\
{[0.416]}\end{array}$ & 0.435 & 377 & $\begin{array}{c}0.972 \\
{[0.406]}\end{array}$ \\
\hline Recent Taker & $\begin{array}{c}0.081 \\
(0.074) \\
{[0.280]} \\
\end{array}$ & 0.278 & 151 & $\begin{array}{c}0.078 \\
(0.080) \\
{[0.335]}\end{array}$ & 0.299 & 137 & $\begin{array}{l}-0.026 \\
(0.078) \\
{[0.737]} \\
\end{array}$ & 0.299 & 139 & $\begin{array}{l}-0.057 \\
(0.045) \\
{[0.207]}\end{array}$ & 0.295 & 377 & $\begin{array}{c}0.655 \\
{[0.580]}\end{array}$ \\
\hline \multicolumn{14}{|c|}{ Panel C: Prior Elicitation } \\
\hline Flu Vaccine Intent & $\begin{array}{c}1.109 \\
(0.560) \\
{[0.050]}\end{array}$ & 2.861 & 151 & $\begin{array}{c}0.420 \\
(0.597) \\
{[0.483]}\end{array}$ & 3.269 & 137 & $\begin{array}{l}-0.407 \\
(0.612) \\
{[0.507]}\end{array}$ & 3.269 & 139 & $\begin{array}{c}0.128 \\
(0.347) \\
{[0.713]}\end{array}$ & 2.912 & 377 & $\begin{array}{c}1.487 \\
{[0.218]}\end{array}$ \\
\hline Likelihood of Contracting Flu & $\begin{array}{c}0.698 \\
(0.513) \\
{[0.176]}\end{array}$ & 2.667 & 151 & $\begin{array}{c}0.001 \\
(0.476) \\
{[0.998]}\end{array}$ & 2.552 & 137 & $\begin{array}{c}0.121 \\
(0.495) \\
{[0.807]}\end{array}$ & 2.552 & 139 & $\begin{array}{l}-0.426 \\
(0.271) \\
{[0.116]}\end{array}$ & 3.249 & 377 & $\begin{array}{c}1.178 \\
{[0.318]}\end{array}$ \\
\hline Belief about Safety of Flu Vaccine & $\begin{array}{c}3.260 \\
(4.600) \\
{[0.480]}\end{array}$ & 47.014 & 151 & $\begin{array}{l}-1.570 \\
(4.802) \\
{[0.744]}\end{array}$ & 44.239 & 137 & $\begin{array}{c}2.863 \\
(4.751) \\
{[0.548]}\end{array}$ & 44.239 & 139 & $\begin{array}{c}3.503 \\
(2.851) \\
{[0.220]}\end{array}$ & 34.005 & 377 & $\begin{array}{c}1.096 \\
{[0.351]}\end{array}$ \\
\hline
\end{tabular}

Notes: Table reports estimates obtained from OLS regressions of each respondent characteristic (rows) on treatment variables by hypothesis based on the follow-up survey sample. Columns (1) to (3) test the effects of the concordant non-expert (vs. concordant expert) treatment with the standard signal, among the sample of Black respondents. Columns (4) to (6) test the effects of the acknowledgement (vs. standard) signal treatment with discordant, expert senders, among the sample of Black respondents. Columns (7) to (9) test the effects of the concordant (vs. discordant) expert treatment with the standard signal, among the sample of Black respondents. Columns (10) to (12) test the effects of concordant (vs. discordant) expert treatment with the standard signal, among the sample of White respondents. See table notes of Appendix Table B4 for the definitions of each respondent characteristic. Stratifying variables (platform and season) are included as controls in the regression but not reported. The reported F-statistics in Column (13) test the null hypothesis that the effects of all four treatments (i.e. concordant expert, discordant expert (standard signal), concordant non-expert, and discordant expert (acknowledgement signal) are the same, among the sample of Black respondents. Robust standard errors are in parentheses. $p$-values are shown in brackets. 
Appendix Table B7: Treatment Effect Estimates for Secondary Outcomes

\begin{tabular}{|c|c|c|c|c|}
\hline & $\begin{array}{c}(1) \\
\text { Signal } \\
\text { Content Recall }\end{array}$ & $\begin{array}{l}(2) \\
\text { Safety } \\
\text { Beliefs }\end{array}$ & $\begin{array}{c}(3) \\
\text { Coupon } \\
\text { Interest }\end{array}$ & $\begin{array}{c}\text { (4) } \\
\text { Flu Vaccine } \\
\text { Take-Up }\end{array}$ \\
\hline \multicolumn{5}{|c|}{$\begin{array}{l}\text { PANEL A: Layperson vs. Expert - Black Respondents } \\
\end{array}$} \\
\hline \multirow[t]{3}{*}{ Layperson Treat } & 0.117 & -0.024 & -0.016 & 0.150 \\
\hline & $(0.067)$ & $(0.068)$ & $(0.069)$ & $(0.083)$ \\
\hline & {$[0.082]$} & [0.722] & [0.813] & [0.075] \\
\hline Mean in control & 0.00 & 0.00 & 0.00 & 0.38 \\
\hline Observations & 845 & 845 & 845 & 151 \\
\hline \multicolumn{5}{|c|}{ PANEL B: Standard vs. Acknowledgement Signal - Black Respondents } \\
\hline \multirow[t]{3}{*}{ Acknowledgement Signal Treat } & 0.004 & -0.107 & 0.028 & -0.120 \\
\hline & $(0.069)$ & $(0.069)$ & $(0.069)$ & $(0.085)$ \\
\hline & [0.952] & [0.124] & [0.683] & [0.159] \\
\hline Mean in control & 0.00 & 0.00 & 0.00 & 0.48 \\
\hline Observations & 827 & 827 & 825 & 137 \\
\hline p-value & 0.241 & 0.396 & 0.647 & 0.021 \\
\hline \multicolumn{5}{|c|}{ PANEL C: Concordant vs. Discordant Expert Sender - Black Respondents } \\
\hline \multirow[t]{3}{*}{ Concordance Treat } & -0.006 & -0.098 & -0.008 & -0.077 \\
\hline & $(0.069)$ & $(0.069)$ & $(0.067)$ & $(0.087)$ \\
\hline & {$[0.928]$} & [0.155] & [0.907] & [0.378] \\
\hline Mean in control & 0.00 & 0.00 & 0.00 & 0.48 \\
\hline Observations & 832 & 832 & 831 & 139 \\
\hline \multicolumn{5}{|c|}{ PANEL D: Concordant vs. Discordant Expert Sender - White Respondents } \\
\hline \multirow[t]{3}{*}{ Concordance Treat } & 0.019 & -0.028 & -0.083 & -0.014 \\
\hline & $(0.057)$ & $(0.058)$ & $(0.056)$ & $(0.049)$ \\
\hline & [0.734] & [0.631] & [0.139] & {$[0.776]$} \\
\hline Mean in control & 0.00 & 0.00 & 0.00 & 0.38 \\
\hline Observations & 1221 & 1221 & 1221 & 377 \\
\hline $\mathrm{p}$-value & 0.774 & 0.437 & 0.388 & 0.520 \\
\hline
\end{tabular}

Notes: Table reports OLS estimates. Each dependent variable in columns (1) to (3) is an inverse-covarianceweighted index as described in Anderson (2008) and standardized to a mean of 0 and standard deviation of 1 . Dependent variable in column (4) is binary. Outcome variables are described in Section III and in Appendix Section E. The $p$-value in Panel (B) tests the null hypothesis that the acknowledgement signal treatment and layperson treatment effects are equal. The $p$-value in Panel (D) tests the null hypothesis that the concordance treatment effects are the same across Black and White respondents. Stratifying variables (platform and season) are included as controls in the regression but not reported; an additional stratifying variable (an indicator $(=1)$ if the respondent is married) is included in the regression of the take-up outcome which measures vaccination of self and/or others in household. Robust standard errors are in parentheses. $p$-values are in brackets. 


\section{Appendix Table B8: Test for Differential Sender Effects - Black Respondents}

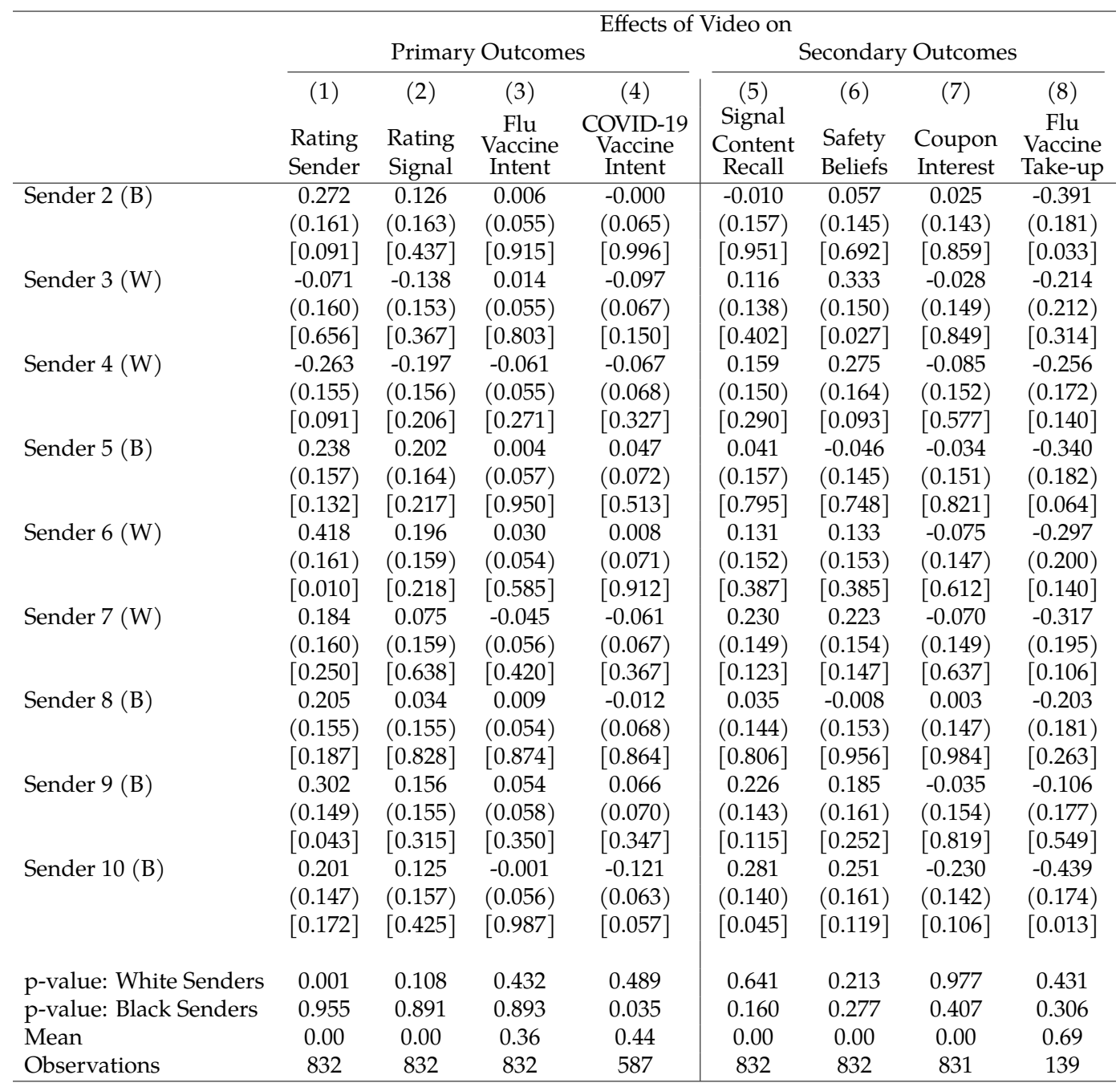

Notes: Table reports OLS estimates among the sample of Black respondents, from a regression of each primary outcome on sender fixed effects. Each dependent variable in columns (1)-(2) and (5)-(7) is an inverse-covarianceweighted index as described in Anderson (2008) and standardized to the mean of 0 and standard deviation of 1. Dependent variables in columns (3) and (4) are on a scale of 0 to 1 . Dependent variable in column (8) is binary. COVID-19 vaccine intent was asked during the 2020-2021 flu season only. Outcome variables are described in Section III and in Appendix Section E. "(B)" indicates Black senders, while "(W)" indicates White senders. The $p$-value labeled "White Senders" tests the null hypothesis that the effect of all White senders is the same. The $p$ value labeled "Black Senders" tests the null hypothesis that the effect of all Black senders is the same. The omitted category is Sender $1(\mathrm{~W})$. Stratifying variables (platform and season) are included as controls in the regression but not reported; an additional stratifying variable (an indicator $(=1)$ if the respondent is married) is included in the regression of the take-up outcome. Robust standard errors are in parentheses. $p$-values are shown in brackets. 


\section{Appendix Table B9: Test for Differential Sender Effects By Expertise - Black Respondents}

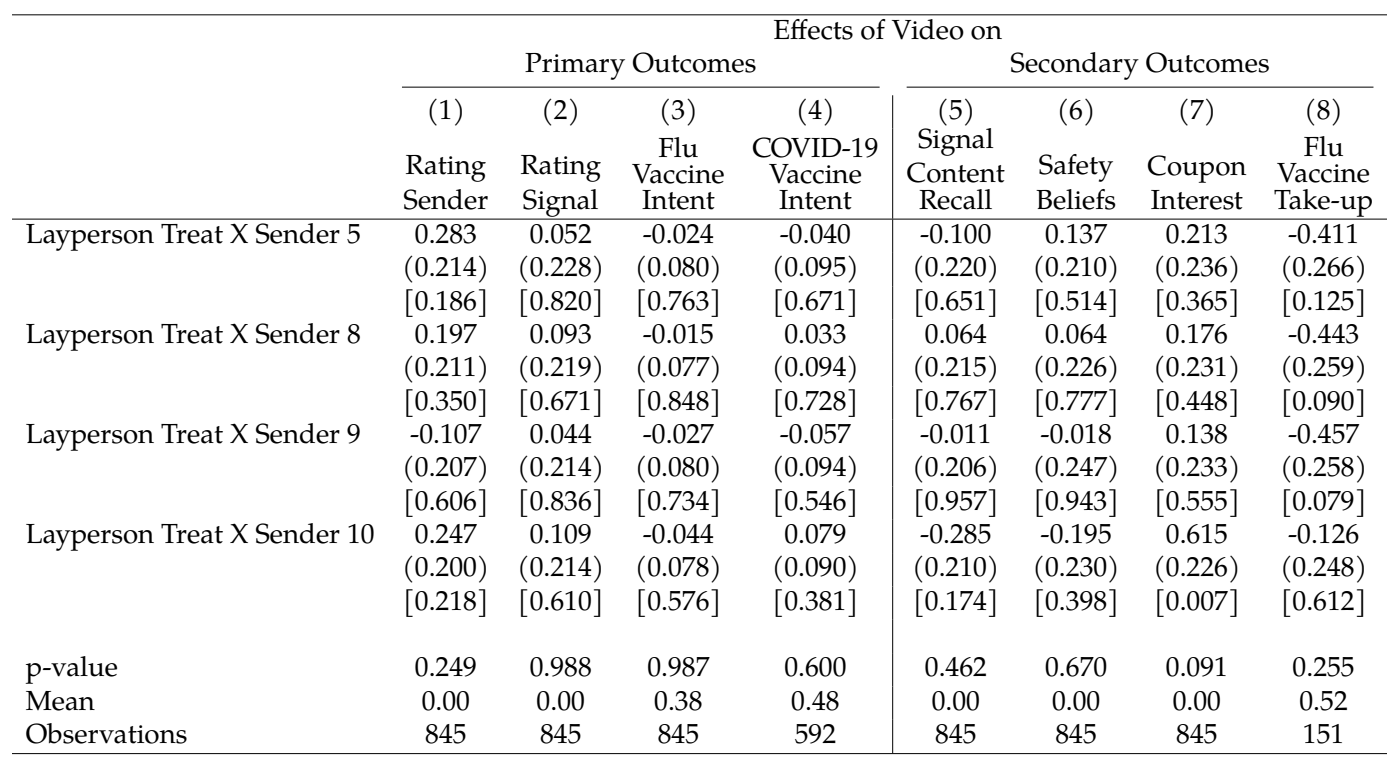

Notes: Table reports OLS estimates among the sample of Black respondents who were assigned to either a layperson or expert Black sender, from a regression of each primary outcome on sender fixed effects, a layperson treatment indicator, and their interaction. Each dependent variable in columns (1) and (2) and (5) to (7) is an inversecovariance-weighted index as described in Anderson (2008) and standardized to the mean of 0 and standard deviation of 1 . Dependent variables in columns (3) and (4) are on a scale of 0 to 1 . Dependent variable in column (8) is binary. COVID-19 vaccine intent was asked during the 2020-2021 flu season only. Outcome variables are described in Section III and in Appendix Section E. The $p$-value tests the null hypothesis that all interaction terms are the same. The omitted sender is Sender 2. Stratifying variables (platform and season) are included as controls in the regression but not reported; an additional stratifying variable (an indicator $(=1)$ if the respondent is married) is included in the regression of the take-up outcome. Robust standard errors are in parentheses. $p$-values are shown in brackets. 


\section{Appendix Table B10: Treatment Effect Estimates with PDS LASSO-Selected Controls}

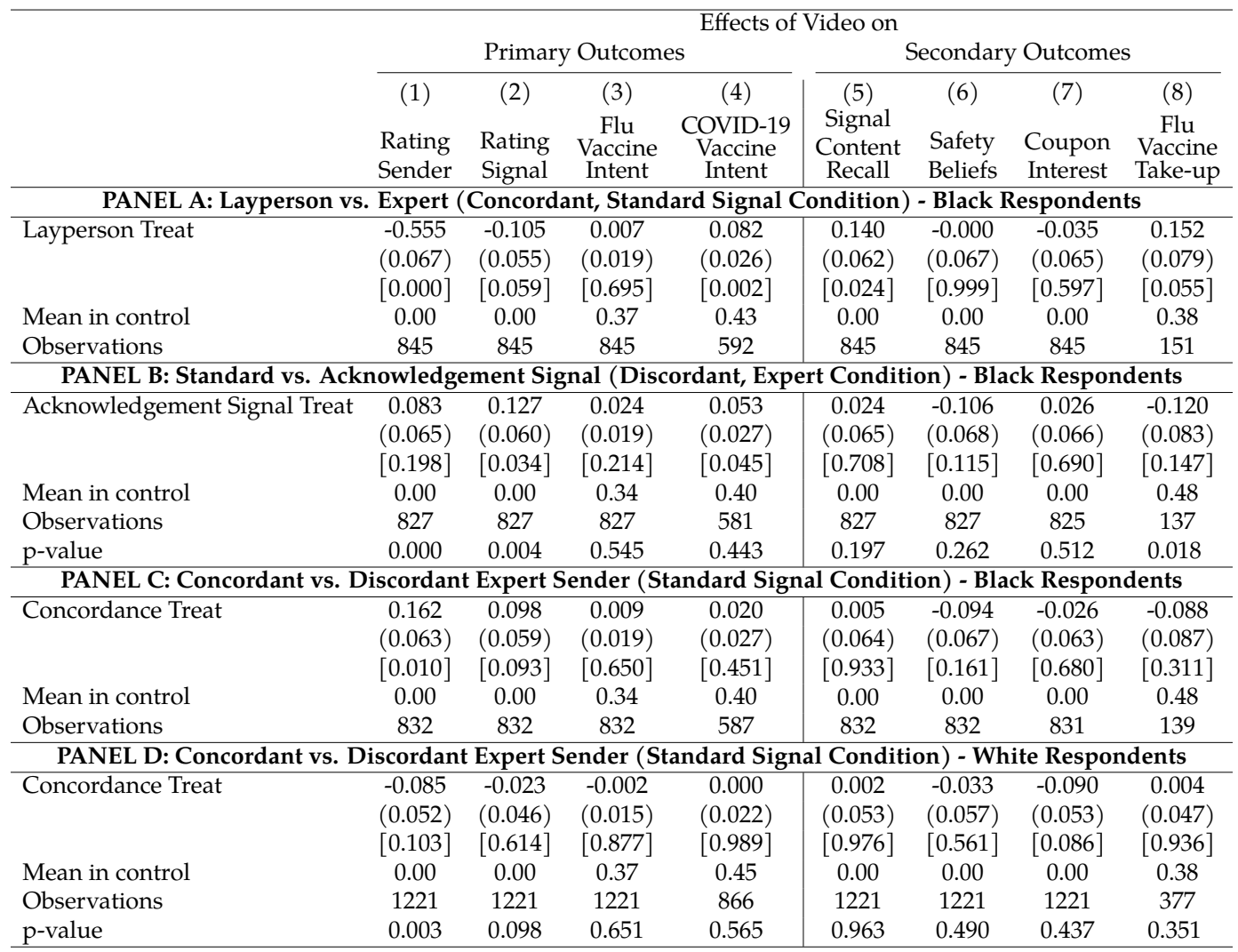

Notes: Table reports OLS estimates including PDS LASSO selected controls. Each dependent variable in columns (1) and (2) and (5) to (7) is an inverse-covariance-weighted index as described in Anderson (2008) and standardized to the mean of 0 and standard deviation of 1 . Dependent variables in columns (3) and (4) are on a scale of 0 to 1 . Dependent variable in column (8) is binary. COVID-19 vaccine intent was asked during the 2020-2021 flu season only. Outcome variables are described in Section III and in Appendix Section E. The $p$-value in Panel (B) tests the null hypothesis that discordant expert (acknowledgement signal) treatment and concordant non-expert (standard signal) treatment effects are equal. The $p$-value in Panel (D) tests the null hypothesis that concordance treatment effects are the same across Black and White respondents. Stratifying variables (platform and season) are forced to be included in the LASSO selection but not reported; an additional stratifying variable (an indicator $(=1)$ if the respondent is married) is forced to be included in the LASSO selection for the take-up outcome. Robust standard errors are in parentheses. $p$-values are in brackets. 


\section{Appendix Table B11: Heterogeneity by Vaccine Hesitancy}

\begin{tabular}{|c|c|c|c|c|c|c|c|c|}
\hline & \multicolumn{8}{|c|}{ Effects of Video on } \\
\hline & \multicolumn{4}{|c|}{ Primary Outcomes } & \multicolumn{4}{|c|}{ Secondary Outcomes } \\
\hline & (1) & $(2)$ & (3) & $(4)$ & $(5)$ & (6) & $(7)$ & $(8)$ \\
\hline & & & Flu & COVID-19 & Signal & & & \\
\hline & Rating & Rating & Vaccine & Vaccine & Content & Safety & Coupon & Vaccine \\
\hline & Sender & Signal & Intent & Intent & Recall & Beliefs & Interest & Take-up \\
\hline \multicolumn{9}{|c|}{ PANEL A: Layperson vs. Expert (Concordant, Standard Signal Condition) - Black Respondents } \\
\hline \multirow[t]{3}{*}{ Layperson Treat $\times$ Most Hesitant } & -0.618 & 0.234 & 0.080 & 0.148 & 0.068 & -0.051 & -0.096 & 0.155 \\
\hline & $(0.141)$ & $(0.141)$ & $(0.042)$ & $(0.058)$ & $(0.137)$ & $(0.139)$ & $(0.135)$ & $(0.146)$ \\
\hline & {$[0.000]$} & {$[0.097]$} & {$[0.054]$} & {$[0.011]$} & {$[0.621]$} & {$[0.716]$} & {$[0.479]$} & {$[0.290]$} \\
\hline \multirow[t]{3}{*}{ Layperson Treat $\times$ Moderate Hesitant } & -0.628 & -0.226 & 0.002 & 0.070 & 0.092 & -0.029 & -0.064 & 0.084 \\
\hline & $(0.107)$ & $(0.109)$ & $(0.035)$ & $(0.046)$ & $(0.095)$ & $(0.116)$ & $(0.111)$ & $(0.127)$ \\
\hline & {$[0.000]$} & {$[0.039]$} & {$[0.963]$} & {$[0.126]$} & {$[0.334]$} & {$[0.802]$} & {$[0.561]$} & {$[0.510]$} \\
\hline \multirow[t]{3}{*}{ Layperson Treat $\times$ Least Hesitant } & -0.385 & -0.199 & -0.022 & 0.061 & 0.179 & -0.022 & 0.093 & 0.156 \\
\hline & $(0.127)$ & $(0.118)$ & $(0.043)$ & $(0.047)$ & $(0.119)$ & $(0.130)$ & $(0.140)$ & $(0.139)$ \\
\hline & {$[0.002]$} & {$[0.092]$} & {$[0.613]$} & [0.192] & {$[0.134]$} & {$[0.864]$} & [0.506] & [0.264] \\
\hline p-value: Most Hesitant=Least Hesitant & 0.217 & 0.019 & 0.089 & 0.247 & 0.541 & 0.881 & 0.332 & 0.994 \\
\hline Mean in control & 0.00 & 0.00 & 0.17 & 0.30 & 0.00 & 0.00 & 0.00 & 0.18 \\
\hline Observations & 845 & 845 & 845 & 592 & 845 & 845 & 845 & 151 \\
\hline \multicolumn{9}{|c|}{ PANEL B: Standard vs. Acknowledgement Signal (Discordant, Expert Condition) - Black Respondents } \\
\hline \multirow[t]{3}{*}{ Acknowledgement Signal Treat $\times$ Most Hesitant } & 0.155 & 0.015 & -0.013 & 0.006 & 0.029 & -0.097 & 0.015 & -0.039 \\
\hline & $(0.122)$ & $(0.120)$ & $(0.041)$ & $(0.053)$ & $(0.128)$ & $(0.133)$ & $(0.128)$ & $(0.155)$ \\
\hline & {$[0.202]$} & {$[0.900]$} & {$[0.744]$} & [0.915] & [0.821] & [0.467] & {$[0.907]$} & {$[0.801]$} \\
\hline \multirow[t]{3}{*}{ Acknowledgement Signal Treat $\times$ Moderate Hesitant } & 0.013 & 0.204 & 0.011 & 0.055 & -0.025 & -0.063 & -0.034 & -0.323 \\
\hline & $(0.098)$ & $(0.103)$ & $(0.037)$ & $(0.046)$ & $(0.098)$ & $(0.104)$ & $(0.114)$ & $(0.120)$ \\
\hline & {$[0.895]$} & {$[0.049]$} & {$[0.756]$} & {$[0.235]$} & {$[0.796]$} & {$[0.546]$} & {$[0.767]$} & {$[0.008]$} \\
\hline \multirow{3}{*}{ Acknowledgement Signal Treat $\times$ Least Hesitant } & 0.193 & 0.200 & 0.101 & 0.154 & 0.078 & -0.173 & 0.172 & 0.010 \\
\hline & $(0.126)$ & $(0.126)$ & $(0.048)$ & $(0.057)$ & $(0.128)$ & $(0.125)$ & $(0.153)$ & $(0.151)$ \\
\hline & {$[0.127]$} & {$[0.113]$} & {$[0.034]$} & {$[0.007]$} & {$[0.540]$} & {$[0.168]$} & {$[0.259]$} & {$[0.948]$} \\
\hline p-value: Most Hesitant=Least Hesitant & 0.830 & 0.287 & 0.069 & 0.057 & 0.786 & 0.681 & 0.432 & 0.822 \\
\hline Mean in control & 0.00 & 0.00 & 0.23 & 0.29 & 0.00 & 0.00 & 0.00 & 0.25 \\
\hline Observations & 827 & 827 & 827 & 581 & 827 & 827 & 825 & 137 \\
\hline \multicolumn{9}{|c|}{ PANEL C: Concordant vs. Discordant Expert Sender (Standard Signal Condition) - Black Respondents } \\
\hline \multirow[t]{3}{*}{ Concordance Treat $\times$ Most Hesitant } & 0.283 & -0.148 & -0.063 & 0.005 & 0.189 & -0.164 & 0.001 & -0.031 \\
\hline & $(0.126)$ & $(0.129)$ & $(0.041)$ & $(0.056)$ & $(0.131)$ & $(0.127)$ & $(0.130)$ & $(0.149)$ \\
\hline & {$[0.025]$} & {$[0.251]$} & {$[0.120]$} & {$[0.925]$} & {$[0.149]$} & {$[0.196]$} & {$[0.992]$} & {$[0.834]$} \\
\hline \multirow[t]{3}{*}{ Concordance Treat $\times$ Moderate Hesitant } & 0.132 & 0.148 & 0.017 & -0.016 & -0.135 & -0.030 & -0.065 & -0.125 \\
\hline & $(0.094)$ & $(0.101)$ & $(0.036)$ & $(0.046)$ & $(0.098)$ & $(0.102)$ & $(0.112)$ & $(0.131)$ \\
\hline & {$[0.160]$} & {$[0.145]$} & {$[0.636]$} & {$[0.721]$} & {$[0.170]$} & {$[0.766]$} & {$[0.561]$} & {$[0.344]$} \\
\hline \multirow[t]{3}{*}{ Concordance Treat $\times$ Least Hesitant } & 0.101 & 0.294 & 0.086 & 0.111 & 0.026 & -0.131 & 0.017 & 0.004 \\
\hline & $(0.122)$ & $(0.118)$ & $(0.047)$ & $(0.053)$ & $(0.124)$ & $(0.134)$ & $(0.140)$ & $(0.160)$ \\
\hline & {$[0.408]$} & {$[0.013]$} & {$[0.070]$} & {$[0.038]$} & {$[0.835]$} & {$[0.327]$} & {$[0.903]$} & {$[0.981]$} \\
\hline p-value: Most Hesitant=Least Hesitant & 0.297 & 0.012 & 0.017 & 0.174 & 0.365 & 0.861 & 0.934 & 0.873 \\
\hline Mean in control & 0.00 & 0.00 & 0.23 & 0.29 & 0.00 & 0.00 & 0.00 & 0.25 \\
\hline Observations & 832 & 832 & 832 & 587 & 832 & 832 & 831 & 139 \\
\hline \multicolumn{9}{|c|}{ PANEL D: Concordant vs. Discordant Expert Sender (Standard Signal Condition) - White Respondents } \\
\hline Concordance Treat $\times$ Most Hesitant & -0.012 & 0.155 & -0.016 & 0.009 & -0.109 & -0.065 & -0.044 & -0.036 \\
\hline & $(0.108)$ & $(0.111)$ & $(0.033)$ & $(0.047)$ & $(0.114)$ & $(0.107)$ & $(0.107)$ & $(0.084)$ \\
\hline & {$[0.912]$} & {$[0.163]$} & {$[0.623]$} & {$[0.855]$} & {$[0.341]$} & {$[0.548]$} & {$[0.683]$} & {$[0.672]$} \\
\hline Concordance Treat $\times$ Moderate Hesitant & -0.159 & -0.088 & -0.012 & 0.025 & 0.106 & -0.067 & 0.006 & 0.047 \\
\hline & $(0.088)$ & $(0.085)$ & $(0.029)$ & $(0.037)$ & $(0.083)$ & $(0.091)$ & $(0.095)$ & $(0.070)$ \\
\hline & {$[0.070]$} & {$[0.300]$} & {$[0.690]$} & {$[0.495]$} & {$[0.201]$} & {$[0.464]$} & {$[0.949]$} & {$[0.505]$} \\
\hline Concordance Treat $\times$ Least Hesitant & -0.006 & -0.038 & 0.050 & -0.000 & 0.010 & 0.072 & -0.305 & -0.031 \\
\hline & $(0.107)$ & $(0.092)$ & $(0.037)$ & $(0.044)$ & $(0.113)$ & $(0.106)$ & $(0.127)$ & $(0.101)$ \\
\hline & {$[0.953]$} & {$[0.677]$} & {$[0.176]$} & {$[1.000]$} & {$[0.932]$} & {$[0.496]$} & {$[0.016]$} & {$[0.757]$} \\
\hline p-value: Most Hesitant=Least Hesitant & 0.970 & 0.181 & 0.182 & 0.893 & 0.459 & 0.366 & 0.115 & 0.972 \\
\hline Mean in control & 0.00 & 0.00 & 0.22 & 0.36 & 0.00 & 0.00 & 0.00 & 0.27 \\
\hline Observations & 1221 & 1221 & 1221 & 866 & 1221 & 1221 & 1221 & 377 \\
\hline
\end{tabular}

Notes: Based on OLS regression of each outcome (listed in the columns) of following form $y_{i}=\alpha+\beta_{1} T_{i} \times$ Most $_{i}+$ $\beta_{2} T_{i} \times$ Moderate $_{i}+\beta_{3} T_{i} \times$ Least $_{i}+\gamma_{1}$ Moderate $_{i}+\gamma_{2}$ Least $_{i}+\mu X_{i}+\epsilon_{i}$. Interaction coefficients are shown. Each dependent variable in columns (1)-(2) and (5)-(7) is an inverse-covariance-weighted index as described in Anderson (2008) and standardized to a mean of 0 and standard deviation of 1 . Dependent variables in columns (3)-(4) are on a scale of 0 to 1 . Dependent variable in column (8) is binary. COVID-19 vaccine intent was asked during the 2020-2021 flu season only. Outcome variables are described in Section III and in Appendix Section E. Most Hesitant is a binary variable equal to 1 if the respondent has never received the flu shot. Moderate Hesitant is a binary variable equal to 1 if the respondent received the flu shot more than 2 years ago. Least Hesitant is a binary variable equal to 1 if the respondent received the flu shot within the past 2 years, not including the current season. The $p$-value: Most Hesitant=Least Hesitant tests the null hypothesis that [treatment $] \times$ Most Hesitant $=[$ treatment $]$ $\times$ Least Hesitant. Stratifying variables (platform and season) are included as controls in the regression but not reported; an additional stratifying variable (an indicator $(=1)$ if the respondent is married) is included in the regression of the take-up outcome. Robust standard errors are in parentheses. $p$-values are in brackets.

$$
\text { A.23 }
$$




\section{Baseline Survey Questionnaire}

The baseline survey questionnaire is available at this link. 


\section{Videos and Scripts}

Appendix Table D12: Treatment Videos

\begin{tabular}{|c|c|c|c|}
\hline Role of Sender & Type of Signal & Race of Sender & Video URL \\
\hline Expert & Standard & White & https://youtu.be/CxxWBT0ew-U \\
\hline Expert & Acknowledgement & White & https://youtu.be/TlrulaBOk3o \\
\hline Expert & Standard & Black & https://youtu.be/esU_77AjaX8 \\
\hline Layperson & Standard & Black & https://youtu.be/bASxTEbfNMA \\
\hline Expert & Standard & White & https://youtu.be/Bt9kSpQf0so \\
\hline Expert & Acknowledgement & White & https://youtu.be/140L1_V9A9g \\
\hline Expert & Standard & White & https://youtu.be/PcDCkUPTBWA \\
\hline Expert & Acknowledgement & White & https://youtu.be/kwbvYwW5S98 \\
\hline Expert & Standard & Black & https://youtu.be/ClLOGMctouE \\
\hline Layperson & Standard & Black & https://youtu.be/202Xj9dWEFI \\
\hline Expert & Standard & White & https://youtu.be/RaPLcepWRUo \\
\hline Expert & Acknowledgement & White & https://youtu.be/V1j7E8aKAgA \\
\hline Expert & Standard & White & https://youtu.be/JWTPr7UCcg4 \\
\hline Expert & Acknowledgement & White & https://youtu.be/du7J6tRZ75g \\
\hline Expert & Standard & Black & https://youtu.be/2-yEncK0qtI \\
\hline Layperson & Standard & Black & https://youtu.be/Vo3223_B_Es \\
\hline Expert & Standard & Black & https://youtu.be/Ft-57zTr8Vg \\
\hline Layperson & Standard & Black & https://youtu.be/UTKojGTRSu4 \\
\hline Expert & Standard & Black & https://youtu.be/YUNCUYWVX1Q \\
\hline Layperson & Standard & Black & https://youtu.be/JTShSxUOFek \\
\hline
\end{tabular}


Appendix Table D13: Scripts

\begin{tabular}{|c|c|}
\hline Standard Signal Script & Acknowledgement Signal Script \\
\hline $\begin{array}{l}\text { The Centers for Disease Control and } \\
\text { Prevention, or CDC, recommends ev- } \\
\text { eryone } 6 \text { months and older get the flu } \\
\text { shot. }\end{array}$ & $\begin{array}{l}\text { The Centers for Disease Control and } \\
\text { Prevention, or CDC, recommends ev- } \\
\text { eryone } 6 \text { months and older get the flu } \\
\text { shot. } \\
\text { I know some people are nervous to } \\
\text { follow medical advice about vaccines. } \\
\text { In the past, there may have been times } \\
\text { when the medical community broke } \\
\text { your trust. But I hope that sharing } \\
\text { some information with you can help } \\
\text { you understand how important the } \\
\text { flu shot is. }\end{array}$ \\
\hline $\begin{array}{l}\text { The shot protects you from getting } \\
\text { sick by cutting your chance of catch- } \\
\text { ing the flu in half. It's also very safe: } \\
\text { less than } 1 \text { in } 100 \text { vaccinated people } \\
\text { experiences a side effect such as fever } \\
\text { or chills. The flu shot does not con- } \\
\text { tain an active flu virus, so you cannot } \\
\text { get the flu virus from the shot. I get } \\
\text { the flu shot every year to protect my- } \\
\text { self, my family, and my community. I } \\
\text { recommend you look into getting vac- } \\
\text { cinated as soon as possible. }\end{array}$ & $\begin{array}{l}\text { The shot protects you from getting } \\
\text { sick by cutting your chance of catch- } \\
\text { ing the flu in half. It's also very safe: } \\
\text { less than } 1 \text { in } 100 \text { vaccinated people } \\
\text { experiences a side effect such as fever } \\
\text { or chills. The flu shot does not con- } \\
\text { tain an active flu virus, so you cannot } \\
\text { get the flu virus from the shot. I get } \\
\text { the flu shot every year to protect my- } \\
\text { self, my family, and my community. I } \\
\text { recommend you look into getting vac- } \\
\text { cinated as soon as possible. }\end{array}$ \\
\hline
\end{tabular}




\section{E Outcome Measures: Question Wording}

\begin{tabular}{|c|c|c|c|}
\hline $\begin{array}{l}\text { Outcome Name } \\
\end{array}$ & Components & $\begin{array}{l}\text { Question Text } \\
\end{array}$ & $\begin{array}{l}\text { Response Options } \\
\end{array}$ \\
\hline \multicolumn{4}{|c|}{$\begin{array}{ll}\text { Primary Outcomes } \\
\end{array}$} \\
\hline \multirow{3}{*}{ Rating Sender } & Trust I & $\begin{array}{l}\text { - If a person like the one in the video was located near you, would you want to ask him } \\
\text { about other health issues? }\end{array}$ & [1: Yes, $0:$ No $]$ \\
\hline & Trust II & $\begin{array}{l}\text { - How much do you agree or disagree with the following statements? I trust the person } \\
\text { in the video to give me medical advice. }\end{array}$ & $\begin{array}{l}\text { [1: Disagree strongly, 2: Disagree, 3: Neither agree nor } \\
\text { disagree, 4: Agree, 5: Agree strongly] }\end{array}$ \\
\hline & Qualification & $\begin{array}{l}\text { - How much do you agree or disagree with the following statements? The person in the } \\
\text { video is qualified to give me medical advice. }\end{array}$ & $\begin{array}{l}\text { [1: Disagree strongly, 2: Disagree, } 3: \text { Neither agree nor } \\
\text { disagree, 4: Agree, 5: Agree strongly] }\end{array}$ \\
\hline \multirow{3}{*}{ Rating Signal } & Endorsement I & • How likely are you to recommend this video to your friends or family? & $\begin{array}{l}\text { [On a scale of } 0 \text { (Not at all likely) to } 10 \text { (Extremely } \\
\text { likely)] }\end{array}$ \\
\hline & Endorsement II & • How likely are you to recommend the flu shot to a family member or friend? & $\begin{array}{l}\text { [On a scale of } 0 \text { (Not at all likely) to } 10 \text { (Extremely } \\
\text { likely)] }\end{array}$ \\
\hline & Relevance & $\begin{array}{l}\text { - How much do you agree or disagree with the following statements? The information } \\
\text { provided in the video applies to people like me. }\end{array}$ & $\begin{array}{l}\text { [1: Disagree strongly, 2: Disagree, } 3: \text { Neither agree nor } \\
\text { disagree, 4: Agree, 5: Agree strongly] }\end{array}$ \\
\hline $\begin{array}{l}\text { Flu Vaccination } \\
\text { Intent }\end{array}$ & $\begin{array}{l}\text { Flu Vaccination } \\
\text { Intent }\end{array}$ & $\begin{array}{l}\text { - How likely are you to get a flu shot between now and February 2020? (2019-20 wave) } \\
\text { - How likely are you to get a flu shot between now and February 2021? (2020-21 wave) }\end{array}$ & $\begin{array}{l}\text { [On a scale of } 0 \text { (Not at all likely) to } 10 \text { (Extremely } \\
\text { likely)] }\end{array}$ \\
\hline $\begin{array}{c}\text { COVID-19 } \\
\text { Vaccination Intent }\end{array}$ & $\begin{array}{c}\text { COVID-19 } \\
\text { Vaccination Intent } \\
\end{array}$ & $\begin{array}{l}\text { - Suppose a vaccine against COVID-19 becomes available to everyone, at no cost. Would } \\
\text { you or would you not get vaccinated against COVID-19? }\end{array}$ & $\begin{array}{l}\text { [On a scale of } 0 \text { (Definitely not get vaccinated) to } 10 \\
\text { (Definitely get vaccinated) }]\end{array}$ \\
\hline \multicolumn{4}{|c|}{ Secondary Outcomes } \\
\hline $\begin{array}{l}\text { Signal Content } \\
\text { Recall }\end{array}$ & $\begin{array}{l}\text { Recall Ingredient } \\
\text { Recall Age }\end{array}$ & $\begin{array}{l}\text {-What did the person in the video say about what the flu shot contains? } \\
\text {-What did the person in the video say about who should get the flu shot? }\end{array}$ & $\begin{array}{l}\text { [1: the respondent chose the option, "Contains no ac- } \\
\text { tive flu virus", } 0 \text { : the respondent chose either "Contains } \\
\text { active flu virus" or "Don't know"] } \\
{[1: \text { the respondent chose the option, "Everyone } 6} \\
\text { months and older", } 0 \text { : the respondent chose either "Ev- } \\
\text { eryone } 5 \text { years and older", "Everyone } 18 \text { years and } \\
\text { older", or "Don't know"] }\end{array}$ \\
\hline Safety Beliefs & Safety Point Belief & $\begin{array}{l}\text { - Safety Point Belief }=\frac{(100-\text { Posterior Belief)-(100-Prior Belief })}{\text { - Prior and posterior of a respondent's estimate of the question: Take } 100 \text { adult men }} \\
\text { from your community, selected at random. Let's say all of the } 100 \text { adult men selected at } \\
\text { random from your community receive a flu shot at the start of the flu season. How many } \\
\text { of them, do you believe, get the flu from the flu shot? } \\
\text { - Safety Certainty = Posterior Number of Balls-Prior Number of Balls } \\
\text { - Prior and posterior of the number of balls placed in the "0-9" bin as a response to the } \\
\text { question: Consider the group of } 100 \text { adult men selected at random from your community, } \\
\text { and suppose all of them get the flu shot. You have } 10 \text { balls that you can put in } 10 \text { different } \\
\text { bins, reflecting what you believe are the chances out of } 10 \text { that the number of men who } \\
\text { get the flu from the flu shot falls in each bin. The more likely you think it is that the } \\
\text { number of men who get the flu from the flu shot falls in a given bin, the more balls you } \\
\text { should place in that bin. For example, if you put all the balls in one bin, it means you } \\
\text { are certain the number of men that will get the flu from the flu shot is somewhere in that } \\
\text { range. }\end{array}$ & {$[$ On a scale of -1 to 1$]$} \\
\hline
\end{tabular}




\begin{tabular}{|c|c|c|c|}
\hline Outcome Name & Components & Question Text & Response Options \\
\hline \multicolumn{4}{|c|}{ Secondary Outcomes (cont.) } \\
\hline \multirow{3}{*}{ Coupon Interest } & $\begin{array}{l}\text { Willingness to } \\
\text { pay (WTP) }\end{array}$ & $\begin{array}{l}\text { - Based on Becker-DeGroot-Marschak elicitation method, with the following wording: } \\
\text { After completion of this survey, you will receive an email with a flu shot coupon that you } \\
\text { can use at major pharmacies near you (including Walgreens, Rite-Aid, CVS, Walmart, } \\
\text { Kroger, costco and Albertsons). The coupon covers the full cost of the flu shot. In order } \\
\text { to redeem the coupon, you just need to present it at the pharmacy, for example on your } \\
\text { smart phone or printed out. You may be offered to trade in your flu shot coupon for an } \\
\text { electronic cash gift card redeemable at Amazon.com and other online retailers. The gift } \\
\text { card would be sent to you by email, within } 5 \text { business days of completing the survey. For } \\
\text { each of the amounts listed below, please select whether, if you are offered that amount, } \\
\text { you would prefer to keep your flu shot coupon, or receive the electronic cash reward } \\
\text { instead. The computer will then randomly select a participant, and will randomly draw } \\
\text { one price offer for the selected participant. If you are the randomly selected participant, } \\
\text { we will implement the choice you made at the randomly selected price. }\end{array}$ & \\
\hline & & $\begin{array}{l}\text { If the computer randomly selects me, and randomly selects a gift card in the amount of } \\
\$ X: \text { I prefer to ... [This question is asked four times, once for each price amount } X \in\{1,2,5,10\}] \text {. } \\
\text { Outcome is coded as the largest amount } X \text { at which the participant prefers the coupon over the } \\
\text { cash amount. If the participant always prefers the cash amount, the outcome is coded as zero. ] }\end{array}$ & $\begin{array}{l}\text { [Option 1: ... keep the flu shot coupon and receive no } \\
\text { cash gift card.; Option 2: ... give up the flu shot coupon } \\
\text { and receive an electronic cash gift card in the amount } \\
\text { of } \$ \mathrm{X} .]\end{array}$ \\
\hline & $\begin{array}{l}\text { Pharmacy } \\
\text { Lookup }\end{array}$ & $\begin{array}{l}\text { - Would you like to receive information about where you can redeem your flu shot } \\
\text { coupon? We can provide you with a link to look up participating pharmacies that ac- } \\
\text { cept the flu shot coupon and that are closest to you. The link would pop up on the final } \\
\text { screen of the survey. }\end{array}$ & [1: Yes, 0: No] \\
\hline Flu Vaccine Take-up & & $\begin{array}{l}\text { - A binary variable equal to } 1 \text { if the respondent redeemed a flu vaccine coupon or the } \\
\text { respondent answered "yes" to one of the questions in the follow-up survey: (1) “Did you } \\
\text { get the flu shot since you completed our first survey?"; (2) "Did your spouse or partner } \\
\text { get a flu shot this season?"; or (3) "Did your children get a flu shot this season?" }\end{array}$ & [1: Yes, 0: No] \\
\hline \multicolumn{4}{|c|}{$\begin{array}{l}\text { Additional Outcomes } \\
\end{array}$} \\
\hline $\begin{array}{l}\text { Self Flu Vaccine } \\
\text { Take-up }\end{array}$ & & $\begin{array}{l}\text { - A binary variable equal to } 1 \text { if the respondent redeemed a flu vaccine coupon or an- } \\
\text { swered "yes" to the question in the follow-up survey: "Did you get the flu shot since you } \\
\text { completed our first survey?" }\end{array}$ & [1: Yes, $0: \mathrm{No}]$ \\
\hline $\begin{array}{l}\text { Flu Vaccine Coupon } \\
\text { Redemption }\end{array}$ & & $\begin{array}{l}\text { - A binary variable equal to } 1 \text { if the respondent redeemed a flu vaccine coupon, and } 0 \\
\text { otherwise. }\end{array}$ & [1: Yes, 0: No] \\
\hline Ratings on Education & & $\begin{array}{l}\text { - This outcome is measured based on a separate MTurk survey sample. Each respondent } \\
\text { was randomly shown one of ten portraits of senders and was asked to respond to the } \\
\text { question: "What is the highest degree or level of schooling that you think the person } \\
\text { completed?" }\end{array}$ & $\begin{array}{l}\text { [1: Less than a high school diploma, 2: High school } \\
\text { diploma or equivalent (for example: GED), 3: Some } \\
\text { college but no degree, 4: Associate's degree, 5: Bach- } \\
\text { elor's degree, 6: Graduate degree (for example: MA, } \\
\text { MBA, JD, PhD) ] }\end{array}$ \\
\hline $\begin{array}{l}\text { Ratings on } \\
\text { Attractiveness }\end{array}$ & & $\begin{array}{l}\text { - This outcome is measured based on a separate MTurk survey sample. Each respondent } \\
\text { was randomly shown one of ten portraits of senders and was asked to respond to the } \\
\text { question: "How attractive is this person?" }\end{array}$ & $\begin{array}{l}\text { [1: Not at all attractive, 2: Somewhat unattractive, } 3 \text { : } \\
\text { Neither attractive nor unattractive, } 4 \text { : Somewhat attrac- } \\
\text { tive, } 5 \text { : Extremely attractive] }\end{array}$ \\
\hline
\end{tabular}

